\title{
On the Mysid Crustacean Genus Heteromysis (Mysidae: Heteromysinae) of the Tasman Sea, with Notes on the Tribe Heteromysini
}

\author{
Mikhail E. Daneliya (i) \\ Faculty of Biological and Environmental Sciences, POB 65, 00014, University of Helsinki, Finland; and \\ Taxonomicum, Sydäntie 8 E 16, 01400, Vantaa, Finland
}

\begin{abstract}
The mysid fauna of the Tasman Sea and its Australian coast, in particular, is barely known. The first special study of the subfamily Heteromysinae (family Mysidae) in the waters of New South Wales, based on the collections in the Australian Museum, yielded seven species of the genus Heteromysis (tribe Heteromysini). The Tasman Sea species of Heteromysis are distributed among three subgenera: Heteromysis s. str., Gnathomysis and Olivemysis. New species of Heteromysis include H. (H.) keablei, sp. nov. and H. (O.) murrayae sp. nov. The Tasman Sea members of the subgenus Heteromysis s. str., together with a number of other congeners, form a group of species with a particular structure of the pereopod 1 endopod and antennulae. Comparative review of the species of Heteromysis resulted in species rearrangement of another Heteromysini member, the genus Heteromysoides (for which a type species is fixed herein), with its species divided between Heteromysis, Platyops and Deltamysis (the tribe Mysidetini). Platyops is transferred to Heteromysini.
\end{abstract}

\section{Introduction}

In October 2015 I was privileged to receive the Visiting Fellowship of the Australian Museum Research Institute (AMRI) and an opportunity to start working on a large mysid crustacean collection, having been accumulated around Australia and the South Pacific and deposited in Sydney. A pioneering collection, largely from the New South Wales coast, contained a considerable amount of unique material, including new taxa. The first smaller part of this study was published within a larger framework of the revision of the Siriella brevicaudata species group from the western Indo-Pacific (Daneliya et al., 2018). In the current account I cover the first findings of representatives of the subfamily Heteromysinae in the coastal waters off New South Wales, the genus Heteromysis S. I. Smith, 1873.

The mysid crustacean fauna of the Australian waters has been studied rather fragmentarily, and on the New South
Wales coast, despite being the most developed coastal area of the country, has remained almost unknown. W. M. Tattersall (1940), in his last mysid paper, also published in the Records of the Australian Museum, reported a small collection of seven species, sampled mostly in Port Stephens and Lake Illawarra. The same year Dakin \& Colefax (1940) mentioned 12 mysid species in their planktonic study of the Broken Bay. Hutchings (1983) first mentioned an introduction of the East Asian Neomysis japonica Nakazawa, 1910, to Australia in Hunter River. More recently, a number of life history studies were made on certain known species in New South Wales (Taylor, 2008). Finally, Daneliya et al. (2018) confirmed the presence of Siriella vincenti W. M. Tattersall, 1927, in the Tasman Sea, based on several new findings.

Representatives of the subfamily Heteromysinae had not been reported from New South Wales until Hutchings et al. (2013) mentioned Heteromysis cf. abrucei, together with Rhopalophthalmus brisbanensis Hodge, 1963 (subfamily

Keywords: Crustacea; Mysidae; Heteromysis; Tasman Sea; taxonomy

Taxonomic registration: urn:Isid:zoobank.org:pub:1BD21A8F-7A38-4273-ABE1-EC9DAD4CC73E

Corresponding author: Mikhail E. Daneliya taxalab@taxonomicum.com

Received: 1 July 2020 Accepted: 1 April 2021 Published: 19 May 2021 (in print and online simultaneously)

Publisher: The Australian Museum, Sydney, Australia (a statutory authority of, and principally funded by, the NSW State Government)

Citation: Daneliya, Mikhail E. 2021. On the Mysid crustacean genus Heteromysis (Mysidae: Heteromysinae) of the Tasman Sea, with notes on the tribe Heteromysini. Records of the Australian Museum 73(1): 1-50. https://doi.org/10.3853/j.2201-4349.73.2021.1737

Copyright: () 2021 Daneliya. This is an open access article licensed under a Creative Commons Attribution 4.0 International License (CC BY 4.0), which permits unrestricted use, distribution, and reproduction in any medium, provided the original author and source are credited. 
Rhopalophthalminae) and some other unidentified Mysidae, collected during a large-scale biodiversity survey of Sydney Harbour. To date, their partial identification remained the only records of heteromysines from New South Wales. Fenton (1986) suggested that many species of heteromysines would be discovered in Australia, and her prediction has been fulfilled.

Outside of New South Wales, significant mysid studies of the Tasman Sea coastal waters were conducted in Tasmania mainly by Fenton (1986, and numerous later works). Concerning the genus Heteromysis, W. M. Tattersall (1927a) described H. tasmanica W. M. Tattersall, 1927, from South Australia and Tasmania. I should also mention that heteromysines have not been recorded from New Zealand.

The genus Heteromysis contains small, somewhat secretive, incidentally collected crustaceans (Clarke, 1955), associated with various benthic invertebrates: sponges, hydroids, corals, gorgonians, ophiuroids, hermit crabs, mollusc shells, cephalopods and ascidians (Brattegard, 1970; Wittmann et al., 2014; Wittmann \& Griffiths, 2017). The name (from Greek "hetero-", meaning "different", and "mysid") denotes differentiation of pereopods, particularly the first and, to certain extent, the second pair. A gnathopodlike, prehensile pereopod 1 endopod gives them a "mantislike" appearance, and is possibly used to catch prey (Meland et al., 2015), as such suggesting carnivorous feeding habits. However, heterogeneity of the locomotory appendages can equally be related to their benthic and commensal way of life, and the prehensile pereopods 1 may serve for attachment to host invertebrates and other substrates, or may be used to hold a sexual partner. Typically overlooked by dredging and trawling, members of this genus are better known by divers, and can be collected mostly by hand-sampling from near benthic invertebrates and reefs. A number of species of uncertain origin have recently been discovered in public marine aquaria all over the world (Wittmann \& AbedNavandi, 2019, 2021).

The Tasman Sea collection of the Australian Museum contains, to-date, seven species of the genus Heteromysis, among which two species are new to science. The Tasman Sea species of Heteromysis belong to three subgenera: Heteromysis sensu stricto, Gnathomysis Bonnier et Pérèz, 1902, and Olivemysis Băcescu, 1968.

\section{Taxonomic history of the genus Heteromysis}

During the end of the 1870 s and beginning of 1880 s, a significant amount of mysid research was being conducted nearly in parallel by various carcinologists, seemingly unaware of each other's publications. Heteromysines were discovered by S. I. Smith (1874) and described as a new mysid genus Heteromysis S. I. Smith, 1873. He particularly noticed the absence of the antennular appendix masculina, despite the presence of a tuft of long setae on the terminal article of the peduncle, the stouter pereopod 1 endopod (which he called "first pair of legs" or "second pair of gnathopods" or "third pair of maxillipeds"), with the 2-segmented carpopropodus plus dactylus (called 3 -segmented "terminal portion"), the pereopod 2, though with multisegmented carpopropodus, like in succeeding pereopods, also with the stouter dactylar unguis ("claw"), and the similarity in pleopods of both sexes, rudimentary, like in females of other mysids.
G. O. Sars (1877), possibly overlooking Smith's work, described Chiromysis G. O. Sars, 1877, i.e. "a mysid with a hand" from Greek, a genus with the robust and prehensile pereopod 1, with the carpopropodus perceived by him as 1-segmented ("tarso biarticulata"), and short pleopods. Hilgendorf (1879), probably also unfamiliar with the Smith's Heteromysis, described a new species for Chiromysis, but S. I. Smith (1879) soon synonymized Chiromysis with Heteromysis. Unlike Sars and Hilgendorf, Smith persisted in naming the pereopod 1 endopod the "endognath of the second pair of gnathopods", with the "tarsus" composed of three segments - carpus, propodus and dactylus. He no longer emphasized the difference of the pereopod 2 from other pereopods, and its diagnostic importance has been forgotten by subsequent workers. Kossmann (1880), as well as Czerniavsky (1882), most probably unaware of Smith's synonymization, mentioned Chiromysis as valid again. Czerniavsky was the first scholar to propose a subfamily structure of Mysidae, and Chiromysis was placed within the subfamily Mysinae Czerniavsky, 1882. He particularly considered its pereopods 1 as prehensile and subchelate. Czerniavsky, in the same work, also described another genus under the homonymic name Heteromysis (type species: Heteromysis mirabilis Czerniavsky, 1882) for two species that now belong to Neomysis Czerniavsky, 1882. Meanwhile, G. O. Sars $(1882,1885)$ accepted synonymization of Chiromysis with Heteromysis. He persisted in considering the pereopod 1 ("first pair of true legs") terminal part as biarticulate (as opposed to three-articulate in Smith), defining by this two schools of morphology of this appendage in Heteromysis, which can be called "the pereopod 1 of Smith" and "the pereopod 1 of Sars".

After Smith (1874) and Sars (1877), for the third time heteromysines were independently discovered by Bonnier \& Pérèz (1902), who seemingly did not know about the works of the previous scholars, establishing another genus, Gnathomysis. Though with typical features of Heteromysis (the structure of the pereopod 1 and pleopods), and this was subsequently revealed by W. M. Tattersall (1922), according to the title of their paper, Bonnier \& Pérèz were going to designate a separate family for Gnathomysis within Schizopoda, but did not name or describe it for some reason.

Hansen (1910), unlike S. I. Smith (1874), noticed that Heteromysis did possess the male lobe on antennula, which was, however, short or rudimentary.

W. M. Tattersall (1922), in his first review of the known species of Heteromysis, synonymized Gnathomysis with Chiromysis, and, thus, re-established the latter. W. M. Tattersall began working with Heteromysis from 1922, accepting the Smith's concept of the pereopod 1, with the distal part of the endopod divided into the carpus, propodus and dactylus (W. M. Tattersall, 1922, 1927a). The Smith's pereopod 1 was also in use by Calman (1932).

Nouvel (1940) first noticed sternal processes in males of Heteromysis, considering this character as unique for the genus. However, such structures were later reported in various mysid genera. Banner (1948) added the short length of the antennal scale to the diagnosis. Indeed, the antennal scale is not longer than the antennular peduncle in the most species, but in a number of them it is longer. Tattersall \& Tattersall (1951) again synonymized Chiromysis with Heteromysis, and mentioned the peculiar tubular penes in the genus, which, similar to reduced pleopods in both 
sexes, was also known in Mysidetes Holt et Tattersall, 1906 and Mysidella G. O. Sars, 1872 (subfamily Mysidellinae Czerniavsky, 1882). Among the distinguishing characters Tattersall \& Tattersall (1951) added two pairs of oostegites. Pillai (1965) added a character of the dactylus with the stout long claw to the diagnosis, and later (Pillai, 1968) the large eyes.

Knowledge of the genus was summarized for the second time by O. S. Tattersall (1967), who revised its diagnosis, but provided a rather broad definition. Although W. M. Tattersall (1922, 1927a) originally considered the carpopropodus to be 2-segmented, he switched back to Sars's concept of the 1 -segmented carpopropodus in the works, posthumously published by O. S. Tattersall (W. M. Tattersall, 1951; W. M. Tattersall \& O. S. Tattersall, 1951). O. S. Tattersall (1967) further followed this principle. She did not differentiate the pereopod 2 from remaining pereopods, as it was originally done by S. I. Smith (1874). O. S. Tattersall also suggested referring to all thoracopods by numbers instead of naming them differently.

Later, the generic name Gnathomysis was downgraded to a subgenus by Băcescu (1968). Băcescu (1968, 1976) recognized four subgenera within the genus Heteromysis: Heteromysis sensu stricto, Gnathomysis, Neoheteromysis Băcescu, 1976, and Olivemysis. The subgeneric division was sometimes ignored or unaccepted (Brattegard, 1970, 1974a; Modlin, 1984, 1987a, b, c; Bamber, 2000a; Hanamura \& Kase, 2001a). Băcescu (1968) also described a new genus Heteromysoides Băcescu, 1968, altering the concept of Heteromysis, which previously was the only heteromysine genus. From then on Heteromysis included species with the well-developed globular or cylindrical ocular cornea, set at the tip of the stalk, the only feature distinguishing it from Heteromysoides, a feature that made Heteromysoides a catch-all for species with the flattened and somewhat square eyes with laterally set cornea (the laterocorneal eye), and that was later found in a number of species of Heteromysis. I discuss taxonomic issues of Heteromysoides separately below. Brattegard $(1969,1970)$ introduced a concept of the Heteromysis-shaped telson, although he did not define it.

Nouvel et al. (1999) raised the rank of Neoheteromysis, previously considered a subgenus of Heteromysis, to the full genus level, but Wittmann (2008) returned it to subgeneric status.

The diagnostics of Heteromysis changed again with description of two genera, Retromysis Wittmann, 2004 and Ischiomysis Wittmann, 2013 (Wittmann, 2004, 2013; Wittmann \& Wirtz, 2017; Wittmann \& Griffiths, 2017). The former genus had special modifications of the male process, the setae of the antennular peduncle and the sternal process on the pereonite 8 of the female absent in Heteromysis. Ischiomysis had an acute process on the preischium of the pereopod 6 and the flagellated spiniform setae on its ischium, and the penes with large apical lobes, again absent in Heteromysis. The finding of three species of Heteromysis with the endopod 3 carpopropodus not stronger than the merus also excluded the stoutness of the carpopropodus from the diagnostics of the genus (Wittmann \& Griffiths, 2017).

\section{The problem of Heteromysoides}

Describing the genus Heteromysoides for the two species, Heteromysoides cotti (Calman, 1932) (originally in Heteromysis) and Heteromysoides spongicola Băcescu, 1968, Băcescu (1968) did not designate a type species. The only mention that "... nous y avons pêché trois espèces nouvelles de Heteromysis, puis une quatrième qui doit être range à côté de $\mathrm{H}$. cotti, dans un genre nouveau, Heteromysoides..." (we caught three new species of Heteromysis there, and a fourth [Heteromysoides spongicola], which must be set next to $H$. cotti, in a new genus, Heteromysoides) (p. 222), could approach such a designation. However, it is not possible to determine which of the two, the new Heteromysoides spongicola or the formerly described Heteromysoides cotti, would be the type species. According to the International Code of Zoological Nomenclature (Article 13.3; ICZN, 1999), to be available, a genus name described after 1930, must have a type species designated in the original publication. Brattegard (1970), mentioning Heteromysoides with a reference to the Băcescu's original description, listed it with two species, without reference to a type species. Compiling a bibliographic reference for the Zoological Record, the Staff of the Zoological Society of London (1972), referring to Băcescu (1968), mentioned Heteromysoides spongicola, as the type species for the genus, but since this was done anonymously (Article 14), Heteromysoides still remained unavailable.

In their list of Mysidacea, Mauchline \& Murano (1977) restricted Heteromysoides to Heteromysoides spongicola, with a reference to Băcescu (1968), and transferred Heteromysoides cotti back to its original genus, Heteromysis. Although Heteromysoides spongicola might then be inferred as being regarded as the type species of Heteromysoides, this action, however, does not constitute a type fixation (Article 69.4; ICZN, 1999). Despite that, all subsequent authors considered the original genus name proposed by Băcescu (1968) for the two species as valid (e.g., Brattegard, 1980), and continued description of more species in Heteromysoides. Only Fenton in Lowry \& Stoddart (2003) recognized that the genus had no type species designated, although no further action was taken. Therefore, Heteromysoides spongicola Băcescu, 1968 is herein designated as the type species of Heteromysoides, thus making the genus name available.

Heteromysoides was originally recognized on the basis of eye structure: somewhat quadrangular from the dorsal view and angular from the lateral view, with the cornea shifted to the lateral side of the eyestalk, and the absence of modifications of the setae on the antennules and pleopods. The latter characters were also shared with a part of Heteromysis. Subsequently, a number of species of Heteromysis, as well as the genus Platyops Băcescu et Iliffe, 1986, have been described with quadrangular eyes and a shifted cornea from the dorsal view (including the current study). Even Băcescu (1986), describing Heteromysis spinosa Băcescu, 1986, mentioned that its eyes had the aspect of Heteromysoides (though not as flattened), an adaptation of symbionts living on coral reefs, in his opinion. Subsequently, heteromysines with the laterocorneal eyes have been found among mud bottom dwellers as well, e.g., certain species of Deltamysis (see below). Eventually, Heteromysoides became a catch-all genus for species with various degrees of eye reduction or modification. 
Heteromysoides included 11 species (Yolanda et al., 2019). The first described species, Heteromysoides cotti, was originally included in Heteromysis (Calman, 1932; Fage \& Monod, 1936; Băcescu, 1941; Clarke, 1955; O. S. Tattersall, 1962), and, apart from some degree in the ocular cornea reduction, completely fit into the concept of the subgenus Heteromysis (Heteromysis) of Băcescu (1968). Particularly, the endopod of pereopod 1 resembled that of the type species, Heteromysis formosa S. I. Smith, 1873. This was obviously the reason Mauchline \& Murano (1977) excluded it from Heteromysoides for Heteromysis, and, together with Nouvel et al. (1999), I agree with the authors. The second species, used in the original designation of Heteromysoides, Heteromysoides spongicola, despite the lack of the pereopod 1 endopod in the specimen, was otherwise similar to other species of Heteromysis. It will be necessary to inspect an entire specimen of Heteromysoides spongicola, in order to make a decision about its taxonomic status. Băcescu (1983) subsequently described Heteromysoides longiseta Băcescu, 1983, with the pereopod 1 endopod and eyes rather similar to numerous species of Heteromysis, but rather peculiar pleopodal modifications. Soon after that, Băcescu \& Müller (1985) described Heteromysoides berberae Băcescu et Müller, 1985, being rather different in the structure of the pereopods from previously established species of Heteromysoides, as well as Heteromysis. It does not seem to be particularly closely related to any heteromysine genera. It is distinguished from Heteromysis also by the exceptionally long spinules of the telson cleft and the absence of any modified setae on the pereopod 1 carpopropodus. Owing to incomplete specimens and short description it is not possible to clearly determine the status of this species, and I propose to place it within Heteromysis as Heteromysis berberae (Băcescu et Müller, 1985) comb. nov.

Again, in clear contrast to the previous species, as well as to Heteromysis, was Heteromysoides dennisi Bowman, 1985. In addition to the corneal reduction, the eyestalk had a prominent anterior spine and the telson was lacking the cleft (Bowman, 1985). The species had several common characters with Platyops. Băcescu \& Iliffe (1986) noticed a resemblance of Platyops to Heteromysis and Heteromysoides, and though with a hesitation, assigned the genus to Mysini. In addition to the two above mentioned characters, the pereopod 1 carpopropodus of Heteromysoides dennisi is 2-segmented, the pereopod 2 carpopropodus is thin and multisegmented, and the uropodal endopod is devoid of the spiniform setae. With this evidence I propose a new combination, Platyops dennisi (Bowman, 1985) comb. nov. (formerly Heteromysoides).

Murano (1988) established Heteromysoides macrops Murano, 1988, which had the eyes with the laterally shifted cornea, as in Heteromysoides cotti and Heteromysoides spongicola, but otherwise not distinguished from Heteromysis. The same author (Murano, 1998) described another two species of Heteromysoides. The first, Heteromysoides nana Murano, 1998, with an almost fully developed ocular cornea, a telson with a slight cleft, and most importantly, with the non-prehensile 3-segmented carpopropodus of the pereopod 1, similar to the pereopod 2, could hardly be attributed to Heteromysoides; considering the shape of the eyes, telson, mandibular palp and pereopods, in my opinion, this species clearly belongs to Deltamysis, and must be transferred there as Deltamysis nana (Murano,
1998) comb. nov. The second species, Heteromysoides sahulensis Murano, 1998, based on a rather incomplete specimen, also had the laterally shifted ocular cornea, but again indistinguishable from Heteromysis and rather similar to Heteromysis keablei sp. nov., which I describe below.

The next species of Heteromysoides came with a work of Hanamura \& Kase (2001b). Heteromysoides simplex Hanamura et Kase, 2001, had a similar anterior spine on the eyestalk, the truncated telson and other features like in Platyops dennisi, but in contrast, rather simple, 3-segmented carpopropodus of the pereopod 1. Soon, Hanamura \& Kase (2004) were able to obtain another specimen of Heteromysoides spongicola, though again incomplete, and described the tenth known species from the genus, Heteromysoides stenoura Hanamura et Kase, 2004, with the anterior spine on the eyestalk (though quite well-developed cornea), the truncated telson and the non-prehensile pereopods 1 and 2, similar to Heteromysoides simplex. Both species in my opinion belong to the same genus, Platyops. An updated diagnosis for Platyops is given in the Additional taxonomic observations section below.

Yolanda et al. (2019) described the most recent species of Heteromysoides, Heteromysoides songkhlaensis Yolanda, Sawamoto et Lheknim, 2019, again based on the reduction of the ocular cornea. They noted its close relation to Heteromysoides nana, which is, as I mentioned above, in fact, a species of Deltamysis. By the structure of the mandibular palps, pereopods, uropods, telson and other organs, Heteromysoides songkhlaensis is clearly a member of Deltamysis to which it is herein transferred as Deltamysis songkhlaensis (Yolanda, Sawamoto et Lheknim, 2019) comb. nov.

Concerning the validity of Heteromysoides, a final decision should be made after a study of a complete specimen of Heteromysoides spongicola in order to determine whether it can be treated as a separate genus or a part of Heteromysis. For the time being, I propose to consider Heteromysoides spongicola as a member of Heteromysis. The following species at some time placed in Heteromysoides are included in Heteromysis: Heteromysis cotti Calman, 1932, Heteromysis longiseta (Băcescu, 1983) comb. nov. (from Heteromysoides), Heteromysis macrops (Murano, 1988) comb. nov. (from Heteromysoides), Heteromysis sahulensis (Murano, 1998) comb. nov. (from Heteromysoides) and Heteromysis spongicola (Băcescu, 1968) comb. nov. (from Heteromysoides).

\section{Physical geographical features of the Tasman Sea}

The Tasman Sea lies between the southeastern Australia, New Zealand, the Coral Sea and the Southern Ocean. The exact sea limits are defined by the International Hydrographic Organization (1953). Considering the particular collection studied here, the most important part is the western Tasman Sea, which reaches Australia, spanning almost the entire New South Wales coast (except its small part north of the parallel $30^{\circ} \mathrm{S}$ ) and the east coast of Tasmania. Describing the oceanography of the sea, I limit myself by the factors that may affect distribution of the fauna along the east Australian coast, consulting Rotschi \& Lemasson (1967).

The northerly border with the Coral Sea is marked by the uplift of the sea floor and the beginning of the coral reefs 
and islands, though the southernmost coral reef is found in the Tasman Sea on Lord Howe Island. The maximum depth of the Tasman Sea is $5943 \mathrm{~m}$, and the deep waters closely approach the coast. Thus, the sublittoral fauna, found above $200 \mathrm{~m}$, is spread only along the coast or around islands.

The atmospheric circulation in the Tasman Sea is rather variable, except for the southern part up to $40^{\circ} \mathrm{S}$, where western winds are predominant all year round, keeping relatively stable cool temperatures, on average $10-11^{\circ} \mathrm{C}$ in the austral winter and $14-15^{\circ} \mathrm{C}$ in summer, when northern winds from tropics meet western winds. The latter are predominant during the year around most of the Tasman Sea. The northern Tasman Sea has a subtropical climate and average surface water temperatures vary from $20^{\circ} \mathrm{C}$ in austral winter to $27^{\circ} \mathrm{C}$ in summer. Correlated with the winds, the surface currents mostly follow them. The currents from the Equator and South Central Pacific flow through the Coral Sea and continue south to the Tasman Sea along the Australian coast. This current, known as the East Australian Current, flows as far south as $40^{\circ} \mathrm{S}$. Meeting the west winds near Tasmania the East Australian Current turns east to New Zealand, and then continues as a convergent current to the north along the New Zealand coast (Figs. 4A, 17A, 22A).

Affected predominantly by western winds, the sea is often stormy. Coastal salinity is $35-35.5 \%$, decreasing only with depths below $650 \mathrm{~m}$. The effect of fresh water from the continent is not significant, and most of the lower reaches of east Australian rivers are brackish to marine at their mouths.

\section{Materials and methods}

The material contains 54 samples from various localities along the New South Wales coast, collected by diving or occasionally by dredge from vessels in expeditions of the Australian Museum (AM), the Commonwealth Scientific and Industrial Research Organisation (CSIRO) and Agriculture and Fisheries Division of New South Wales Department of Primary Industries (NSW Fisheries). Most of the samples were originally fixed in formaldehyde and later transferred into $80 \%$ ethanol. After the preliminary identification, one or two specimens of each species were partly dissected, put on permanent slides with Aquatex medium, studied in detail, measured and illustrated using camera lucida on a compound microscope. The remaining material was examined without dissection. The collection is deposited at the Australian Museum, Sydney (AM).

All samples, except for one, come from the Tasman Sea, New South Wales, Australia, and this information will not be repeated in the material listing. One sample was collected formally in the southern Coral Sea, bordering the Tasman Sea, which is mentioned explicitly in the material.

In the Taxonomy section, in addition to the synonymies, I attempted to compile also a complete index, mentioning all pages, where a name was used.

Measurements. Body length: from anterodorsal margin of carapace to posterior margin of telson (terminal spiniform setae not included). Eye length: from cornea distal surface to proximal margin of stalk, dorsal view. Head width: between anterolateral corners of the carapace, dorsal view. Abdominal somite 6 length: from its dorsal posterior margin to the dorsal posterior margin of somite 5 , not including posterolateral lobes, dorsal or lateral view. Telson length: from anterior margin to posterolateral margins, excluding terminal spiniform setae, dorsal or lateral view. Telson anterior width: between the most distant points of anterior part. Telson posterior width: between outer posterior corners of terminal spiniform setae (outer if two). Cleft occupancy with spinules: from the base of last posterior spinule to the cleft anterior margin. Telson lateral spiniform setae number: including terminal. Pereopod 1 dactylus length includes dactylus and its unguis combined.

\section{Taxonomy}

\section{Mysida Boas, 1883 Mysidae Haworth, 1885 Heteromysinae Norman, 1892 Heteromysini Norman, 1892}

\footnotetext{
Heteromysinae Norman, 1892: 148, 158.

Heteromysini.-Wittmann, 2008: 353; 2020: 242.Wittmann et al., 2014: 320, 340, 346.-Wittmann \& Chevaldonné, 2016: 2.-Wittmann \& Wirtz, 2017: 132-133, 147.-Wittmann \& Griffiths, 2017: 17, 42.-Wittmann \& Ariani, 2019: 5.-Wittmann \& AbedNavandi, 2019: 82; 2021: 136.-Meland et al., 2015: 7.-_Ortiz \& Lalana, 2017: 67.-—Price et al., 2018: 2.
}

Diagnosis. Male process of antennula rather small, rudimentary. Pereopod 1 endopod differentiated from pereopod 2 endopod, more or less prehensile, with 2 -segmented carpopropodus (3-segmented only in Platyops stenoura comb. nov., see below). All pleopods reduced to simple plates in both sexes.

Comparison. Only two rather important features separate Heteromysini from Harmelinellini Wittmann, Ariani et Lagardère, 2014: a rudimentary nature of the male process on the antennula and of all pleopods in both sexes. In Harmelinellini, the male process is rather well-developed, and the male pleopod 3 is uniquely long and 2-segmented. From the members of the tribe Mysidetini Holt et Tattersall, 1906 , it can be distinguished by the differentiation between the pereopods 1 and 2 endopods (rather similar in Mysidetini), among which the endopod 1 carpopropodus is 2 -segmented (in all species except Platyops stenoura comb. nov. (see below), where it is 3 -segmented) and stronger than endopod 2 carpopropodus, and endopod 2 carpopropodus is 3-segmented or multisegmented. In Mysidetini, both endopods are rather similar, with carpopropodus typically 3 -segmented or multisegmented (similar, but 2-segment only in Corellamysis).

Remarks. Heteromysini received separate tribal status within the subfamily Heteromysinae in the work of Wittmann (2008), with the reference to the study of Meland \& Wilassen (2007), where, in fact, the former tribe Heteromysini within the subfamily Mysinae was upgraded to the subfamily level. Only in the subsequent monographic study Wittmann et al. (2014) distinguished the tribe Heteromysini from the other two tribes, Harmelinellini and Mysidetini within the subfamily Heteromysinae, and provided a diagnosis of the tribe. The nominotypical tribe Heteromysini was retained for the heteromysine genera with a very small or reduced appendix masculina, a prehensile endopod of the 
pereopod 1 with a 2 -segmented or fused carpopropodus, normal endopods of the pereopods 2-6, two or three pairs of oostegites, large or small, mostly tubular penes, mostly with distinct terminal lobes, males of certain species with some pleopods bearing modified setae, the telson with the cleft (despite the absence of the cleft in certain Heteromysoides) and smooth margins or distally with spiniform setae (despite the presence of spiniform setae along the entire margin in certain Heteromysis species). The tribe contained five genera: Heteromysis, Heteromysoides, Ischiomysis, Platymysis Brattegard, 1980 and Retromysis. The only feature that was thought to distinguish Heteromysini from Mysidetini was a prehensile pereopod 1 endopod. The first issue here was the genus Heteromysoides, which contained species both with a prehensile and a non-prehensile pereopod 1 endopod. The second issue, which came simultaneously with the work of Wittmann et al. (2014), was the genus Corellamysis San Vicente et Monniot, 2014. A clear member of the subfamily Heteromysinae, Corellamysis has a unique structure of the pereopods. All the endopods are prehensile, and the first three pairs rather similar, but differentiated from other endopods (San Vicente \& Monniot, 2014). The genus could either be separated in its own tribe or incorporated into an existing one. Curiously, in a recent study, Shimomura \& Fujita (2017) completely avoided the use of family-group heteromysine taxa.

There is a rather clear discrimination of Heteromysini from Harmelinellini, as discussed above in the Comparison. However, in comparing Heteromysini and Mysidetini a clear difference is seen only between marginal genera (subgenera) from these tribes, respectively, like Heteromysis (Gnathomysis), with an extremely developed gnathopodlike pereopod 1 carpopropodus, and Mysidetes Holt et Tattersall, 1906, with a normal, multisegmented one. Within Heteromysis, certain species have a rather weekly prehensile pereopod 1 carpopropodus, while it is clearly differentiated from other pereopods, though not so strongly, in Deltamysis from Mysidetini.

Heteromysini and Mysidetini can be distinguished by the 2-segmented pereopod 1 carpopropodus vs. 3-segmented or multisegmented. As a result, I also transfer here Bermudamysis Băcescu et Iliffe, 1986. The only exclusion is Platyops stenoura comb. nov. (see below), with the 3 -segmented carpopropodus of the pereopod 1, when the other three members of the genus Platyops, which incorporates certain former species of Heteromysoides, have the 2-segmented carpopropodus, and even prehensile, as in P. dennisi. Thus, formally Platyops would belong to Heteromysini, but the genus, indeed, is a connection between the two tribes. Still another character that can be used to distinguish Heteromysini from Mysidetini is the differentiation between the pereopod 1 and 2 endopods, which are nearly identical in Mysidetini. The importance of this character was first realized by S. I. Smith (1874), subsequently forgotten, and I recover it here.

Composition. The tribe contains six genera: Heteromysis, Bermudamysis, Ischiomysis, Platymysis, Platyops and Retromysis, among which only members of Heteromysis are found in the Tasman Sea.

\section{Heteromysis S. I. Smith, 1873}

Heteromysis S. I. Smith, 1873 (issued in 1874): 553; 1879: 101.-G. O. Sars, 1882 (issued in 1883): 55; 1885: 11, 172, 173, 216.-Norman, 1892: 147, 158.-Holt \& W. M. Tattersall, 1906a: 10.-W. M. Tattersall, 1908: 32; 1922: 495; 1927a: 236, 253; 1927b: 185, 195; 1951: 235.-W. M. Tattersall \& O. S. Tattersall, 1951: 72, 414.—Zimmer, 1909: 48, 140.-Hansen, 1910: 5, 7, 8; 1925: 110.-Illig, 1930: 599. - Calman, 1932: 128, 131.—Fage \& Monod, 1936: 110, 111.-Nouvel, 1940: 3, 4; 1949: 3; 1957 : 331; 1964: 37, 38.-Nouvel et al., 1999: 44, 53, 54, 75, 79.-Băcescu, 1941: 35-36; 1968: 221, 222, 225, 226, 231, 234-236; 1970: 15, 16; 1975: 41; 1976: 86, 89-91; 1979: 143, 144, 146; 1983: 7, 8, 11; 1986: 93, 94.-Băcescu \& Bruce, 1980: 67, 71.—Băcescu \& Iliffe, 1986: 99, 100.-Băcescu \& Ortiz, 1984: 22.-Banner, 1948: 67, 106.-Clarke, 1955: 7-11.-O. S. Tattersall, 1949: 450; 1955: 141; 1961: 145, 156; 1962: 222-236; 1965: 17, 19; 1967: 161, 162, 164-167, 203, 208, 211.-Pillai, 1961: 32; 1965: 1725; 1968: 47-51.- Ii, 1964: 282, 568.-Brattegard, 1969: 96, 98; 1970: 129, 130, 133, 136, 143, 147, 151; 1980: 50.-Mauchline \& Murano, 1977: 58.—Lagardère \& Nouvel, 1980: 376, 873.-Mauchline, 1980: 36.-Bowman, 1981: 458.Modlin, 1984: 283; 1987a: 296; 1987b: 116, 120; 1987c: 653.-Fenton, 1986: 8, 15, 24, 141, 162, 191.-Kathman et al., 1986: 24, 163.-Murano, 1988: 46; 1998: 31.Murano \& Hanamura, 2002: 75.- Murano \& Fukuoka, 2003: 185.-Ledoyer, 1989: 41.-Escobar-Briones \& Soto, 1990: 131; 1991: 85, 87.-Bowman \& Orsi, 1992: 738, 739.-Müller, 1993: 218.-Vannini et al., 1993: 190, 192; 1994: 137.-Bravo \& Murano, 1996: 483.Wittmann, 1996: 229; 2000: 279, 280, 284, 286, 287; 2001: 93, 104, 105; 2004: 782; 2008: 352, 360, 367-370; 2013: 505; 2020: 141-143, 151, 156.-Wittmann et al., 2014: 213, 214, 231, 235, 253, 270, 309-311, 324, 341, 405.-Wittmann \& Chevaldonné, 2016: 1, 7.—Wittmann \& Wirtz, 2017: 143, 146, 148.-Wittmann \& Griffiths, 2017: 16, 17, 39-42.-Wittmann \& Abed-Navandi, 2019: 81, 82, 92-95; 2021: 133-138, 159, 170-172.-Bamber, 2000a: 129, 133; 2000b: 57, 58.-Price \& Heard, 2000: 88; 2008: 143, 147; 2011: 33, 37, 43.-Price et al., 2018: 2, 8.-Hanamura \& Kase, 2001a: 11, 12, 15, 17, 19; 2001b: 70.-Hanamura et al., 2012: 11, 12.-Fukuoka, 2004: 1353, 1354, 1359, 1366, 1369.-Daneliya, 2012: 135, 136.-Chevaldonné et al., 2014: 1, 6-7.-Noël et al., 2014: 30, 55.-San Vicente \& Monniot, 2014: 333, 334, 338-340.--Lavesque et al., 2016: 2, 3, 4.-Pérez et al., 2016: 306.- - Ortiz \& Lalana, 2017: 71, 74, 76.

[Non Heteromysis Czerniavsky, 1882: 57, 62 (junior homonym)].

Chiromysis G. O. Sars, 1877: 56.-Hilgendorf, 1878 (issued in 1879): 845 , partim [synonymized with Heteromysis by S. I. Smith, 1879: 101; mentioned as valid in Kossmann, 1880: 92; Czerniavsky, 1882: 16, 58, 63; mentioned as synonym of Heteromysis in G. O. Sars, 1885: 216].

Type species. Heteromysis formosa S. I. Smith, 1873, by monotypy.

Diagnosis. Body moderately robust, not notably compressed dorsoventrally. Abdominal segments without pleurites. Telson trapezoidal, with apical cleft; its spinules not exceptionally long. Eyes with cornea; eyestalk without distolateral lobe. Antennular peduncle distomedial setae not directed backwards; male process without posteromedial lobe. Pereopod 1 carpopropodus with medial spiniform or other modified setae. Pereopod 2 carpopropodus multisegmented. 
Pereopods 3-6 preischium without process; ischium without flagellated spiniform setae. Penes without large apical lobes, tubular. Females without sternal plate projecting behind marsupium. Uropodal endopod with spiniform setae.

Comparison. The genus Heteromysis has no unique characters shared by all of its members. The structure of the pereopod 1 carpopropodus, previously considered as distinguishing Heteromysis from other genera, although shared by the congeners, is also found in other genera. It is most similar to Ischiomysis, Platymysis and Retromysis. Ischiomysis differs by the presence of the acute process on the preischium of the pereopod 6 , the flagellated spiniform setae on its ischium, and the penes with the large apical lobes (all three features missing in Heteromysis). Platymysis has a dorsoventrally compressed body and the abdominal pleurites (not compressed and the pleurites absent in Heteromysis), its eyestalk with the prominent distolateral lobe (absent in Heteromysis) and the pereopod 1 carpopropodus with seemingly secondarily fused segments (the distal segment is at a different stage of reduction, but always present in Heteromysis). Retromysis differs by the distomedial setae of the antennular peduncle, directed backwards (forward in Heteromysis), the presence of the posteromedial lobe on the male process (absent in Heteromysis) and the sternal plate projecting behind the marsupium (absent or not projecting in Heteromysis). Even a combination of these three or any other heteromysine genera does not produce common unique features. In contrast, rather clearly defined groups are found within Heteromysis, recognized as subgenera.

Remarks. Comparing Heteromysis with all described heteromysine genera, I attempted here to re-diagnose the genus to include only characters common for all species and distinguish them from representatives of other genera. The following characters are no longer considered diagnostic: the size and general shape of the eyes, the size of the processus masculinus, the shape and length of the antennal scale, the presence of the sternal processes, and the number of the oostegites.

The concept of the pereopod 1 of G. O. Sars (1877), as defined earlier, with 1-segmented carpopropodus, was followed after O. S. Tattersall (1967) by various authors (Brattegard, 1969, 1970, etc.; Modlin, 1984, 1987a, b, c; Fenton, 1986; Murano \& Hanamura, 2002; Murano \& Fukuoka, 2003). Some scholars followed Smith's concept (S. I. Smith, 1874) of the 2-segmented carpopropodus and illustrated the distinct dactylus as separate from the unguis and the second segment of the carpopropodus (e.g., Pillai, 1961, plate 6N; Băcescu, 1979, fig. 1O,N; 1986, fig. 1O,P;
Wittmann, 2000, figs 11, 12; 2001, fig. 3B; 2008, figs 11, m, 4j, k; 2020, fig. 4A,D, G,K,Q; Wittmann et al., 2014, figs $54.18 \mathrm{H}, 54.35 \mathrm{~F}$, G; Wittmann \& Chevaldonné, 2017, fig. 2A, B; Wittmann \& Wirtz, 2017, figs 3D,E, Wittmann \& Griffiths, 2017, fig. 4A,B, etc.; Fukuoka, 2004, fig. 2C; Hanamura et al., 2012, fig. 1g; Price \& Heard, 2011, fig. 2C; Price et al., 2018, fig. 3C). As can be seen from the illustrations in the current work (Figs 2F, 7B, 10G, 14H, 19C, 24D), the dactylus, occupies the proximal part of what was considered a dactylar claw. The border between the dactylus and the dactylar claw is recognized by the typical small distomedial setae. I therefore confirm that the propodus (or more correctly the carpopropodus) of Heteromysis consists of two segments.

The nominate subgenus, Heteromysis, has been a heterogeneous catch-all that contained species that did not belong to any of the three other known subgenera. Based on a detailed comparison of the pereopod 1 endopod and the antennular peduncle, particularly in new material from the Tasman Sea, a well-defined group of species can be established within the subgenus Heteromysis s. str. Many species of Heteromysis have been described rather inadequately, and the possible taxonomic status of this group can only be defined after re-examination of a better preserved material across the genus.

Distribution and Habitat. Cosmopolitan. In-shore, shallow water (upper sublittoral). The characteristic ecological feature of Heteromysis is commensalism (Nouvel et al., 1999).

Life history. Nouvel (1940) observed copulation in $H$. formosa, which took place at night and immediately after the molting of the female and the liberation the young from the brood pouch. During copulation a male took position under a female, head to tail and the ventral surface to the ventral surface, and clasping thoracopods around the abdomen; the penis was inserted between the marsupial plates and the sperm ejected into the marsupial chambers. Only two eggs develop in the marsupium.

Composition. To date 105 species are known in the genus Heteromysis. From them 82 species are divided between four subgenera: Heteromysis (Heteromysis), Heteromysis (Gnathomysis) Bonnier et Perez, 1902, Heteromysis (Neoheteromysis) Băcescu, 1976, and Heteromysis (Olivemysis) Băcescu, 1976, among which three subgenera Heteromysis, Gnathomysis and Olivemysis are found in the Tasman Sea. The remaining species have been described from incomplete specimens or rather inadequately, and their subgeneric assignment in still pending.

\section{Key to the Tasman Sea subgenera of Heteromysis}

1 Uropodal endopod shorter than exopod. Antennular peduncle segment 3 with flagellated distomedial spiniform setae (Figs 1A,F; 5A,F; 9A,F; 18A; 23A). Pereopod 1 ischium with smooth medial margin (not counting setae, spine-setae and slight tubercles)

Uropodal endopod as long as or slightly longer than exopod.

Antennular peduncle segment 3 with simple, non-flagellated distomedial setae. Pereopod 1 ischium with serrated medial margin 
2 Pereopod 1 merus with distomedial triangular process (not known in males of Heteromysis tasmanica) (Figs 2E, 7A,B, $10 \mathrm{~F}, 14 \mathrm{H}$ ); carpopropodus segment 2 with strong, serrated paradactylary setae (Figs 2G, 7A-C, 10F, G, 14H,I). Eyestalk lacking distomedial spine or tubercle (Figs 1A, 5A, 9A, 13B) .... Heteromysis s. str.

Pereopod 1 merus without distomedial triangular process; carpopropodus segment 2 without strong, serrated paradactylary setae (Figs 19G, 24D). Eyestalk with distomedial spine or rarely tubercle (Figs 18A, 23A) Olivemysis Băcescu, 1968

\section{Heteromysis (Heteromysis) S. I. Smith, 1873}

Heteromysis (Heteromysis).-Băcescu, 1968: 234-237; 1979: 145.-Bravo \& Murano, 1996: 483.-Price \& Heard, 2000: 88, 92, 93.-Wittmann, 2000: 287; 2001: 94, 104; 2008: 368; 2020: 142, 154.-Wittmann \& Wirtz, 2017: 149.-Wittmann \& Griffiths, 2017: 17, 39-40.Hanamura \& Kase, 2001a: 17.—Daneliya, 2012: 146.Hanamura et al., 2012: 17.-San Vicente \& Monniot, 2014: 340.-Levesque et al., 2016: 2.

Type species. Heteromysis formosa S. I. Smith, 1873.

Diagnosis. Ischium of pereopod 1 endopod two to three times as long as wide; medially without denticles. Pleopods unmodified, setose in both sexes. Uropodal endopod shorter than exopod.

Comparison. The subgenus Heteromysis (Heteromysis) as currently composed does not have unique characters common to all its members, representing a heterogeneous group. Its members are distinguished from the species of the subgenus Heteromysis (Gnathomysis) by the smooth and narrow ischium of pereopod 1 endopod (nearly as long as wide, with denticles in Gnathomysis), and by the uropodal endopods being shorter than exopods (equal or slightly longer in Gnathomysis). From the members of the subgenus Heteromysis (Olivemysis) the species of Heteromysis s. str. are distinguished by non-modified pleopods.

Remarks. Băcescu (1968) designated the subgenus Heteromysis s. str., based on absence of the pleopod modifications. This has remained the only reason, by which newly described species not fitting into the other known Heteromysis subgenera, have been included in the nominotypical subgenus (Wittmann \& Griffiths, 2017).

I have attempted, in addition to the study of the Tasman Sea species, to compare all known Heteromysis from the available literature. A number of rather clearly defined groups can be established within the subgenus. However, because of insufficient descriptions and illustrations, some species remain incertae sedis, and the taxonomic status of such groups can be clarified only after the study of actual material. Meanwhile, it is possible to define one such group, which includes all the Tasman Sea species, and which I call the microps-group.

Composition. The nominate subgenus of Heteromysis currently contains 31 species, among which four species can be found in the Tasman Sea: Heteromysis (H.) communis Băcescu, 1986, Heteromysis (H.) macropsis Pillai, 1961, Heteromysis (H.) keablei sp. nov., Heteromysis (H.) tasmanica.

\section{Heteromysis microps group}

Diagnosis. Eye without distomedial spine (spines) or tubercle. Antennular peduncle segment 3 with two or rarely three, flagellated (but never further modified) spiniform setae, one of them directed anteriorly, another laterally. Merus of pereopod 1 endopod with distomedial process; its medial margin with flagellated spiniform setae in most of species (occasionally absent). Carpopropodus of pereopod 1 rather massive, longer than merus, with medial spiniform setae and long serrated paradactylary setae. Penis slightly widening apically, mostly with setae.

Comparison. Members of the microps-group are clearly distinguished from other species of Heteromysis (Heteromysis) by the structure of the pereopod 1 endopod, particularly by the presence of the distomedial process on the merus, found only in this group. The flagellated spiniform setae on the merus medial margin are almost exclusively found in the microps-group, though absent in certain species. It further differs from other Heteromysis (Heteromysis) by presence of the flagellated distomedial setae on the antennular peduncle segment 3. There is a variety of shapes in these setae in Heteromysis sensu lato, including larger number (up to seven) of the smooth setae, the presence of rather modified structures. The flagellated spiniform setae of the antennular peduncle segment 3 of the microps-group are reminiscent of those found in Heteromysis (Olivemysis). From Heteromysis (Olivemysis) the microps-group species also differ by the eyestalk lacking the distomedial process (also present in certain members of the subgenus Heteromysis s. str.); the pereopod 1 carpopropodus longer than the merus (predominantly shorter in Olivemysis), and other unique features mentioned above.

Remarks. The characteristic feature of the micropsgroup, the distomedial process of the pereopod 1 merus, is also found in the type species of the genus Heteromysis, H. formosa. It has not been previously described or illustrated, but discovered during preparation of this manuscript in detailed examination by Karl Wittmann (personal communication). Further examination of this and other species of Heteromysis will shed light on the taxonomic importance of the microps species group.

Composition. The following 19 species clearly belong to the microps-group, including four from the Tasman Sea (marked with asterisk): Heteromysis (Heteromysis) abednavandii Wittmann, 2020; Heteromysis (H.) australica Băcescu et Bruce, 1980; Heteromysis (H.) communis*; Heteromysis (H.) dentata Hanamura et Kase, 2001; Heteromysis (H.) gracilis Murano, 1988; Heteromysis (H.) heronensis Băcescu, 1979; Heteromysis (H.) japonica Murano et Hanamura, 


\section{Key to the Tasman Sea species of the microps-group}

1 Telson with lateral spiniform setae only in posterior part (Figs 1C, 9C, 13C). Uropodal endopod with medial spiniform setae set distantly apart from each other (Figs 1D, 9E, 13E)

Telson with lateral spiniform setae along entire or nearly entire margins (Fig. 5C). Uropodal endopod with spiniform setae set close to each other (Fig. 5E) H. (H.) keablei sp. nov.

2 Telson cleft spinules along entire cleft length (Figs 1C, 13C). Pereopod 1 carpopropodus, segment 1 with bifurcated distomedial spiniform setae (Figs 2F,G, 14H,J) .... 3

Telson cleft spinules only in anterior part $(0.1-0.7$ of cleft length) (Fig. 9C,D). Pereopod 1 carpopropodus, segment 1 with normal, non-bifurcated distomedial spiniform setae (Fig. 10G) H. (H.) macropsis

3 Telson with rather deep cleft, about 0.3 of telson length (Fig. 1C). Telson lateral margins with six to eleven spiniform setae. Eyes with distomedial rim (Fig. 1A,B). Pereopod 3-6 unguis rather short and thick (Fig. 3A-C). Uropodal endopod with two to five proximal spiniform setae (Fig. 1D) H. (H.) communis

Telson with rather shallow cleft, about $0.14-0.15$ of telson length (Fig. 13C). Telson lateral margins with 13 to 20 spiniform setae. Eyes without distomedial rim (Fig. 13B). Pereopod 3-6 unguis rather long and thin (Fig. 15C,D). Uropodal endopod with 8 to 16 spiniform setae along almost entire length (Fig. 13E)

H. (H.) tasmanica

2002; Heteromysis (H.) keablei sp. nov.*; Heteromysis (H.) macropsis*; Heteromysis (H.) microps (G. O. Sars, 1877); Heteromysis (H.) minuta O. S. Tattersall, 1967; Heteromysis (H.) nomurai Murano et Fukuoka, 2003; Heteromysis (H.) nouveli Brattegard, 1969; Heteromysis (H.) proxima $\mathrm{W} . \mathrm{M}$. Tattersall, 1922; Heteromysis (H.) sahulensis; Heteromysis (H.) spinosa Băcescu, 1986; Heteromysis (H.) spottei Price et Heard, 2000; Heteromysis (H.) tasmanica*; and Heteromysis (H.) thailandica Fukuoka et Murano, 2002. Heteromysis sahulensis, despite the absence of a complete specimen with the pereopod I, is rather similar to $H$. (H.) keablei sp. nov. and $H$. (H.) communis, and, thus, also belongs in the nominate subgenus and the microps-group.

\section{Heteromysis (Heteromysis) communis Băcescu, 1986}

\section{Figs 1-3}

Heteromysis communis Băcescu, 1986: 22, figs 1M-S, 2A-G.-Hanamura \& Kase, 2001a: 18.-Lowry \& Stoddart, 2003: 447.

Heteromysis (Heteromysis) communis.-Murano, 1988: 27, 29, 48, fig. 3.-Daneliya, 2012: 135, 146.-San Vicente \& Monniot, 2014: 335.-Sawamoto, 2014: 7.

Type specimens. Holotype, female, $4 \mathrm{~mm}$, Australia, Northern Territory, Port Darwin, Channel Island, pool among corals, tide level, 07 Feb 1985, coll. A. J. Bruce, st. A.J.B. 22 (Museum of Art and Gallery of Northern Territory, Australia [NTM]). M. Băcescu (1986) also mentioned the allotype male, found from the same locality to be deposited at the "Grigore Antipa" National Museum of Natural History (Bucureşti) (MGAB) under accession no 711, but this is absent among the MGAB mysid types (Petrescu \& Wittmann, 2009; and Wittmann, personal communication).

Tasman Sea material. Male (+slide), $4 \mathrm{~mm}, 14$ males, $3.5-4 \mathrm{~mm}, 16$ females, $4-4.5 \mathrm{~mm}, 8$ subadults, 31 juveniles, south of Batemans Bay, north side of Burrewarra Point, $35^{\circ} 49.888^{\prime} \mathrm{S} 150^{\circ} 14.112^{\prime} \mathrm{E}, 19.5 \mathrm{~m}, 22.2 \mathrm{C}$, rocky reef with vertical faces and sediment pockets, honeycomb sponge, 9:57, 27 Mar 2004, coll. RV Baragula and RV Sula, st. NSW 2599, P. Berents, K. Attwood, R. Johnson, S. Keable, S. Kiely, K. Monro, A. Murray, R. Springthorpe, J. Watson, by hand on SCUBA (AM P.98680); 1 subadult, Batemans Bay, west of Tollgate Islands, $35^{\circ} 44.827^{\prime} \mathrm{S} 150^{\circ} 15.42^{\prime} \mathrm{E}, 7.5$ $\mathrm{m}, 22.1 \mathrm{C}$, patches of reef, sand, stones and Ecklonia radiata, Herdmania grandis (as H. momus), 29 Mar 2004, coll. RV Baragula \& RV Sula, st. NSW 2638, same collectors and gear (AM P.98681); 3 males, 3.5 mm, 10 females, 3.5-4 mm, 5 juveniles, 1 dried specimen, north side of Burrewarra Point, south of Batemans Bay, $35^{\circ} 49.807^{\prime} \mathrm{S} 150^{\circ} 14.014^{\prime} \mathrm{E}, 20 \mathrm{~m}$, $22.5 \mathrm{C}$, rocky reef with vertical faces, honeycomb sponge, 23 Mar 2004, coll. RV Baragula \& RV Sula, st. NSW 2502, same collectors and gear (AM P.98682); 2 specimens, Jervis Bay, Montagu Roadstead, $35^{\circ} 02^{\prime} 12^{\prime \prime S} 150^{\circ} 46^{\prime} \mathrm{E}, 12 \mathrm{~m}$, unvegetated sediment, Aug 1989, coll. Jervis Bay Baseline Study (CSIRO), site 3, \#5, hand held corer (AM P.98683).

Diagnosis. Rostrum (Fig. 1A) apically blunt, reaching half of antennular peduncle segment 1 ; its lateral margins slightly concave, without lateral tubercle, covering eyestalk bases. Eyestalk (Fig. 1A,B) with distomedial rim, more or less produced or pointed; cornea narrower than stalk. 


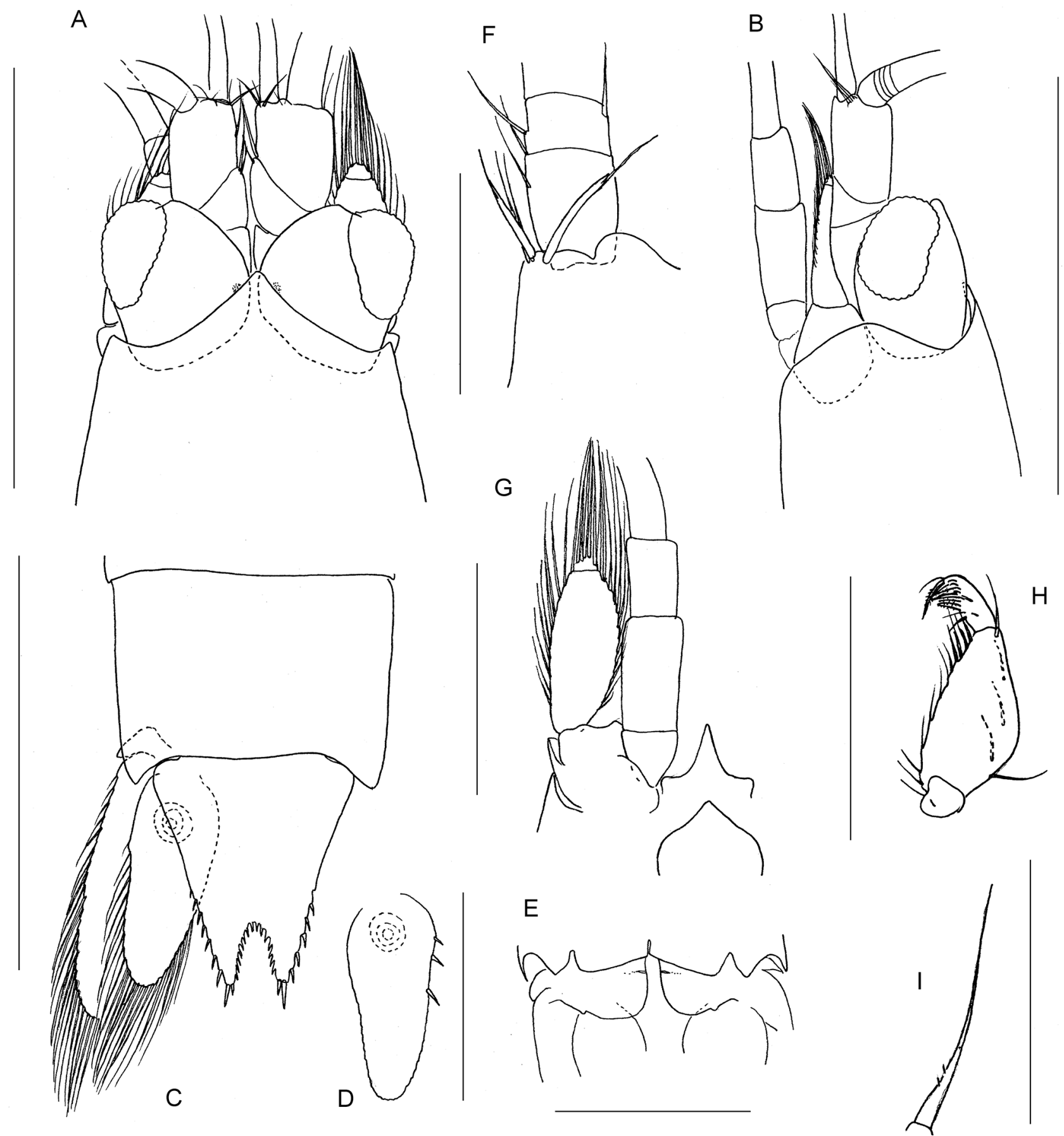

Figure 1. Heteromysis (H.) communis, male, 4 mm, AM P.98680. $(A)$ head, dorsal; $(B)$ head, lateral; $(C)$ posterior part of body, dorsal; $(D)$ uropodal endopod, ventral; $(E)$ posterior margin of abdomen, ventral; $(F)$ distomedial setae of antennular segment 3, dorsal; $(G)$ antenna 2, interocular process and labrum, ventral; $(H)$ mandibular palp, lateral; $(I)$ posterior seta of mandibular palp segment 2 . Scales $(\mathrm{mm}): \mathrm{A}-\mathrm{C}=1.0 ; \mathrm{D}, \mathrm{E}, \mathrm{G}, \mathrm{H}=0.5 ; \mathrm{F}, \mathrm{I}=0.25$.

Eye length $0.56-0.61$ of head width. Telson (Fig. 1C) 1.1 times length of abdominal somite $6,1.1-1.2$ times as long as wide, $0.30-0.38$ times as wide posteriorly as anteriorly. Cleft $0.27-0.31$ of telson length, with 15 to 23 spinules, occupying entire cleft and $0.40-0.44$ times as long as last posterolateral spiniform setae. Telson lateral margins nearly straight, with six to eleven spiniform setae, including two terminal, occupying posterior part. Inner terminal spiniform setae $0.43-0.56$ times as long as outer. Outer spiniform setae $0.10-0.13$ times as long as telson and 1.3-2.0 times as long as last posterolateral spiniform setae. Antennular peduncle segment 3 with two almost equally long flagellated spiniform setae (Fig. 1F). Antennal scale (Fig. 1G) 2.6-2.7 times as long as wide, reaching half of antennular peduncle segment 3 and half of antennal peduncle segment 3. Pereopod 1 (Fig. 2E-G) ischium 2.4-2.8 times as long as wide; merus 3.5-3.6 times as long as wide and 1.3-1.5 times as long as ischium, medially with four or five flagellated setae and distomedial process. Pereopod 1 carpopropodus slightly stronger in male; segment 1 is 2.8-3.9 times as long as wide and $0.98-1.1$ times as long as merus, its medial margin with four single spiniform setae, then distally with a pair of one regular and one slightly excavate spiniform setae, and two pairs with one slightly excavate and one tooth-like, clearly 


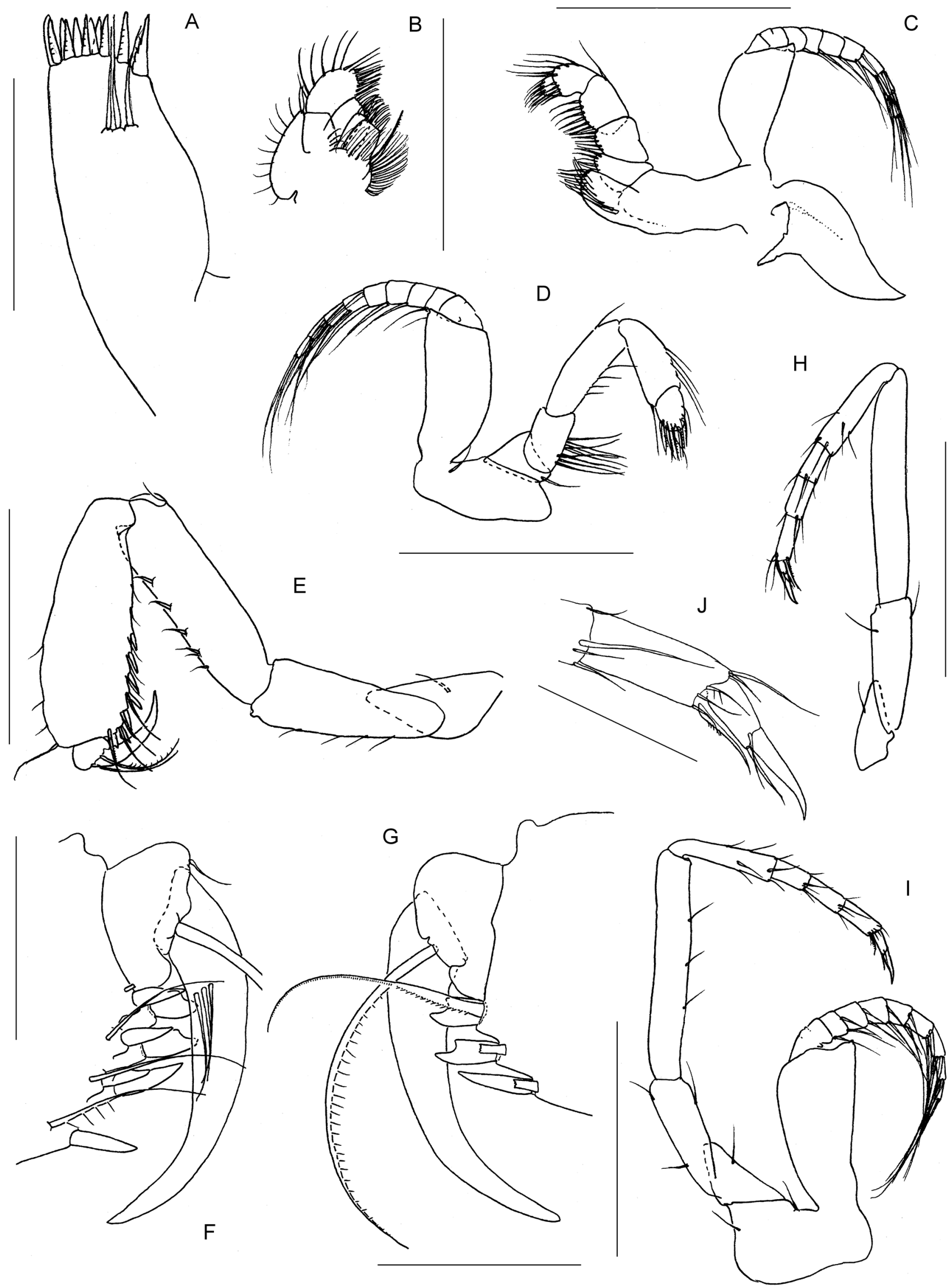

Figure 2. Heteromysis (H.) communis, male, 4 mm, AM P.98680. $(A)$ maxilla 1, anterior; $(B)$ maxilla 2, anterior; $(C)$ maxilliped 1, anterior; $(D)$ maxilliped 2, posterior; $(E)$ pereopod 1 endopod, posterior; $(F)$ distal part of pereopod 1 endopod, anterior; $(G)$ distal part of pereopod 1 endopod, posterior; $(H)$ pereopod 2 endopod, anterior; $(I)$ pereopod 3, posterior; $(J)$ distal part of pereopod 3 endopod, posterior. Scales $(\mathrm{mm}): \mathrm{A}, \mathrm{F}, \mathrm{G}, \mathrm{J}=0.25 ; \mathrm{B}-\mathrm{E}, \mathrm{H}, \mathrm{I}=0.5$. 


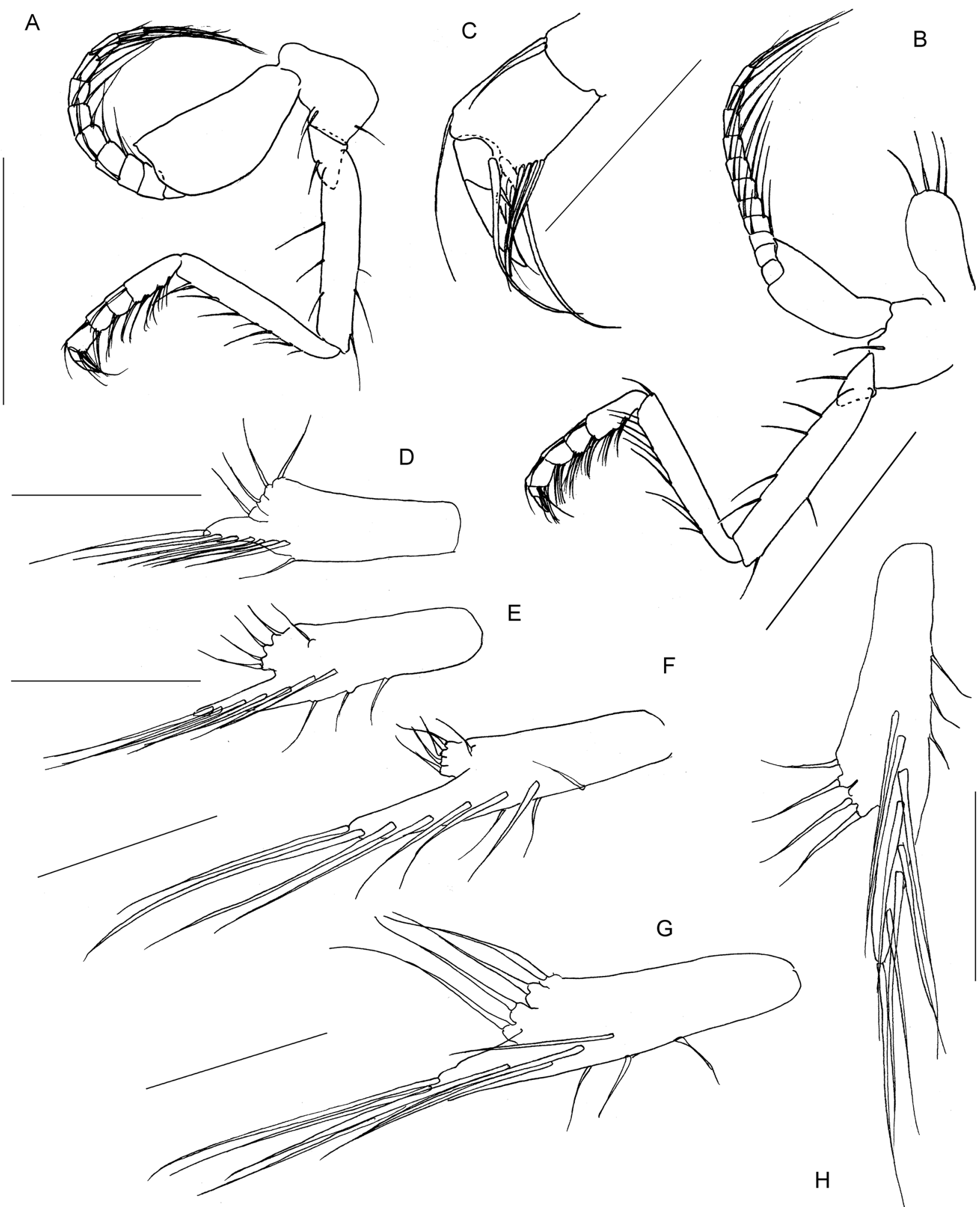

Figure 3. Heteromysis (H.) communis, male, $4 \mathrm{~mm}$, AM P.98680. $(A)$ pereopod 5, posterior; $(B)$ pereopod 6 with penis, posterior; $(C)$ distal part of pereopod 6 endopod, posterior; $(D-H)$ pleopods $1-5$, anterior. Scales $(\mathrm{mm})$ : A, B $=0.5 ; \mathrm{C}-\mathrm{H}=0.25$.

bifurcate spiniform setae; each single or pair of spiniform setae provided medially with long seta, bearing small number of long proximal setules, and laterally with stronger seta, bearing numerous short setules in thick proximal part and microsetules in thin distal; segment 2 with slight distomedial tubercle, with long paradactylary seta, bearing numerous long setules. Dactylus $0.27-0.40$ times as long as carpopropodus, semilunar, not meandering. Pereopod 2-6 (Fig. $2 \mathrm{H}-\mathrm{J}, 3 \mathrm{~A}-\mathrm{C}$ ) carpopropodus 4-segmented; unguis nearly straight, smooth and nearly as thick as dactylus, becoming thicker in posterior endopods. Pereopod exopod basal joint with outer acute process. Penis (Fig. 3B) with one to four distal setae. Uropodal endopod (Fig. 1C,D) 0.79-0.84 times as long as exopod, with two to five (mostly three) 
medial spiniform setae in proximal part; exopod 3.0-3.1 times as long as wide.

Body length. Males $3.5-4 \mathrm{~mm}$ (3 $\mathrm{mm}$ in the type locality), females $3.5-4.5 \mathrm{~mm}$ ( $4 \mathrm{~mm}$ in the type locality).

Comparison. Heteromysis (Heteromysis) communis is a rather distinct species, with its thick and almost straight unguis of pereopods 2-6. Apart from being clearly a member of the microps species group, it is not particularly similar to any species. Among the Tasman Sea species it somewhat resembles $H$. (H.) keablei sp. nov., but it is readily distinguished from it by a larger number of the telson cleft spinules (15 to 23 against 6 to 10 in H. keablei), which occupy the entire cleft (only anterior part in H. keablei), less number of the telson lateral spiniform setae (6 to 11 against 15 to 23 in H. keablei), which occupy only the posterior part (the entire or almost entire length in $H$. keablei), less number of the spiniform setae on the uropodal endopod ( 2 to 5 against 12 to 27 in H. keablei), the strong dactylar unguis of the pereopods 2-6 (rather slender in H. keablei) and other characters.

Description of Tasman Sea specimens. Rostrum angular, apically blunt, reaching half of peduncle segment 1 of antennula; lateral margins slightly concave, covering bases of eyestalks, without lateral tubercles. Telson 1.1 times length of abdominal somite $6,1.1-1.2$ times as long as wide, $0.30-0.38$ times as wide posteriorly as anteriorly. Telson cleft $0.27-0.31$ times of entire telson length, with 15 to 19 spinules, occupying almost entire cleft length, 0.4-0.7 times as long as last posterolateral spiniform setae; lateral margins nearly straight, with eight or nine spiniform setae, including two apical; inner terminal spiniform setae $0.55-0.56$ times as long as outer. Outer spiniform setae $0.10-0.12$ times as long as telson and 1.5-2.0 times as long as last posterolateral spiniform setae. Lateral spiniform setae absent in proximal half of telson.

Eyes slightly flattened dorsoventrally, nearly conical from dorsal view; eye length about 1.1-1.2 eye width, and 0.6 times anterior head width. Cornea 0.8 times as wide as stalk and 0.4 times of entire eye length. Eyestalk with distomedial rim, more or less produced. Antennular peduncle segment 3 with two long flagellated setae, one of them directed laterally. Antennal scale 2.6-2.7 times as long as wide, reaching half of antennular peduncle segment 3 and half of antennal peduncle segment 3 .

Labrum produced, apically blunt. Mandibular palp, segment 2 with setae along entire posterior margin; segment 3 with two posterior and one medial setae in proximal half. Maxilla 1 outer ramus with serrated apical spiniform setae. Thoracopod exopods 8-10-segmented; basal segment with acute outer process. Maxilliped 2 carpopropodus 0.7 times as long as merus.

Pereopod 1 endopod. Ischium 2.8 times as long as wide, only with short and fine posterior setae. Merus 3.6 times as long as wide and 1.2 times as long as ischium; its medial margin with five strong flagellated setae and distal sharp process. Carpopropodus segment 1 is 2.8 times as long as wide and 1.1 times as long as merus; with four single spiniform setae, then distally with a pair of one regular and one slightly excavate spiniform setae, and two pairs with one slightly excavate and one tooth-like, clearly bifurcate spiniform setae; each single or pair of spiniform setae provided medially with long seta, bearing small number of long proximal setules, and laterally with stronger seta, bearing numerous short setules in thick proximal part and microsetules in thin distal; segment 2 with slight distomedial tubercle, with long paradactylary seta, bearing numerous long setules. Dactylus 0.39-0.40 times as long as carpopropodus, with semilunar unguis.

Pereopod 2-6 endopods rather thin, carpopropodus 4-segmented; unguis nearly straight, smooth and nearly as thick as dactylus, becoming thicker in posterior endopods. Preischium with one seta. Pereopod 2, ischium shorter than merus; both segments with only few setae; carpopropodus rather long, nearly as long as merus; carpopropodal segments prolonged, with short setae; paradactylary setae short and serrated. Pereopod 3-6, ischium slightly longer than merus, with setae along anterior and distal half of posterior margins; merus posterior margin with numerous setae; carpopropodus 0.8 times as long as merus, with four rather short segments and long setae; paradactylary setae rather thin and smooth, longer than unguis.

Penis with four distal setae. Pleopods with seven to ten setae along rather short ramus. Uropodal endopod $0.79-0.84$ times as long as exopod, with three to five medial spiniform setae in proximal part; exopod 3.0-3.1 times as long as wide.

Variation. The original description already noted some range of the eye shape variation (Băcescu, 1986). Later Murano (1988) also mentioned that the distomedial corner may be more or less pointed or produced; additionally, the eye shape from dorsal view can vary from nearly rounded to slightly conical. The pereopod 1 carpopropodus in the Tasman Sea specimens is slightly wider in the male, and not as narrow as depicted by Băcescu (1986) from the type specimens, where the carpopropodus length is four times width, rather like mentioned by Murano (1988). The penis is armed with one seta in the holotype, but with two setae in the Murano's males; yet the Tasman Sea males have four apical setae. The telson cleft is armed by fewer, 15 to 19 , spinules ( 20 to 23 as recorded elsewhere), and the uropod endopod bears two to five spiniform setae (mostly three), compared to three to five, mostly four or five in the Northern Territory specimens. Although Murano (1988) considered the observed variation in his specimens unusual, the Tasman Sea specimens further extend the documented range of variation in the species.

Distribution. Australia: Channel Island at Darwin Harbour (Northern Territory) as the type locality; later also collected from Dudley Point Reef and Fort Hill Wharf of the same Darwin Harbour (Murano, 1988). First time reported from the eastern Australian coast in this study, namely from Batemans Bay near Burrewarra Point, Tollgate Island, and from Jervis Bay (Fig. 4).

Habitat and life history. Depth 5-12 m; on sponges: honeycomb sponge, and surrounding reefs. Băcescu (1986) found harpactocoids from the stomachs of Heteromysis communis, supposing its predatorial habits.

Remarks. Băcescu (1986), though being the author of the Heteromysis subgeneric system (Băcescu, 1968), did not attribute this species to any subgenus. That was done by Murano (1988), who assigned it into the nominotypical subgenus. The species was originally distinguished from the other species by the eyestalk with slightly produced anteromedial corner, the telson cleft deep, with more than 20 spinules (in fact, can be from 15), the telson lateral margins with six to nine spiniform setae in the posterior half (in fact, up to eleven) and the pereopod 1 endopods only 


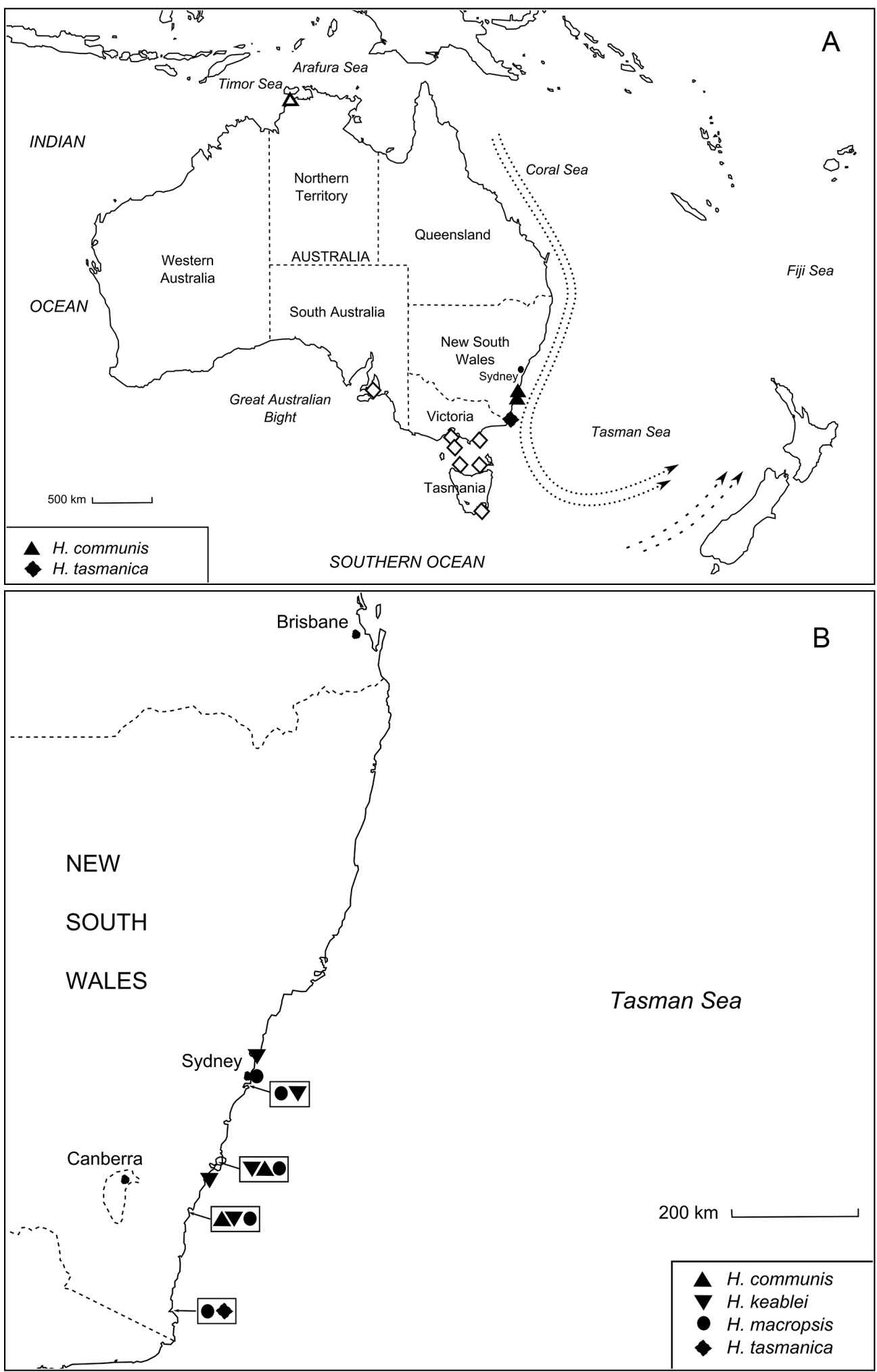

Figure 4. Distribution of the Tasman Sea Heteromysis (Heteromysis) species. (A) general distribution of $H$. (H.) communis and $H$. (H.) tasmanica (the white signs indicate former records); (B) $H$. (H.) communis, H. (H.) keablei sp. nov., H. (H.) macropsis and H. (H.) tasmanica in the Tasman Sea.

slightly sexually dimorphic. Murano (1988) also added the rostrum, which was narrowly rounded at the apex, extending to the middle of the antennular peduncle segment 1 and covering the basal parts of the eye stalks; the pereopod 1 merus subequal in length to the carpopropodus, with four (can also be five) small flagellated spiniform setae and the distomedial triangular process; the pereopod 2 endopod with the 4-segmented carpopropodus more slender and hirsute than the posterior endopods, and with the straight unguis (this concerns the ungue of the other pereopods too). The species has many more diagnostic characters documented here after the comparison with the other species of the microps-group. 
Heteromysis (Heteromysis) keablei sp. nov. urn:Isid:zoobank.org:act:2C711FD7-E6EE-4B80-AECD-E3C9D5EE80E7

\section{Figs $5-8$}

Etymology. Named after Stephen John Keable, a collection manager at the Australian Museum, for his assistance on various stages of this and other Australian mysid research, collecting numerous specimens for this study and for his contribution to the carcinology and marine biology.

Holotype. Male (+slide), $4.5 \mathrm{~mm}$, north side of Burrewarra Point, south of Batemans Bay, 3549'48"S 150¹4'01"E, 22.2 $\mathrm{m}, 22.5^{\circ} \mathrm{C}$, coarse sand and shell, dead barnacles, bryozoans, ascidians and solitary coral, 23 Mar 2004, coll. RV Baragula \& RV Sula, NSW 2494, P. Berents, K. Attwood, R. Johnson, S. Keable, S. Kiely, K. Monro, A. Murray, R. Springthorpe, J. Watson, airlift on SCUBA (Australian Museum P.75281).

Paratypes. Female, $4.5 \mathrm{~mm}$, juvenile, same data as for holotype (AM P.98695); female, $4.5 \mathrm{~mm}$, same locality, $35^{\circ} 49.776^{\prime} \mathrm{S} 150^{\circ} 13.955^{\prime} \mathrm{E}, 15 \mathrm{~m}, 22^{\circ} \mathrm{C}$, rocky reef with sand patches and some large boulders with vertical faces, some patches of Ecklonia, under stones with small stones, very little sediment, 24 Mar 2004, NSW 2540, same collectors and gear (AM P.98692); male, $4.5 \mathrm{~mm}$, female, $4.5 \mathrm{~mm}$, juvenile, same locality as previous, $35^{\circ} 49.776^{\prime} \mathrm{S} 150^{\circ} 13.955^{\prime} \mathrm{E}, 17 \mathrm{~m}$, $22^{\circ} \mathrm{C}$, rocky reef with sand patches and some large boulders with vertical faces, some patches of Ecklonia, under stones in sand, 24 Mar 2004, NSW 2538, same collectors and gear (AM P.98693); male, $4 \mathrm{~mm}$, female, $4.5 \mathrm{~mm}, 35^{\circ} 49.776^{\prime} \mathrm{S}$ $150^{\circ} 13.955^{\prime} \mathrm{E}, 17 \mathrm{~m}, 22^{\circ} \mathrm{C}$, rocky reef with sand patches and some large boulders with vertical faces, some patches of Ecklonia, under stones in sand, 24 Mar 2004, NSW 2538, same collectors and gear (AM P.98694); female, $5 \mathrm{~mm}$, Jervis Bay, Hole in the Wall, $35^{\circ} 07^{\prime} 36^{\prime \prime S} 150^{\circ} 44^{\prime} 48^{\prime \prime E}, 12 \mathrm{~m}, 12$ Nov 1989, coll. Jervis Bay Baseline Study (CSIRO), site 1, \#4 (AM P.98696).

Additional specimens. Male (+slide), 6 mm, Hawkesbury River, near Hungry Beach, $33^{\circ} 35^{\prime} \mathrm{S} 151^{\circ} 17^{\prime} \mathrm{E}, 4 \mathrm{~m}$, sandy mud, 9 Nov 1984, coll. A. R. Jones \& A. Murray; HRS 1-1 Nov 84, Smith-McIntyre Grab (AM P.53661); female, 6 $\mathrm{mm}$, same data as in previous (AM P.98706); 2 immature specimens, 4-4.5 mm, same locality, $33^{\circ} 35^{\prime} \mathrm{S} 151^{\circ} 17^{\prime} \mathrm{E}$, 4 m, sandy mud, 11 Nov 1983, HRS 1-1 Nov 83, same collectors and gear (AM P.53662); male, $4.5 \mathrm{~mm}$, Botany Bay, 335' $11^{\prime \prime S} 151^{\circ} 11^{\prime} 10^{\prime \prime E}, 18.4$ m, sandy mud, 16 Dec 1994, coll. Australian Museum party, FAC2 07Bot2/1a (AM P.59284); damaged specimen, west of Tollgate Islands, Batemans Bay, $35^{\circ} 44.827^{\prime} \mathrm{S} 150^{\circ} 15.42^{\prime} \mathrm{E}, 7 \mathrm{~m}, 22.1^{\circ} \mathrm{C}$, patches of reef, stones and Ecklonia radiata, under large stones, 29 Mar 2004, coll. RV Baragula \& RV Sula, NSW 2642, P. Berents, K. Attwood, R. Johnson, S. Keable, S. Kiely, K. Monro, A. Murray, R. Springthorpe, J. Watson, airlift on SCUBA (AM P.98697); 1 juvenile, Ulladulla, northern side of Bannister Head, 35 $19.15^{\prime}$ 'S $150^{\circ} 29.12^{\prime} \mathrm{E}, 18$ m, 06 May 1997, coll. K. B. Attwood \& R. T. Springthorpe, NSW 1347, airlift (AM P.98698).

Diagnosis. Rostrum (Fig. 5A) angular, apically blunt or rounded, reaching proximal part or half of antennular peduncle segment 1; its lateral margins slightly concave, without lateral tubercle, covering eyestalk bases. Eyestalk with only slight distomedial rim, not pointed; cornea slightly narrower than stalk, but not significantly reduced. Eye length $0.49-0.53$ of head width. Telson (Fig. 5C,D) $1.0-1.2$ times as long as abdominal somite $6,1.2-1.3$ times as long as wide, $0.18-0.19$ times as wide posteriorly as anteriorly. Cleft $0.19-0.20$ of telson length, with six to ten spinules, occupying $0.28-0.51$ of cleft length. Telson lateral margins with 15 to 27 spiniform setae, occupying entire or almost entire sides, including two terminal spiniform setae, with wing-like extensions. Inner terminal spiniform setae $0.75-0.85$ times as long as outer. Outer spiniform setae $0.09-0.16$ times as long as telson and 1.2-1.4 times as long as last posterolateral spiniform setae. Antennular peduncle (Fig. 5F-H) segment 3 with two rather long flagellated spiniform setae. Antennal scale (Fig. 5I) 2.4-3.4 times as long as wide, stretching little beyond half of antennular peduncle segment 3 and beyond half of antennal peduncle segment 3. Pereopod 1 (Fig. 7A-E) ischium 1.7 times as long as wide; merus 3.4 times as long as wide and 2.0 times as long as ischium, medially with seven flagellated setae and distomedial process. Pereopod 1 carpopropodus segment 1 is 3.3 times as long as wide and 1.1 times as long as merus, its medial margin with seven smooth and a pair of smooth and shorter bifurcated spiniform setae; each of first six spiniform setae laterally provided with posteroand anterodistally serrated long seta; and distally with two stronger setae with posteroproximal serration; segment 2 without distomedial process, with three long paradactylary setae, proximally with thin long separate spinules and distally numerous short denticles. Dactylus $0.39-0.40$ times as long as carpopropodus, meandering. Pereopod 2-6 (Figs 7F, 8A-D) carpopropodus 5-7-segmented; unguis rather thin, smooth. Pereopod exopod basal segment without outer acute process. Penis (Fig. 8E) with two or three anterodistal and one or three posterodistal setae. Uropodal endopod (Fig. 5E) $0.78-0.89$ times as long as exopod, with 16 to 27 medial spiniform setae, closely set along entire margin.

Body length of male 4.0-6.0 mm, female 4.5-6.0 $\mathrm{mm}$.

Comparison. In the microps-group, Heteromysis (Heteromysis) keablei sp. nov. is most similar to Heteromysis (H.) nomurai, and Heteromysis (H.) sahulensis. It differs from the first species (found in the Japanese waters) by the shorter rostrum, which is nearly reaching the distal margin of the antennular peduncle segment 1 and uniquely has a pair of lateral tubercles or swellings above the eyestalk in $H$. nomurai; the shorter telson (1.5 times as long as the last abdominal somite in $H$. nomurai); and larger number of the telson lateral spiniform setae (15 to 27 against 13 , which occupy the posterior part of the telson in H. nomurai); the telson terminal spiniform setae clearly longer than the last posterolateral spiniform setae (as long as or shorter in $H$. nomurai); the ischium of the pereopod 1 smooth (with small flagellated setae in $H$. nomurai); less number of the penis setae (about ten posterior setae in $H$. nomurai); a larger number of the uropodal endopod spiniform setae (16 to 27 against 12 to 14 in $H$. nomurai). In the micropsgroup, Heteromysis $(H$.) keablei shares the largest number of the spiniform setae on the medial margin of the uropodal endopod, set rather close to each other, with Heteromysis (H.) sahulensis. From this species it is distinguished by less developed distomedial rim of the eyestalk (rather strongly developed in $H$. sahulensis); relatively large cornea (notably reduced in $H$. sahulensis); less prolonged telson (1.2-1.3 

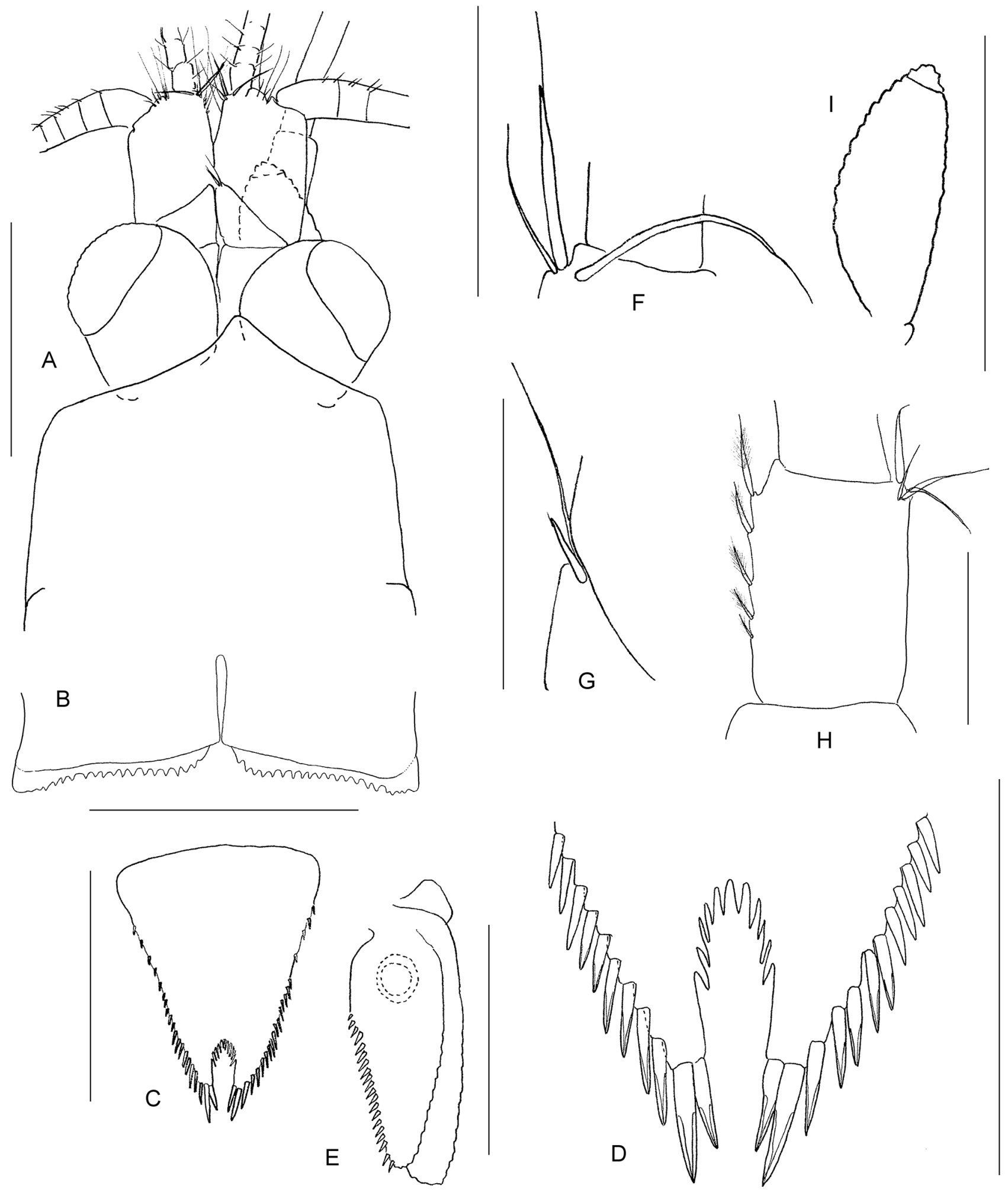

Figure 5. Heteromysis (Heteromysis) keablei sp. nov., holotype, male, $4.5 \mathrm{~mm}$, AM P.75281: $(A)$ head, dorsal; $(B)$ abdominal somite 6 posteroventral margin; $(C)$ telson; $(D)$ telson posterior part; $(E)$ uropod, dorsal; $(F)$ distomedial spiniform setae of antenna 1 peduncle segment 3; $(G)$ distomedial spiniform setae of antenna 1 peduncle segment $2 ;(H)$ segment 3 of antenna 2 peduncle, ventral; $(I)$ antennal scale. Scales (mm): A-E, I = 0.5; F-H =0.25.

as long as proximal width against 1.5 in $H$. sahulensis); posteriorly more narrowing telson, with the posterior width $0.18-0.19$ times the anterior width $(0.3$ in $H$. sahulensis); shallower telson cleft $(0.19-0.20$ times as long as telson against 0.3 in $H$. sahulensis); fewer cleft spinules (6 to 10 against $24 \mathrm{H}$. sahulensis); occupying less than a half of the cleft (0.7 in H. sahulensis); two against anomalously one terminal spiniform setae in $H$. sahulensis; longer antennal scale, extending beyond the middle of the antennular and antennal peduncles segment 3 (reaching only the proximal part in $H$. sahulensis); the uropodal endopod clearly shorter than the exopod (nearly equal in $H$. sahulensis). 


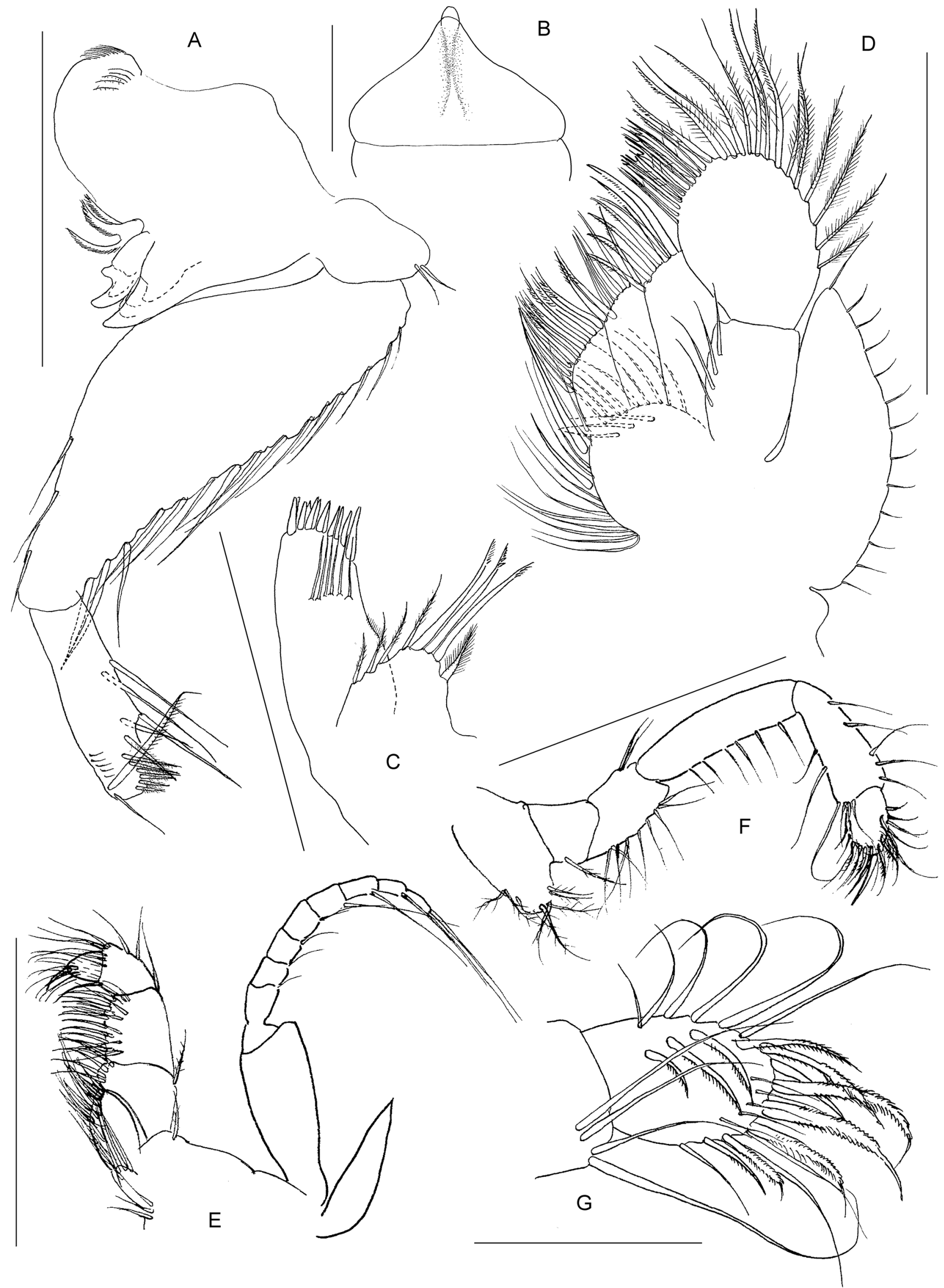

Figure 6. Heteromysis (Heteromysis) keablei sp. nov., holotype, male, $4.5 \mathrm{~mm}$, AM P.75281: $(A)$ mandible, left; $(B)$ labrum, posterior; $(C)$ maxilla 1, posterior; $(D)$ maxilla 2, anterior; $(E)$ maxilliped 1, anterior; $(F)$ maxilliped 2, posterior; $(G)$ maxilliped 2 distal part, posterior. Scales (mm): A, C-F $=0.5 ; \mathrm{B}, \mathrm{G}=0.25$. 


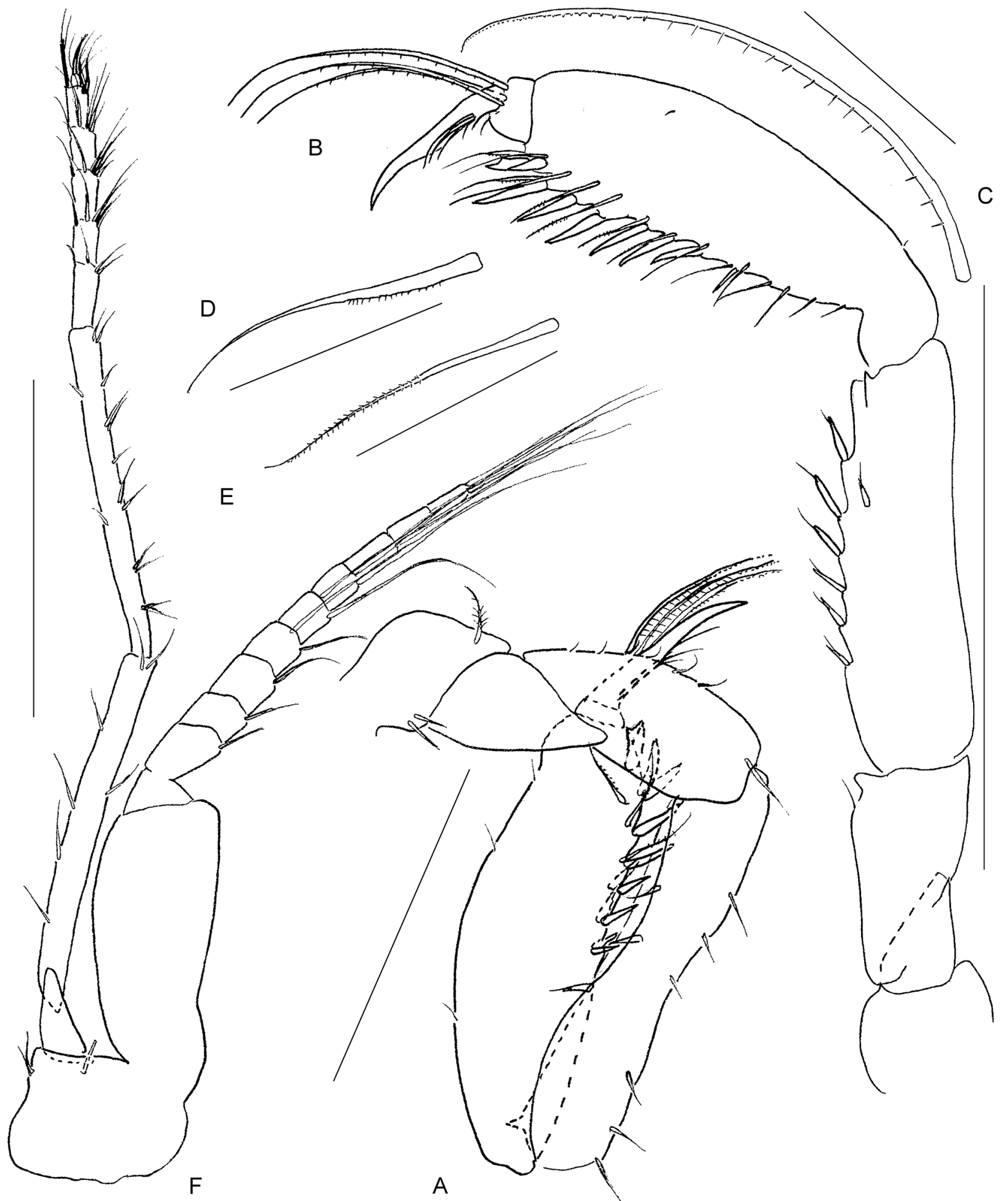

Figure 7. Heteromysis (Heteromysis) keablei sp. nov. (A, C, F) holotype, male, $4.5 \mathrm{~mm}$, AM P.75281; $(B, D, E)$ paratype, male, 4.5 $\mathrm{mm}$, AM P.98693. (A) pereopod 1 endopod, posterior; $(B)$ pereopod 1 endopod, posterior; $(C)$ distal seta of pereopod 1 carpopropodus segment $2 ;(D)$ distolateral seta of pereopod 1 carpopropodus segment $1 ;(E)$ posterolateral seta of pereopod 1 carpopropodus segment $1 ;(F)$ pereopod 3. Scales $(\mathrm{mm}): \mathrm{A}, \mathrm{F}=0.5 ; \mathrm{B}=1 ; \mathrm{C}-\mathrm{E}=0.25$.

Description of holotype. Rostrum triangular, apically blunt, reaching half of peduncle segment 1 of antennula; lateral margins slightly concave, covering bases of eyestalks. Posteroventral margin of abdominal somite 6 serrated. Telson about as long as last abdominal somite, 1.2 times as long as wide anteriorly, tapering posteriorly, 0.19 times as wide posteriorly as anteriorly. Telson cleft 0.2 times of entire telson length, with ten spinules, occupying about half of cleft; lateral margins slightly sinusoid, with 20 and 21 spiniform setae, including two apical, with distal wing-like expansions; outer terminal spiniform setae 1.5 times as long as inner. Lateral spiniform setae absent in anterior part of telson. 


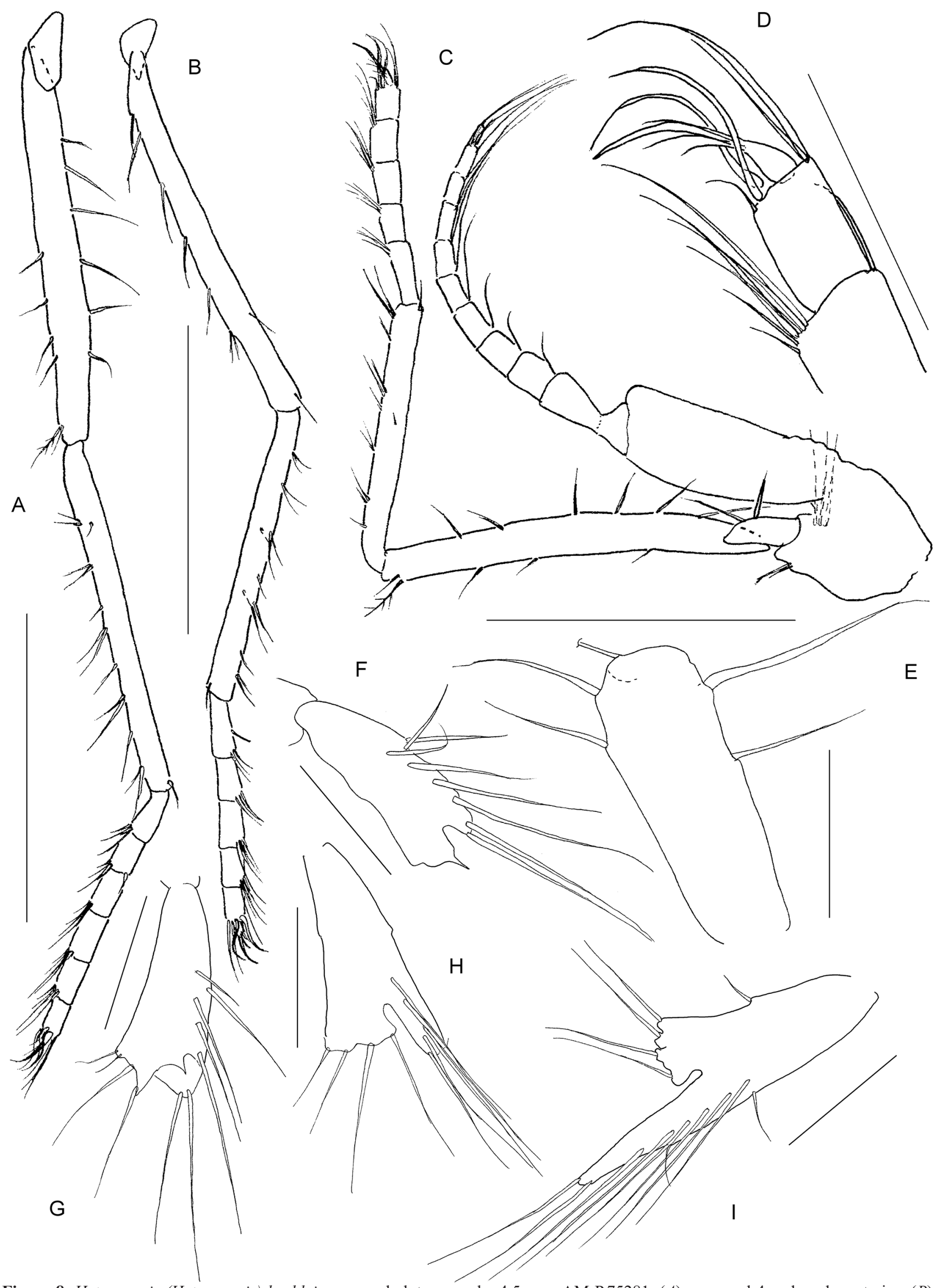

Figure 8. Heteromysis (Heteromysis) keablei sp. nov., holotype, male, $4.5 \mathrm{~mm}$, AM P.75281. (A) pereopod 4 endopod, posterior; (B) pereopod 5 endopod, anterior; $(C)$ pereopod 6 , anterior; $(D)$ distal part of pereopod 6 endopod, anterior; $(E)$ penis; $(F)$ pleopod 2 , posterior; $(G)$ pleopod 3, posterior; $(H)$ pleopod 4, posterior; $(I)$ pleopod 5, posterior. Scales $(\mathrm{mm})$ : A-C $=0.5$; D-I $=0.25$. 
Eyes flattened dorsoventrally, nearly rounded from dorsal view; eye length about 1.0 eye width, and 0.6 times anterior head width. Cornea 0.7 times as wide as stalk and 0.3 times of entire eye length. Antennular peduncle segment 3 with two long flagellated setae, one of them directed laterally. Antennal scale rather wide, 2.4 times as long as wide, reaching level of about half of antennal and antennular peduncles segment 3 or slightly beyond that.

Labrum produced, apically rounded, with keel. Mandibular palp, segment 2 with setae along entire posterior margin; segment 3 with two posterior and two medial setae in distal half. Maxilla 1 outer ramus with smooth apical spiniform setae. Thoracopod exopods 9-segmented; basal segment without acute outer process. Maxilliped 2 carpopropodus 0.7 times as long as merus.

Pereopod 1 endopod. Ischium 1.7 times as long as wide, only with short and fine posterior seta. Merus 3.4 times as long as wide and 2.0 times as long as ischium; its medial margin with seven strong flagellated setae and distal sharp process. Carpopropodus segment 1 is 3.3 times as long as wide and 1.1 times as long as merus; its medial margin with seven smooth and a pair of smooth and shorter bifurcated spiniform setae; each of first six spiniform setae laterally provided with postero- and anterodistally serrated long seta; and distal two stronger setae with posteroproximal serration; segment 2 without distomedial process, with three long paradactylary setae, proximally with thin long separate spinules and distally numerous short denticles. Dactylus 0.39-0.40 times as long as carpopropodus, with meandering unguis.

Pereopod 3-6 endopods rather thin and long. Preischium without or with two setae. Ischium only slightly longer and wider than merus, with setae along anterior and distal half of posterior margins (along entire posterior in pereopod 6). Merus posterior margin with five pairs and single intermediate setae. Carpopropodus $0.7-0.8$ times as long as merus, with five or six prolonged segments. Paradactylary setae and unguis rather thin and smooth.

Penis with three anterior and two posterior setae. Pleopods with seven or eight setae along rather short ramus. Uropod endopod shorter than exopod, with 20 and 22 rather short and closely set spiniform setae on medial margin.

Color. From a rather low resolution photograph, made soon after the sampling, which I do not publish here, it is possible to see that a living specimen had a transparent cuticle, without any coloration. Eye cornea black.

Variation. The specimens from near Sydney (Hawkesbury River Mouth and Botany Bay) differ from the specimens of the southern New South Wales coast (Batemans Bay and Jervis Bay) by the rostrum shape (apically rounded against blunt), narrower antennal scales (3.2-3.4 against 2.4 times as long as wide) and a larger number of the telson lateral spiniform setae (25 to 27 against 15 to 23 ), spread along the entire margins (the spiniform setae absent in the most anterior part of the telson in the southern NSW). I hesitate in establishment of separate taxonomic status for the Sydney specimens before larger and more extensive material is collected.

Distribution. Australia, New South Wales: Batemans Bay (type locality), Ulladulla, Jervis Bay, Hawkesbury River Mouth, Hungry Beach, Botany Bay. So far recorded only in the Tasman Sea (Fig. 4B).
Habitat and life history. Sublittoral species, found at a depth of 4-22 m. Bottom: rocky reefs with coarse sand and shell, large boulders with vertical faces, dead barnacles, bryozoans, ascidians and solitary coral, patches of brown alga Ecklonia radiata; found under stones with small stones and very little sediment or under stones in sand; sandy-muddy bottom. Marsupium of a $4.5 \mathrm{~mm}$ female from Batemans Bay contained three embryos on 23 March and at temperature of $22.5^{\circ} \mathrm{C}$.

\section{Heteromysis (Heteromysis) macropsis Pillai, 1961}

$$
\text { Figs 9-12 }
$$

Heteromysis macropsis Pillai, 1961: 32, plate 6K-S; 1965: 1684, 1726, fig. 96.-O. S. Tattersall: 1967: 169.-Mauchline \& Murano, 1977: 59.-Müller, 1993: 225.-Neyt, 2002: 11.-Fukuoka \& Murano, 2002: 94.-Wittmann, 2020: 154, 155.

Type material. Two immature specimens, 4-5 mm, off Kollam (former Quilon), State of Kerala, India (Pillai, 1961). Status unknown.

Type locality. Off Kollam (former Quilon), Kerala State, India (Pillai, 1961).

Tasman Sea material. Female (+slide), $4 \mathrm{~mm}$, north east corner of Clark Island, $33^{\circ} 51.85^{\prime} \mathrm{S} 151^{\circ} 14.47 \mathrm{\prime} \mathrm{E}, 4-5 \mathrm{~m}$, Ecklonia holdfast, 17 Apr 1996, coll. P. A. Hutchings, st. NSW 1244, by hand on SCUBA (AM P.98707); male, 3.5 $\mathrm{mm}$ (pereopod endopods missing), same data as previous (AM P.98708); 4 females, same data as previous (AM P.98709); female, $4.5 \mathrm{~mm}$ (pereopod endopods missing), same locality and depth, encrustation on outside of bottle, 17 Apr 1996, coll. P. A. Hutchings, st. NSW 1243 (AM P.98710); female, subadult, juvenile, south of Vaucluse Point, Port Jackson, 33 ${ }^{\circ} 52^{\prime} \mathrm{S} 151^{\circ} 17^{\prime} \mathrm{E}, 3 \mathrm{~m}$, sponge, 22 Jun 1982, coll. J. K. Lowry, st. NSW 108 (AM P.98711); female, 5 mm, Clark Island, 7 m, kelp holdfast with sponges, 06 Jun 2001, coll. R. T. Springthorpe (AM P.98712); female, subadult female, juvenile, Port Jackson, south west of Camp Cove, $33^{\circ} 50^{\prime} 24.65^{\prime \prime S} 151^{\circ} 16^{\prime} 35.63^{\prime \prime E}, 11 \mathrm{~m}$, drift algae on sediment covered coarse shell, 19 Feb 2010, coll. RV Baragula, MI NSW 3998, S. J. Keable, by hand on SCUBA (AM P.98719); female (pereopods absent), 6 mm, Lady Robinsons Beach North (2), Botany Bay, 3357'30"S 151 09'30"E, $7 \mathrm{~m}$, rock scraping, 29 Oct 1998 (NSW Fisheries; BB LR2 qual) (P.58590); male, $4.5 \mathrm{~mm}$ (pereopods missing), female (pereopods missing), $4.5 \mathrm{~mm}$, Jervis Bay, 05 Jun 1990, coll. Jervis Bay Baseline Study (CSIRO), site 3, \#1 (AM P.98718); female (in two parts, pereopods missing), 4 mm, same locality and collector, Aug 1989, site 4, \#1 (AM P.98713); 2 specimens (appendages missing), same locality and collector, Aug 1989, site 3, \#2 (AM P.98714); male, 4 $\mathrm{mm}$ (pereopods missing; penis illustrated), female, $4.5 \mathrm{~mm}$ (appendages missing), same locality and collector, 17 Aug 1989, site 1, \#1 (AM P.98715); female, 3.5 mm (pereopods missing), same locality and collector, 12 Nov 1989, site 1, \#4 (AM P.98716); female, $4.5 \mathrm{~mm}$ (pereopods missing), same locality and collector, 05 Jun 1990, coll. same locality and collector, site 3, \#1 (AM P.98717); female, 4 mm, north side of Burrewarra Point, south of Batemans Bay, 3549.807'S $150^{\circ} 14.014 ' \mathrm{E}, 22 \mathrm{~m}, 22.5 \mathrm{C}$, rocky reef with vertical faces, 
under stones, sand bottom, 23 Mar 2004, coll. RV Baragula \& RV Sula, st. NSW 2515, P. Berents, K. Attwood, R. Johnson, S. Keable, S. Kiely, K. Monro, A. Murray, R. Springthorpe and J. Watson, airlift on SCUBA (AM P.98720); 2 subadult specimens, same locality and collectors, $35^{\circ} 49.807^{\prime} \mathrm{S}$ $150^{\circ} 14.014 ' \mathrm{E}, 17 \mathrm{~m}, 22.5 \mathrm{C}$, rocky reef with vertical faces, rock with Hydrodendron australe and other encrusting fauna, 23 Mar 2004, st. NSW 2511 (AM P.98721); subadult, west of Tollgate Island, $35^{\circ} 44.827^{\prime} \mathrm{S} 150^{\circ} 15.42^{\prime} \mathrm{E}, 8.2 \mathrm{~m}, 22.1 \mathrm{C}$, patches of reef, sand, stones and Ecklonia radiata, under rock, 29 Mar 2004, coll. RV Baragula, NSW 2652, same collectors and gear (AM P.98723); subadult female, $3 \mathrm{~mm}$, juvenile, south of Batemans Bay, north side of Burrewarra Point, $35^{\circ} 49.776$ 'S $150^{\circ} 13.955^{\prime} \mathrm{E}, 15 \mathrm{~m}, 22 \mathrm{C}$, rocky reef with sand patches and some large boulders with vertical faces, some patches of Ecklonia, black leathery finger sponge, 24 Mar 2004, coll. RV Baragula, st. NSW 2530, same collectors and gear (AM P.98722); juvenile, same locality, $35^{\circ} 49.807^{\prime} \mathrm{S}$ $150^{\circ} 14.014 ' \mathrm{E}, 20.8 \mathrm{~m}, 22.5 \mathrm{C}$, rocky reef with vertical faces, dead and live bryozoan cf. Triphyllozoon, 23 Mar 2004, coll. RV Baragula, st. NSW 2500, same collectors and gear (AM P.98724); female, $4.5 \mathrm{~mm}$, male, $4.5 \mathrm{~mm}$, Twofold Bay, Murrumbulga Point, Quarantine Bay side, $37^{\circ} 04^{\prime} 42^{\prime \prime S}$ $149^{\circ} 53^{\prime} 06^{\prime} \mathrm{E}, 15 \mathrm{~m}$, subtidal breakwater wall, 17 Sep 1985 , coll. P. A. Hutchings \& S. J. Keable (P.36619).

Diagnosis. Rostrum (Fig. 9A) lateral margins slightly concave, without tubercle, extending to proximal or middle part of antennular peduncle segment 1. Eye cornea (Fig. 9A,B) narrower than stalk. Stalk with slight distomedial rim, barely reaching antennular peduncle segment 3 . Male sternites (Fig. 11E) with smooth processes. Telson (Fig. B-D) 1.2 times as long as last abdominal somite, 1.1-1.4 times as long as wide; its posterior width $0.2-0.3$ of anterior width; cleft $0.21-0.27$ of telson length, with four to fifteen spinules, occupying anterior $0.37-0.77$ of cleft. Telson lateral margins with 11 to 16 spiniform setae, occupying posterior part; outer terminal spiniform setae $0.10-0.13$ of telson length and 1.2-2.3 times as long as last posterolateral spiniform setae; inner terminal spiniform setae $0.53-0.73$ times as long as outer. Peduncle of antennula (Fig. 9F) with two distomedial flagellated setae of about equal length and width. Antennal scale (Fig. 9G) longer than middle of antennular peduncle segment 3 , reaching distal margin of antennal peduncle, 2.8-3.0 times as long as wide. Pereopod 1 (Fig. 10F,G) ischium 1.8-1.9 times as long as wide, merus 2.8-4.1 times as long as wide and 1.7-1.8 times as long as ischium, medially without flagellated setae, but simple long setae, and with distomedial process; carpopropodus segment 1 about as long as merus, $3-4$ times as long as wide; its medial margin with non-flagellated spiniform setae, provided medially with smooth long seta; segment 2 without distomedial process, with long paradactylary setae, bearing numerous long setules. Dactylar unguis semilunar, not meandering. Pereopod 2 (Fig. 10H, I) carpopropodus 5-segmented. Pereopod 3-6 (Fig. 11A,B) carpopropodus 4to 6-segmented; unguis strong, but not as thick as dactylus, serrated in posterior endopods. Pereopod exopod basal joint without outer acute process. Penis (Fig. 11F) with setae. Uropodal endopod 0.9 times as long as exopod, with eight to fifteen spiniform setae along medial margin.

Body length $3.5-6 \mathrm{~mm}$.
Comparison. Heteromysis (Heteromysis) macropsis is rather close to Heteromysis (H.) thailandica, $H$. (H.) spinosa and $H$. (H.) minuta. Heteromysis thailandica was described based on an incomplete specimen, lacking most of the pereopods, and differing from $H$. macropsis by the slightly longer rostrum, extending beyond the middle of the antennular peduncle segment 3 (extending to the proximal or middle part in H. macropsis), the 4-segmented carpopropodus of the pereopod 2 (5-segmented H. macropsis), and, possibly, by the structure of the sternal processes, not studied in H. macropsis types. From $H$. spinosa it differs by the distomedial rim of the eyestalk barely produced beyond the cornea (strongly produced in $H$. spinosa), usually larger number of the telson lateral spiniform setae (11 to 16 against 8 to 11 in $H$. spinosa), the shorter terminal spiniform setae of the telson $(<0.13$ against $>0.14$ of the telson length in $H$. spinosa $)$, the longer antennal scale, stretching far beyond the eyes and the middle of the antennular peduncle segment 3 (rather short antennal scale, barely stretching beyond the eye and not reaching the middle of the antennular peduncle segment 3 in H. spinosa). From H. minuta it differs by the distomedial rim of the eyestalk barely produced beyond the cornea (strongly produced in $H$. minuta), the longer antennal scale, stretching beyond the middle of the antennular peduncle segment 3 (not reaching middle of the antennular peduncle segment 3 in $H$. minuta), the wider pereopod 1 endopod (rather slender in $H$. minuta), and less spiniform setae on the uropodal endopod (8 to 15 against $20-22$ in H. minuta).

Description of Tasman Sea specimens. Rostrum angular, apically blunt or pointed; lateral margins slightly concave, covering half of eyes and half of segment 1 of antenna 1 peduncle. Thoracic sternites of male with triangular smooth processes; largest on sternite 1. Telson 1.2 times as long as last abdominal somite; length $1.2-1.4$ its anterior width; posterior width $0.20-0.27$ of anterior width; lateral margins with eleven to fifteen spiniform setae, absent in anterior part, with distal wing-like expansions; inner terminal spiniform setae $0.68-0.73$ as long as outer; outer $1.2-1.4$ times as long as lateral subterminal spiniform seta and 0.10 of entire telson length. Telson cleft $0.24-0.27$ of telson full length, with four to fifteen spinules, occupying $0.64-0.73$ of cleft length, 0.6-0.7 times as long as last lateral spiniform setae.

Eyes 1.0-1.1 times as long as wide from dorsal view, slightly flattened dorsoventrally. Eye length $0.5-0.6$ of anterior head width. Eyestalk with slightly produced distal dorsomedial rim, visible also from lateral view, not extending beyond cornea. Cornea narrower than stalk $(0.7-0.8$ times as long as stalk) and 0.3-0.4 times as long as eye entire length.

Antennular peduncle, dorsal distomedial corner of segment 3 with two simple setae, directed forward, and two relatively thin and equally long flagellated setae, directed inward and outward, respectively. Antennal scale reaching level of from about half to nearly distal margin of antennular peduncle segment 3, and 3.0 times as long as wide. Mouthparts and maxillipeds typical for the genus. Mandibular palp with flagellated setae; segment 3 is 0.4 times as long as segment 2, with two medial setae. Maxilla 1 outer ramus with four caudal setae.

Thoracopodal exopods with smooth distolateral corner of basal segment. Pereopod 1 endopod, ischium 1.9 times as long as wide, with six short medial setae; merus 4.1 times as long as wide and 1.9 times as long as ischium, with 


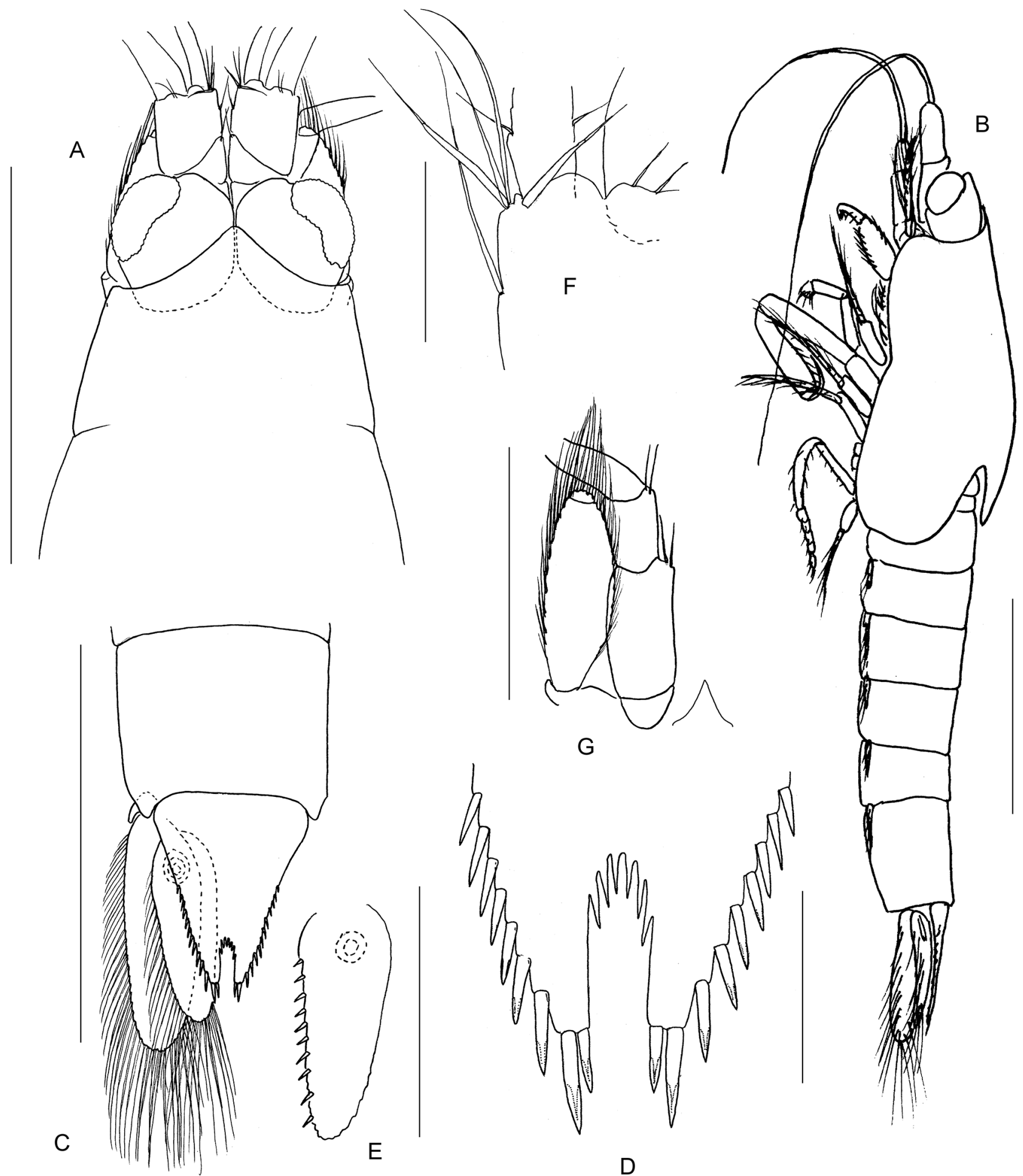

Figure 9. Heteromysis (Heteromysis) macropsis, female, $4 \mathrm{~mm}$, AM P.98707. (A) head, dorsal; $(B)$ habitus, lateral; $(C)$ posterior part of body (abdominal somite 6, telson, uropods), dorsal; $(D)$ telson posterior part; $(E)$ uropodal endopod, ventral; $(F)$ distomedial setae of antennular segment 3, dorsal; $(G)$ antenna 2 and interocular process, ventral. Scales $(\mathrm{mm})$ : $\mathrm{A}-\mathrm{C}=1 ; \mathrm{D}, \mathrm{F}=0.25 ; \mathrm{E}, \mathrm{G}=0.5$.

six short and long medial setae and distomedial process. Carpopropodus segment 1 is 3.8 times as long as wide and 1.0 times as long as merus, its medial margin with four single smooth spiniform setae, then distally with a pair of one smooth and one slightly anteriorly serrated (but no excavated) spiniform setae; each single and distal pair of spiniform setae provided medially with smooth long seta; distal pair laterally also with longer seta, distally bearing numerous fine setules; segment 2 without distomedial process, with long paradactylary seta, bearing numerous long setules. Dactylus 0.34 times as long as carpopropodus, semilunar, not meandering. Pereopod 2 endopod, preischium with one seta; ischium 4.1 times as long as wide, with two distomedial setae; merus 1.5 times as long as ischium and 7.1 


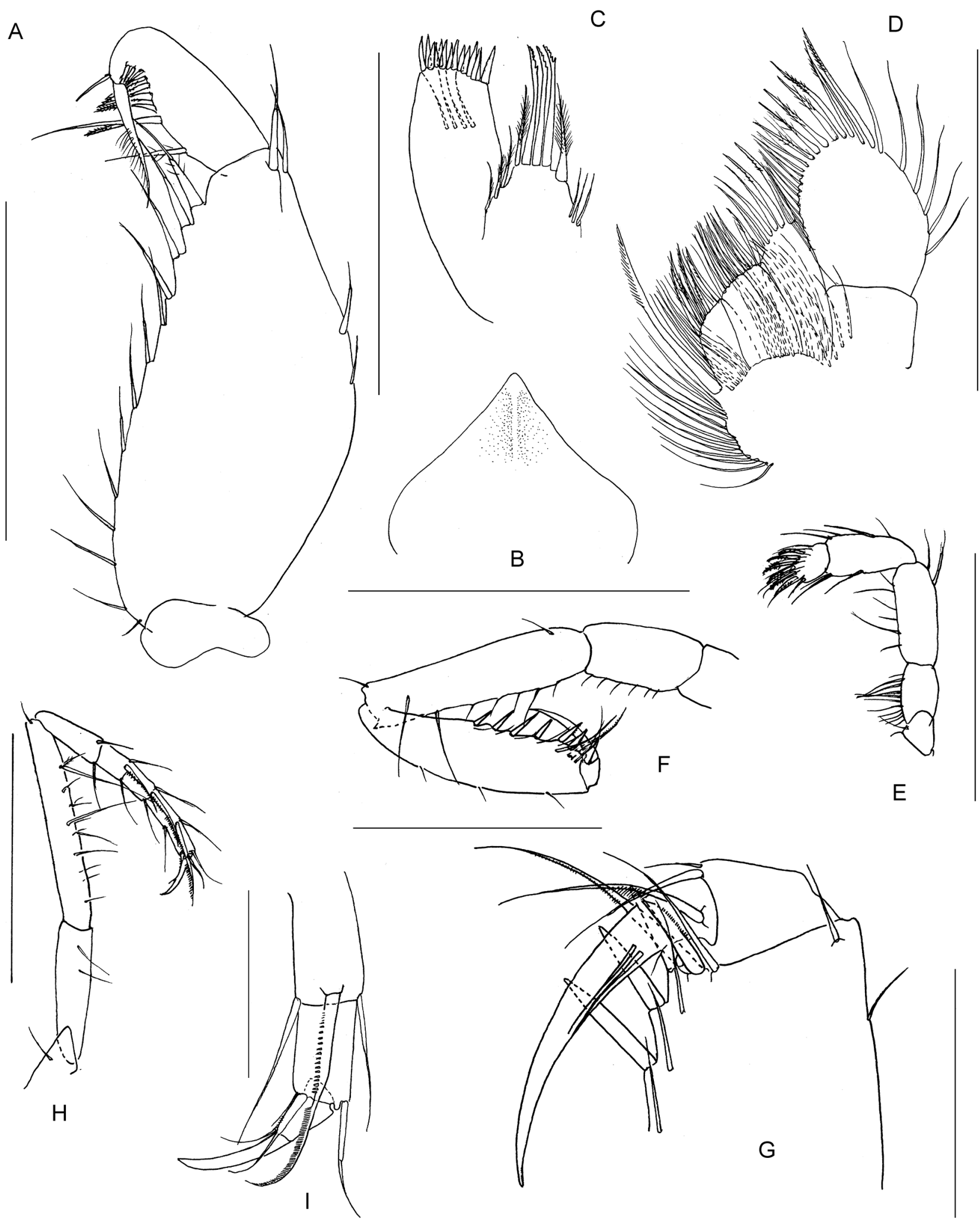

Figure 10. Heteromysis (Heteromysis) macropsis, female, 4 mm, AM P.98707. $(A)$ mandibular palp, medial; $(B)$ labrum, ventral; $(C)$ maxilla 1, posterior; $(D)$ maxilla 2, posterior; $(E)$ maxilliped 2 endopod, anterior; $(F)$ pereopod 1 endopod, anterior; $(G)$ distal part of pereopod 1 endopod, anterior; $(H)$ pereopod 2 endopod, anterior; $(I)$ distal part of pereopod 2 endopod, anterior. Scales (mm): $A-F, H$ $=0.5 ; G, I=0.25$.

times as long as wide, with eight medial bunches of one or two setae; carpopropodus 5-segmented, each segment with serrated distolateral seta; serrated setae with strong denticles in proximal part and fine denticles in distal; paradactylary seta proximally serrated; dactylus 0.6 times as long as last carpopropodal segment; unguis rather strong, 1.7 times as long as dactylus. Pereopod 6 exopod 8-segmented. Endopod, ischium rather long and slender, 6.8 times as long as wide, with three lateral setae; merus 0.8 times as long as ischium and 5.8 times as long as wide, with six medial bunches of 
B
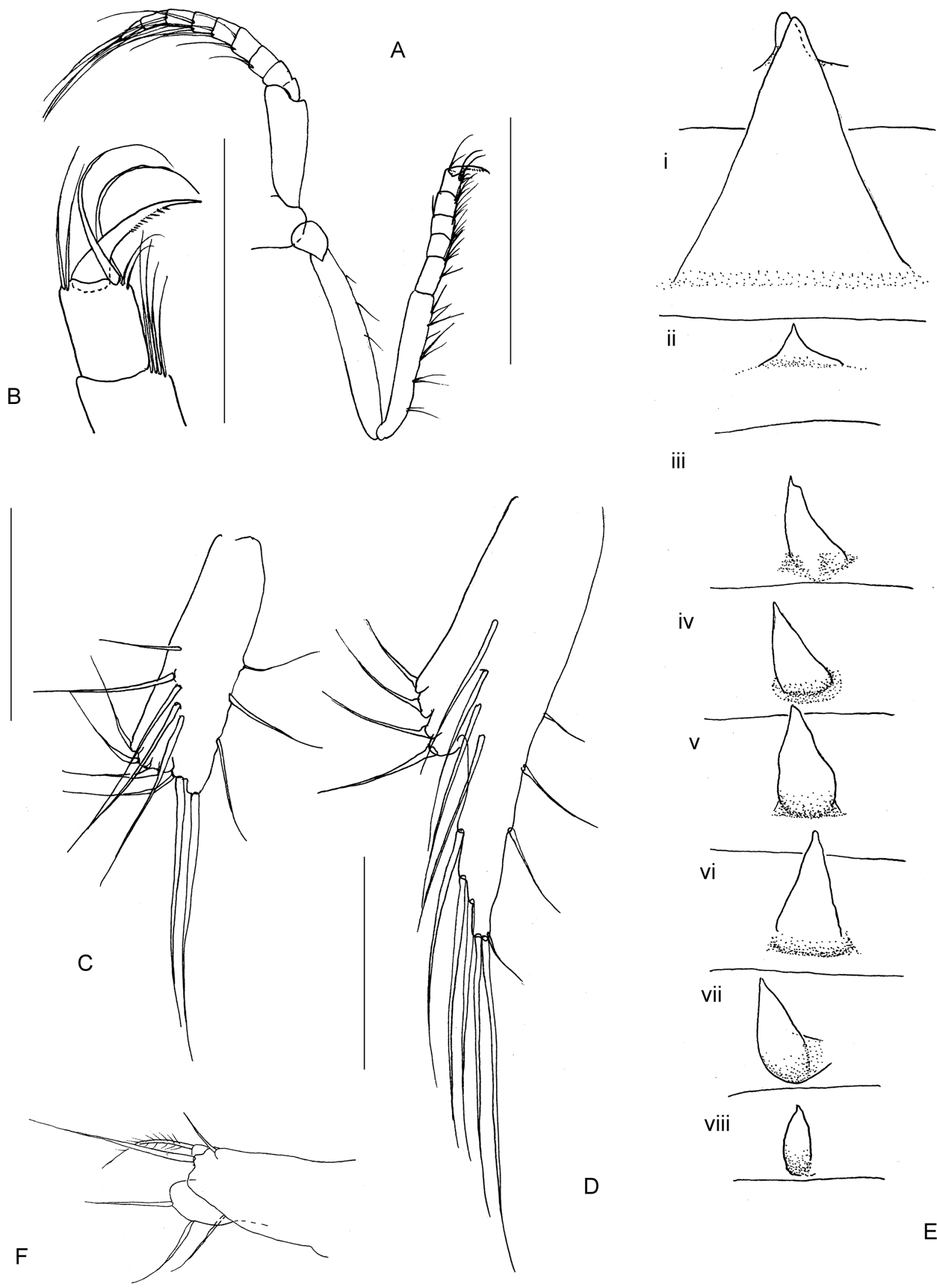

$E$

Figure 11. Heteromysis (Heteromysis) macropsis. $(A-D)$ female, 4 mm, AM P.98707; $(E, F)$ male, 3.5 mm, AM P.98708. (A) pereopod 6, anterior; $(B)$ distal part of pereopod 6 endopod, anterior; $(C)$ pleopod 2, anterior; $(D)$ pleopod 5 , anterior; $(E)$ thoracic sternites with processes, ventral; $(F)$ penis distal part; $(i-v i i i)$ thoracic sternites numbers. Scales $(\mathrm{mm}): A, E=0.5 ; B-D, F=0.25$. 

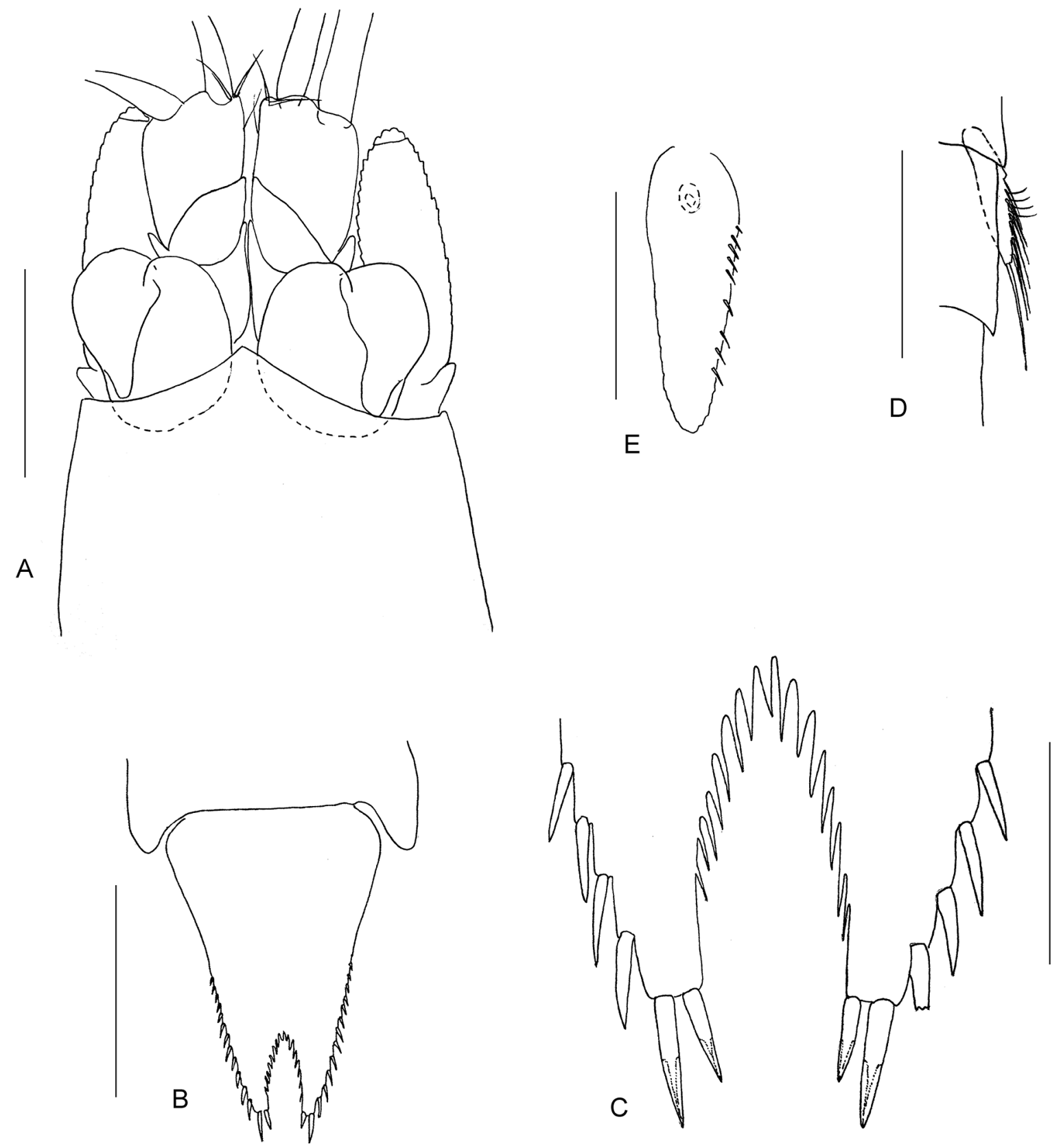

Figure 12. Heteromysis (Heteromysis) macropsis, female, $6 \mathrm{~mm}$, AM P.58590. $(A)$ head, dorsal; $(B)$ telson; $(C)$ telson posterior part; $(D)$ pleopod 4, right; $(E)$ uropod endopod, ventral. Scales $(\mathrm{mm})$ : A, B, D, E $=0.5 ; \mathrm{C}=0.25$.

one or two setae; carpopropodus 5-segmented, last segment with two smooth paradactylary setae; dactylus small, 0.6 the length of last carpopropodal segment; unguis strong, weekly serrated in median part, 2.3 times as long as dactylus.

Penis with rather setose tip: three anterior and three posterior long setae on a lobe. Longest seta of pleopod 5 is 0.8 times as long as ramus. Uropodal endopod 0.88 times as long as exopod, with eight to fifteen spiniform setae along almost entire margin. Uropodal exopod 3.0 times as long as wide.

Variation. The species is considerably variable even within the Tasman Sea, particularly in the length of the antennal scale and armature of the telson. Compared with the original illustrations of Pillai (1961), the Tasman Sea specimens are distinguishable from the Indian Ocean types by the longer rostrum, covering the eyestalk bases and reaching half of the antennular peduncle segment 1 (not covering the stalk and reaching only the proximal part of the antennular peduncle segment 1 in the types), more prominent distomedial rim of the eyestalk (barely established in the types), in the telson outer terminal spiniform setae only slightly $(1.2-1.4)$ longer than the last posterolateral (1.9-2.3 times as long in the types), the paradactylary setae of the pereopod 1 carpopropodus segment 2 shorter than the dactylar unguis (longer than the unguis in the type specimens). The significance of these differences must be confirmed by comparison with actual Indian specimens.

Distribution. Indian Ocean: known here only from the type locality off Kollam in Kerala, India (Pillai, 1961). Pacific Ocean: in this study collected in the Tasman Sea from the Sydney Harbour and further south along the Australian coast 
in Botany Bay, Jervis Bay, Batemans Bay and Twofold Bay.

Habitat and life history. Sublittoral species, found at a depth of 3 to $22 \mathrm{~m}$. Originally collected in plankton. In this study it was found in the holdfasts of the brown alga Ecklonia radiata, and may possibly be also associated with sponges. Otherwise, found among and under rocks in the presence of brown algae, bryozoans and hydroids. Female from Burrewarra with two embryos.

Remarks. Heteromysis (Heteromysis) macropsis has not been recorded since its originally description as Heteromysis macropsis Pillai, 1961, and remained without subgeneric assignment until now. It is clearly a member of the micropsgroup. Pillai (1961) compared it with $H$. proxima, belonging to the same group, which, in fact, became rather distant from $H$. macropsis after the description of more similar $H$. thailandica, $H$. spinos $a$ and $H$. minuta. The revised diagnosis includes characters comparing it with all the species of microps-group.

Due to considerable variation within Heteromysis macropsis, as well as a similar level difference between $H$. macropsis, $H$. minuta, $H$. spinosa and $H$. thailandica, all of these species probably represent a complex of closely related taxa, H. macropsis complex. Their geographical relations and actual taxonomic level should be revealed after a more extensive material is studied. I also prefer to provide here a more detailed description of the Tasman Sea specimens.

\section{Heteromysis (Heteromysis) tasmanica W. M. Tattersall, 1927}

$$
\text { Figs } 13-15
$$

Heteromysis tasmanica W. M. Tattersall, 1927a: 255.-Hale, 1929: 363.-Illig, 1930: 600.-Gordan, 1957: 353.-O. S. Tattersall, 1962: 234, 237, 238; 1967: 165-167, 211.-Pillai, 1968: 49.--Mauchline \& Murano, 1977: 60.-Mauchline, 1980: 341.-Murano, 1988: 27, 48.Daneliya, 2012: 136.

Heteromysis (Heteromysis) tasmanica.-Fenton, 1986: 15, $145,169,183,186,372-377$, figs 2.52E, 3.7, 3.8.-Lowry \& Stoddart, 2003: 448.

Type specimens. Syntypes: 3 males, Australia, Tasmania, D'Entrecasteaux Channel, 10 Aug 2014, coll. W. M. Tattersall (Natural History Museum, London, 1946.11.26.81-82). Deposited under the name Heteromysis tasmaniae, and labeled as "types".

Type locality. Tasman Sea: Australia, Tasmania, D'Entrecasteaux Channel (W. M. Tattersall, 1927a).

Tasman Sea material. Female (+slide), $6 \mathrm{~mm}$, Twofold Bay, Munganno Point, $37^{\circ} 06^{\prime} 12^{\prime \prime S} 149^{\circ} 55^{\prime} 42^{\prime \prime E}, 15$ m, subtidal wharf pile, 27 Jun 1985, coll. S. J. Keable \& A. L. Reid, site M8 (P.36618); female, $5.5 \mathrm{~mm}$, same locality, 0-7 m, subtidal rock platform, 10 Oct 1984, coll. P. A. Hutchings, site M3 (P.36617).

Diagnosis. Rostrum (Fig. 13B) reaching half of antennular peduncle segment 1; its lateral margins without lateral tubercle. Eyestalk without distomedial rim. Telson (Fig. 13C,D) cleft $0.14-0.15$ of telson length, with 6 to 24 spinules, occupying entire cleft length. Telson lateral margins straight, with 13 to 20 spiniform setae, occupying posterior part, including two terminal. Inner terminal spiniform setae $0.5-0.7$ times as long as outer. Outer spiniform setae 0.07-0.09 times as long as telson and 1.4-2.0 times as long as last posterolateral spiniform setae. Pereonite 3 of males with allantoid sternal process, extended backwards between pereopodal bases. Antennal scale (Fig. 13B) 2.5-2.9 times as long as wide, extending beyond middle of antennular peduncle segment 3. Pereopod 1 (Fig. 14H-J) merus 2.7-3.1 times as long as wide, medially with thin setae or without them, but without flagellated spiniform setae. Pereopod 1 carpopropodus segment 1 is $2.4-2.5$ times as long as wide and $0.89-0.94$ times as long as merus, its medial margin with eight or nine spiniform setae, two distal of them also stronger and apically bifurcated, with additional smooth spiniform seta medially to them; each spiniform seta medially provided with long seta; segment 2 without distomedial process, with long paradactylary seta on each side, about as long as unguis, bearing dense serrations. Dactylus $0.36-0.42$ times as long as carpopropodus. Pereopod 2-6 (Fig. 15A-E) carpopropodus 6-7-segmented; unguis strong, but not as thick as dactylus. Pereopod exopod basal joint without outer acute process. Uropodal endopod (Fig. 13C,E) 0.79-0.88 times as long as exopod, with 8 to 16 medial spiniform setae along entire margin, though not reaching endopodal apex.

Body length 5.5-12 $\mathrm{mm}$.

Comparison. Heteromysis (Heteromysis) tasmanica has the shallowest telson cleft in relation to the telson length $(0.14-0.15)$ in the group. It is not particularly related to any species, though has a similarity to the species of the $H$. macropsis complex, from which it is distinguished, in addition, by the complete absence of the distomedial rim on the eyestalk, the cleft spinules, occupying the entire cleft length $(0.17-0.77$ of cleft length in the $H$. macropsis complex), shorter outer terminal spiniform setae of the telson in relation to the telson length $(0.07-0.09$ against $0.10-0.33$ the $H$. macropsis complex), the presence of the bifurcated spiniform setae on the pereopod 1 carpopropodus segment 1 (absent in the H. macropsis complex).

Description of Tasman Sea specimens. Anterior margin of carapace angular, apically smoothly rounded, covering half of eyes and half of segment 1 of antenna 1 peduncle; lateral margins slightly concave. Telson 1.1 times as long as last abdominal somite; length 1.3 its anterior width; posterior width 0.3 of anterior width; lateral margins with 18 and 19 spiniform setae, including two terminal, absent in anterior part: inner 0.5 as long as outer; outer 1.4 times as long as lateral subterminal spiniform seta. Telson cleft rather shallow, 0.15 of telson full length, with 16 spinules, shorter than lateral spiniform setae.

Eyes nearly globular from dorsal view, 0.9-1.0 times as long as wide and slightly flattened dorsoventrally. Cornea narrower than stalk ( 0.8 times as long as stalk) and 0.3-0.4 times as long as eye entire length. Antennular peduncle segment 3 with two nearly equally long flagellate spiniform setae. Antennal scale reaching level of about half of antennular peduncle segment 3 or extending slightly beyond that, and 2.5 times as long as wide. Mouthparts and maxillipeds typical for the genus. Maxilla 1 outer ramus with six caudal setae. Exopod of thoracopods, basal segment outer margin apically rounded.

Pereopod 1 endopod, preischium with one seta; ischium 


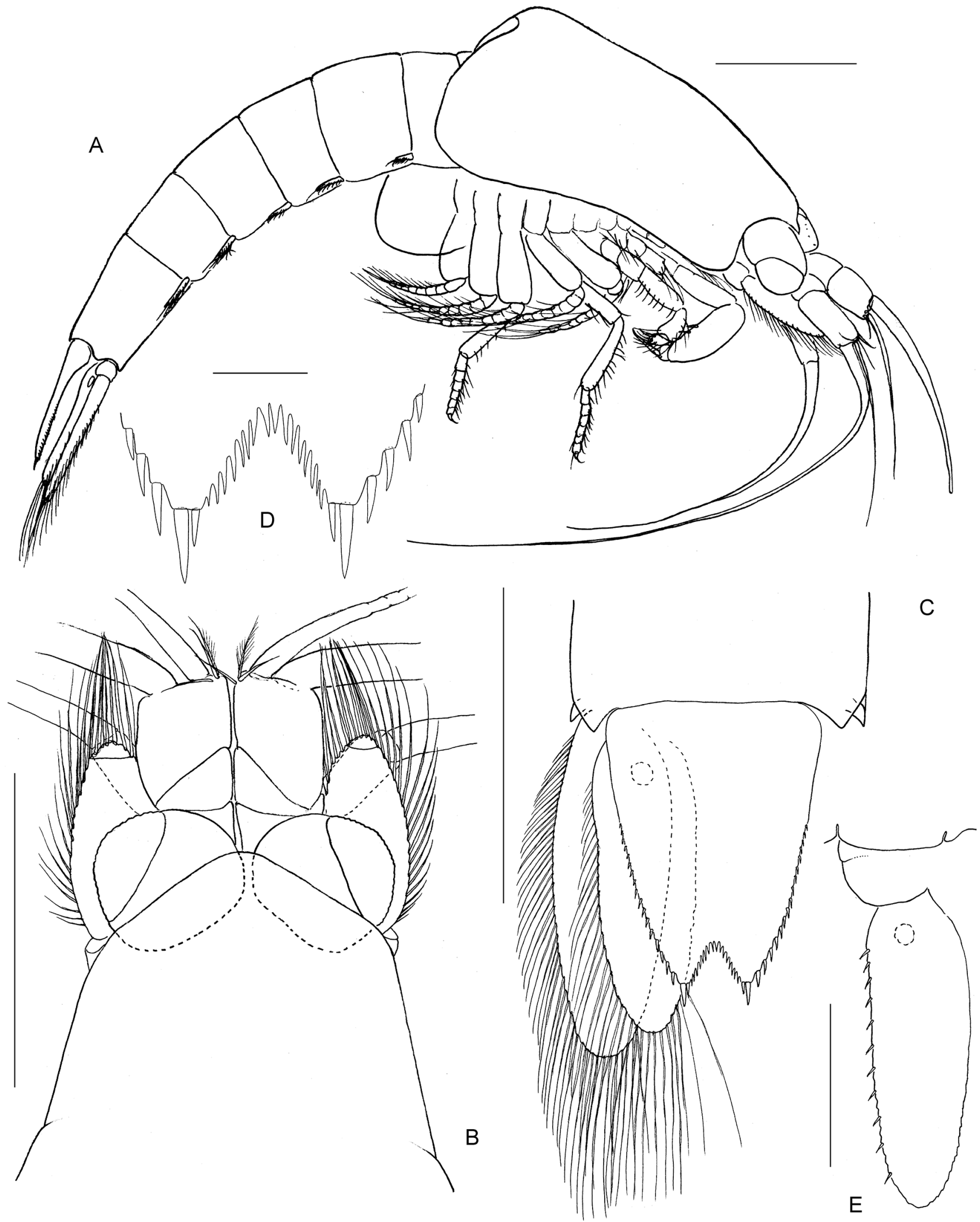

Figure 13. Heteromysis (Heteromysis) tasmanica, female, $6 \mathrm{~mm}$, AM P.36618. $(A)$ habitus, lateral; $(B)$, head, dorsal; $(C)$ posterior part of body (abdominal somite 6 , telson, uropods), dorsal; $(D)$ telson posterior part; $(E)$ uropodal endopod, ventral. $\mathrm{Scales}(\mathrm{mm})$ : $\mathrm{A}-\mathrm{C}=1$; $\mathrm{D}=0.25 ; \mathrm{E}=0.5$.

with six short medial setae; merus with 12 short medial setae and distomedial process. Carpopropodus about as long and as wide as merus; segment 1 is $2.4-2.5$ times as long as wide, its medial margin with seven spiniform setae, finely serrated anteriorly, among which two distal rather strong, with accessory subterminal spine (bifurcated); in addition a smooth spiniform seta present medially to them; pair of thin setae at base of each spiniform seta, one of each pair with posterodistal 

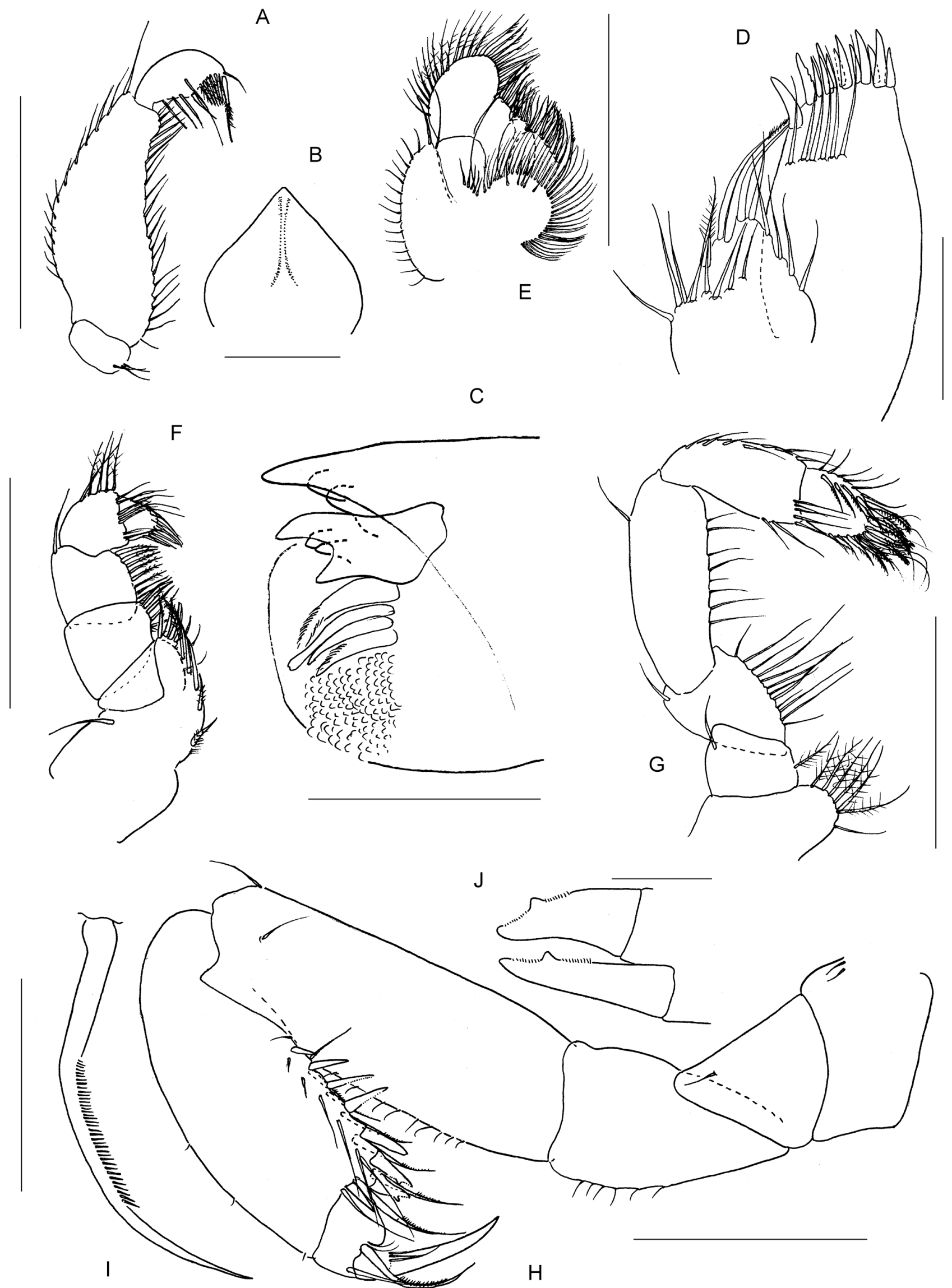

Figure 14. Heteromysis (Heteromysis) tasmanica, female, $6 \mathrm{~mm}$, AM P.36618. (A) mandibular palp, medial; $(B)$ labrum, ventral; $(C)$ mandible, left; $(D)$ maxilla 1, anterior; $(E)$ maxilla 2, anterior; $(F)$ maxilliped 1 endopod, posterior; $(G)$ maxilliped 2 endopod, anterior; $(H)$ pereopod 1 endopod, anterior; $(I)$ distal seta of pereopod 1 carpopropodus segment 2; $(J)$ distal cuspidate setae of pereopod 1 carpopropodus segment 1 . Scales $(\mathrm{mm})$ : $\mathrm{A}, \mathrm{E}-\mathrm{H}=0.5 ; \mathrm{B}-\mathrm{D}, \mathrm{I}=0.25 ; \mathrm{J}=0.1$. 


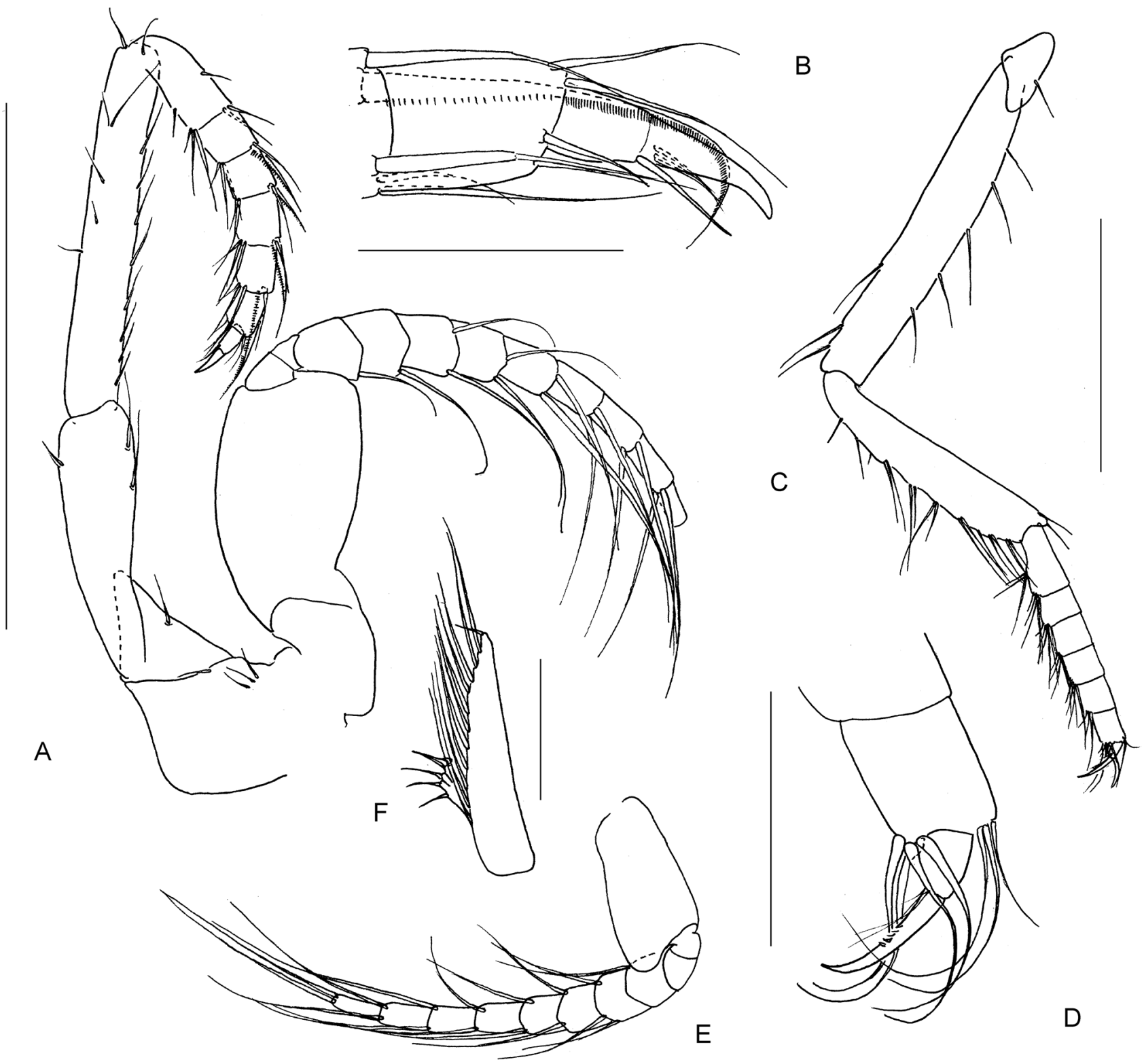

Figure 15. Heteromysis (Heteromysis) tasmanica, female, $6 \mathrm{~mm}$, AM P.36618. (A) pereopod 2, posterior; $(B)$ distal part of pereopod 2 endopod, posterior; $(C)$ pereopod 6 endopod, posterior; $(D)$ distal part of pereopod 6 endopod, posterior; $(E)$ pereopod 6 exopod, posterior; $(F)$ pleopod 5, anterior. Scales (mm): $\mathrm{A}=1 ; \mathrm{B}, \mathrm{D}, \mathrm{F}=0.25 ; \mathrm{C}, \mathrm{E}=0.5$.

serration; segment 2 with strong paradactylary seta, serrated in median part. Dactylus length 0.36 of carpopropodus length; unguis semilunar, not meandering, smooth. Pereopod 2 exopod 10 -segmented. Endopod, preischium with one seta; ischium 6.4 times as long as wide, with a distomedial bunch and two distolateral setae; merus 1.4 times as long as ischium and 7.2 times as long as wide, with eight medial setae; carpopropodus 6-segmented, each segment with serrated distolateral seta; dactylus 0.5 times as long as last carpopropodal segment; unguis rather strong, 1.7 times as long as dactylus. Pereopod 4 exopod 10-segmented. Pereopod 6 exopod 9-segmented. Endopod, preischium with one seta; ischium rather long and slender, 6.0 times as long as wide, with five lateral and three distomedial setae; merus 0.7 times as long as ischium and 5.0 time as long as wide, with 10 medial bunches of one or two setae; carpopropodus 6-segmented, last segment with four smooth paradactylary setae; dactylus small, 0.5 the length of last carpopropodal segment; unguis strong, weakly serrated in median part, 2.0 times as long as dactylus. Carpopropodus of pereopods 2, 3 and 6 (others missing) is 6-segmented. Uropodal endopod shorter than exopod, with 11 spiniform setae along entire margin.

Variation. The female specimens from the Twofold Bay are distinguished from the males from the type locality in Tasmania (as illustrated by W. M. Tattersall, 1927a) by the rostrum being apically rounded with straight lateral margins (apically pointed, with concave margins in the types); the eyes being about as long as wide, with the cornea narrower than the eyestalk (eyes longer than wide, with the cornea wider or about as wide as the stalk in the types); the telson being 1.03-1.06 times as long as the abdominal somite 6 (1.25-1.3 in the types); the telson lateral margins bearing 17 to 20 spiniform setae (13 to 15 in the types); the antennal scale barely extending beyond the half of the antennular peduncle segment 3 (nearly reaching the peduncle 
distal margin in the types); the pereopod 1 merus bearing distomedial triangular process (absent in the male type specimens); the pereopod 2-6 carpopropodus 6-segmented (7-segmented in the types). There is still a chance that the observed differences are due to sexual dimorphism, since no females are known from the original description and no males were available for this study from New South Wales. I will leave this question open.

Distribution. Except for the type locality in Tasmania, D'Entrecasteaux Channel, it was also originally recorded in the South Australian coast, Gulf of St. Vincent (W. M. Tattersall, 1927a), and later in several localities of the Bass Strait (Fenton, 1986). In this study the species was collected from Twofold Bay, New South Wales (Fig. 4).

Habitat. Sublittoral species, found at depths of 0-79 m (W. M. Tattersall, 1927a; Fenton, 1986; this study), at the bottom with coarse shell, muddy shell-grit, muddy fine shell, fine, very fine sand and rocks (Fenton, 1986; this study). The species has not been recorded yet in association with any invertebrates. It is the southernmost species of the group, found in cooler waters of the southern and southeastern coast of Australia.

Remarks. W. M. Tattersall (1927a) made a rather detailed description of Heteromysis tasmanica, comparing it only with Heteromysis waitei W. M. Tattersall, 1927, which belongs to the subgenus Olivemysis. Here I provide a diagnosis of the species in comparison with other species of the microps-group. The allantoid sternal process on the pereonite 3 is so far known only in the males from the southern Australian populations. The status of the South Australian populations requires clarification. Particularly, as expressed by W. M. Tattersall (1927a), their telson cleft bears six spinules compared to 24 in Tasmania and 16 or 17 in New South Wales, and the uropodal endopod has eight spiniform setae against 16 and 9 to 12 , respectively. More material is necessary to check the importance of these characters.

\section{Heteromysis (Gnathomysis) Bonnier et Perez, 1902}

\footnotetext{
Gnathomysis Bonnier et Perez, 1902: 117 (originally as a genus).

Chiromysis.-Hilgendorf, 1878: 845, partim.

Heteromysis (Gnathomysis).-Băcescu, 1968: 235, 236.Băcescu \& Bruce, 1980: 70.-Bowman \& Orsi, 1992: 739.--Vannini et al., 1993: 190.-Bravo \& Murano, 1996: 483.-Bamber, 2000a: 133.-Wittmann, 2000: 287; 2008: 370.-Wittmann \& Abed-Navandi, 2019: 81.-Hanamura \& Kase, 2001a: 15, 17, 18.-Lowry \& Stoddart, 2003: 446.-Daneliya, 2012: 146.- San Vicente \& Monniot, 2014: 340.
}

Type species. Gnathomysis gerlachei Bonnier et Perez, 1902: 117, by monotypy.

Diagnosis. Eye without distomedial spine (spines) or tubercles. Antennular peduncle segment 3 with nonflagellated and non-modified setae. Ischium of pereopod 1 endopod nearly as long as wide, triangular; medially with denticles. Merus of pereopod 1 endopod semilunar in crosssection, sulcate medially; without distomedial process; its medial margin without flagellated spiniform setae, and lateral margin with smooth setae. Carpopropodus of pereopod 1 rather massive, longer than or as long as merus, with medial spiniform setae, and without long serrated paradactylary setae. Penis tubular, without setae. Pleopods unmodified in both sexes. Uropodal endopod longer than exopod.

Comparison. Gnathomysis is uniquely characterized by the exceptionally developed pereopod 1 endopods, which have the broad, nearly triangular, serrated ischium and the semilunar in cross-section merus; the uropodal endopod is longer than the exopod. From Neoheteromysis, in addition to the mentioned unique features, Gnathomysis differs by the penis that has no setae (present in Neoheteromysis), and the absence of the male pleopod modifications. Comparison with Olivemysis can be found here in the relevant subgeneric section.

Remarks. Bonnier \& Perez (1902) described Gnathomysis as a genus, and, in fact, as the type genus for a new family, which they did not name. They provided a rather detailed description of the genus, which was distinguished by the particularly enlarged pereopod 1 endopod (gnathopod) and the rudimentary pleopods in both sexes. W. M. Tattersall (1922) clearly recognized a heteromysine in it and synonymized Gnathomysis with Chiromysis, and it was considered so (at least by W. M. Tattersall, 1951) until Băcescu (1968) re-established the name under the subgeneric status. He considered the pereopod 1 as a maxilliped 3 (later he abandoned this term). Its endopod was so enlarged that M. Băcescu thought it had a reduced exopod (repeated by subsequent authors: Bowman \& Orsi, 1992; Bravo \& Murano, 1996). He also noticed that the uropodal endopod was longer than the exopod in Gnathomysis, compared to other subgenera, where it is shorter. Later (Băcescu \& Bruce, 1980) he also added a "half-moon-like" shape of the pereopod 1 merus and roughly triangular shape of the ischium with the serrations to the diagnosis. Hanamura \& Kase (2001a) preferred not to distinguish subgenera within Heteromysis at all, but rather considered groups, particularly naming Gnathomysis species as Heteromysis harpax group. Wittmann (2008), in turn, accepted the subgenera and added some negative features to the diagnosis of Gnathomysis: the absence of modified setae on the antennular peduncle and pleopods, and the absence of the sternal processes. Earlier I studied specimens of $H$. (G.) harpaxoides and found that the pereopod 1 exopod is equally developed as other exopods, looking contrastingly short only in comparison with the tremendously enlarged endopod. Also the males had the short conical sternal processes, especially developed on the sternites 1-3 (Daneliya, 2012). I mentioned that the uropodal endopod was as long as the exopod, but previous authors were more correct indicating that the endopod was indeed slightly longer than the exopod. Here I provide a revised diagnosis of the subgenus, comparing it with the other subgenera.

Băcescu \& Bruce (1980) informally distinguished two groups in the subgenus based on the structure of the pereopod 1 endopod: one with the merus finely serrate only on the posteromedial margin, bearing spiniform setae in the distal part, and the carpopropodus having two sets of the spiniform setae, proximal and distal; and another group with only rougher serrations on both antero- and posteromedial margins of the merus, without spiniform setae and the carpopropodus with one set of medial spiniform setae along the margin. The latter group is confined only to the Australian waters. 
Distribution. The species of Gnathomysis so far have been recorded exclusively from the West Indo-Pacific Region.

Habitat. Specialization for commensalism with hermit crabs (Vannini et al., 1993).

Composition. The subgenus Heteromysis (Gnathomysis) includes four species: Heteromysis (Gnathomysis) gerlachei (Bonnier et Perez, 1902), Heteromysis (Gnathomysis) harpax (Hilgendorf, 1878), Heteromysis (Gnathomysis) harpaxoides Băcescu et Bruce, 1980, Heteromysis (Gnathomysis) stellata Băcescu et Bruce, 1980. Among them one species, H. (G.) harpaxoides, is recorded from the Tasman Sea.

\section{Heteromysis (Gnathomysis) harpaxoides Băcescu et Bruce, 1980}

\author{
Fig. 16
}

Heteromysis (Gnathomysis) harpaxoides Băcescu et Bruce, 1980: 68, figs 2M-N, 3A-H.-Murano, 1988: 27, 41, 48.--Vannini et al., 1993: 190.--Hanamura \& Kase, 2001: 18.-Lowry \& Stoddart, 2003: 446.-Wittmann, 2008: 369.-Petrescu \& Wittmann, 2009: 58.-Daneliya, 2012: 135, 136, 141-146, figs 28-53.-San Vicente \& Monniot, 2014: 337.

Heteromysis harpaxoides.-Müller, 1993: 270.-Hanamura, 2007: 35, 37-38, fig. 2.-Wittmann et al., 2014: 201, 349, fig. 54.4M.

Type specimens. Holotype, male, Australia, Great Barrier Reef, Wistari Reef, st. 563, 01 Feb 1979, coll. A. J. Bruce \& B. Coates (MGAB 49322). Allotype, female, same data as holotype (MGAB 49375). Paratypes, male, female, same as previous (MGAB 49375) (Petrescu \& Wittmann, 2009).

Tasman Sea material. Male, $8.5 \mathrm{~mm}$, female, $8 \mathrm{~mm}$, 5 subadult specimens, 3.5-4 mm, Coral Sea, Coral Sea Islands, Middleton Reef, bommie east of lagoon entrance, $29^{\circ} 27^{\prime} 48^{\prime \prime S} 159^{\circ} 5^{\prime} 6^{\prime \prime E}$, inside dead clam shell, 06 Dec 1987, coll. Elizabeth \& Middleton Reefs Expedition, 1987, site 11 (P.38239) (det. by J. K. Lowry in 1988 as Heteromysis cf. tethysiana); male (photographed), $7.5 \mathrm{~mm}$, north of Tathra, south of Baronda Head, 36 41'12"S 149 $59^{\prime} 53^{\prime \prime E}, 9.2 \mathrm{~m}$, 17 C, 5 Apr 2008, coll. RV Baragula, MI NSW 3287, K. B. Attwood, airlift on SCUBA (P.77631); 1 specimen (only pereopod 1), Inflammable Liquids Berth, Port Kembla Outer Harbour, $34^{\circ} 27^{\prime} 57^{\prime \prime S} 150^{\circ} 54^{\prime} 15 " \mathrm{E}, 0.5 \mathrm{~m}$, pylon/piling scraping, 13 May 2000, coll. NSW Fisheries, PK ILB P3-0, scraping (AM P.99046).

Diagnosis. Head part of carapace dorsally smooth, without tubercles. Telson 1.5-1.7 times as long as last abdominal segment, and 1.6-1.8 times as long as wide anteriorly. Eye cornea narrower than stalk. Antennal scale reaching half of antennular peduncle segment 3. Pereopod 1 merus medial inner and outer margins roughly serrate, without spiniform setae. Carpopropodus medial margin with three or four strong, finely serrated proximal spiniform setae and three or four roughly serrated distal spiniform setae, without gap between proximal and distal groups.

Body length of males 4.5-5 mm, female $6 \mathrm{~mm}$.

Comparison. Heteromysis (Gnathomysis) harpaxoides is most similar to $H$. (G.) stellata, found on the hermit crab Aniculus sp., and is still known only from the original

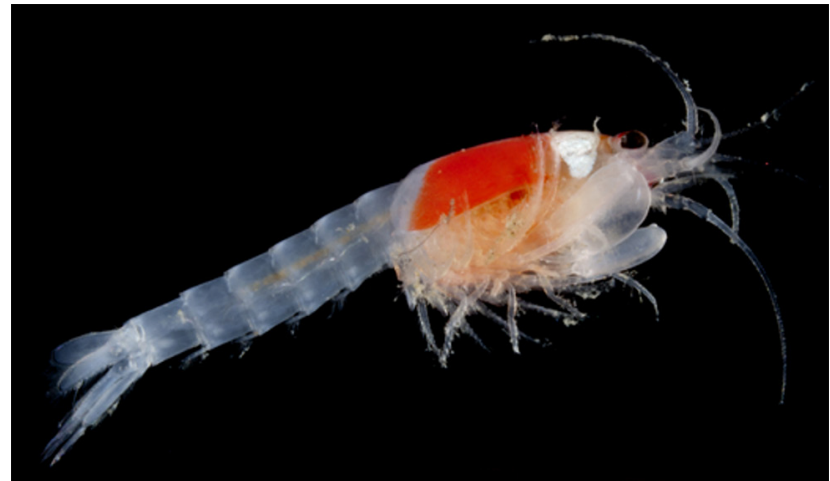

Figure 16. Heteromysis (Gnathomysis) harpaxoides, male, 7.5 mm, Tasman Sea, New South Wales, north of Tathra, AM P.77631. Photographed live by R. T. Springthorpe, Australian Museum.

publication and its type locality (Coral Sea, Heron Island, Queensland). It differs only by the absence of the tubercles of the head part of the carapace (four rows of white-bluish tubercles on pink-white background in $H$. stellata). The species of the subgenus Gnathomysis have not significantly diverged morphologically from each other, mostly differing in the structure of the pereopod 1 endopod.

Description of Tasman Sea specimens. Rostrum triangular, apex almost acute, reaching half of antennule peduncle segment 1; lateral margins covering eyestalk bases. Posterolateral lobes of carapace nearly reaching posterior margin of first abdominal somite. Posteroventral margin of last abdominal somite with serrated plates. Telson 1.5 times as long as last abdominal somite; 1.6 times as long as wide anteriorly and 0.4 times as wide posteriorly as anteriorly. Telson cleft with 16 to 23 spinules (34 in type locality), occupying entire cleft. Cleft acute angular, 0.2 of telson length. Lateral margins of telson with 8 to 15 spiniform setae, occupying posterior half of telson, among them terminal spiniform seta shorter than subterminal.

Eyes 1.1 times as long as wide, slightly flattened dorsoventrally. Eye length 0.5 of anterior head width. Cornea narrower than stalk ( 0.8 times as long as stalk) and 0.4 times as long as eye entire length.

Antennular peduncle segment 3, distomedial margin with two long simple setae. Antennal scale reaching half of segment 3 of antennal and antennular peduncles, 2.0 times as long as wide. Labrum apically pointed, without spine. Mouthparts and maxillipeds typical for the genus (as illustrated earlier in Daneliya, 2012). Maxilla 1 with four posterior setae.

Exopod of thoracopods, basal segment outer margin apically rounded; exopod 1 and 8 are 8-segmented, the rest 9-segmented. Pereopod 1 endopod. Ischium rather broad, almost triangular, 0.5 times as long as merus; its medial margin serrated, with seta at each notch of crenulation, with seven teeth. Merus with medial concavity, bearing anteroand posteromedial margins serrated, also with seta in notches of crenulations. Carpopropodus strongly inflated, 1.9 times as long as wide, as long as merus and 2.0 times as wide as merus, with four short strong distomedial spiniform setae, roughly serrated anteriorly, and three or four medial strong spiniform setae, distally finely serrated and with curved tips. Unguis long, semilunar, but not meandering, 0.7 times as long as carpopropodus. 

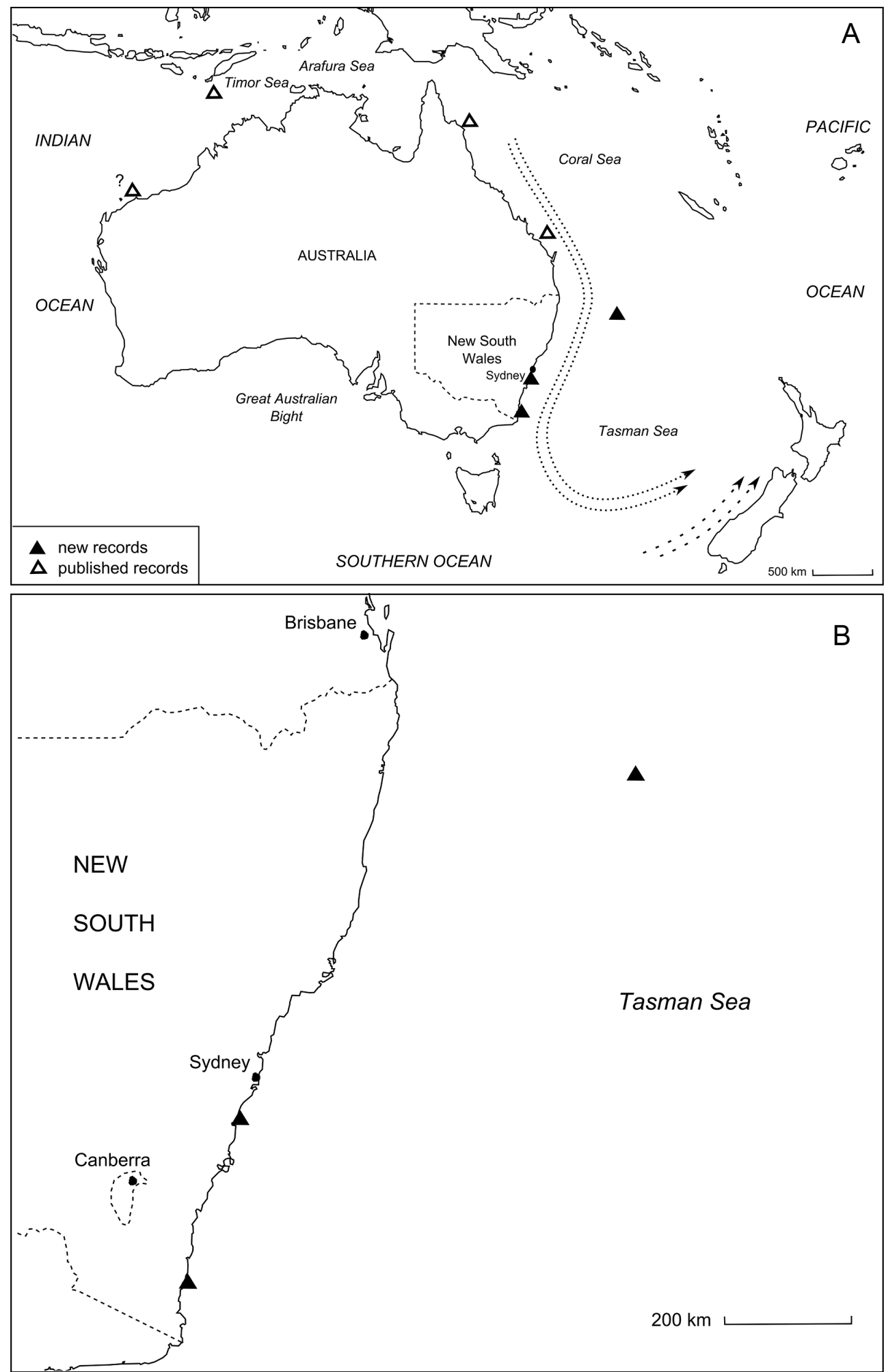

Figure 17. Distribution of Heteromysis (Gnathomysis) harpaxoides. $(A)$ general distribution (the white signs indicate former records); $(B)$ distribution in the Tasman Sea.

Pereopod 2 endopod. Ischium rather short, 0.6 times as long as merus, without bending between ischium and merus. Merus with seven medial groups of one to three setae. Carpopropodus 7-8-segmented (5-6-segmented in Coral Sea); segments prolonged; segment 1 almost as long as segments 2-4 combined. Dactylus longer than dactylus of pereopods $4-6$, with strong unguis. Pereopod 3-6 endopods. Preischium with one seta. Ischium rather long, 1.7-1.9 times as long as merus; ischium and merus forming angle. Merus 2.9-3.6 times as long as wide, with five medial bunches of setae. Carpopropodus 5-6-segmented (4-segmented in the Coral Sea); segment 1 shorter than segments 2 and 3 combined; segments $2-5$ about as long as wide; segment 6 slightly longer than wide. Paradactylary setae smooth. Dactylus rather short, 0.5 as long as last segment of carpopropodus, with strong unguis, 2.3 times as long as dactylus. Penis tubular. 
Pleopods similar in male and female with seven to nine long setae. Uropod exopod slightly shorter than endopod. Endopod inner margin with 9 to 12 spiniform setae.

Color. Similar to that in Lizard Island specimens in the Coral Sea (Daneliya, 2012): cephalic part of carapace snow white; thoracic part of carapace from pleurocervical fissures to the posterior margin blood red; eyes with dorsal red stripe; cornea black; abdomen and appendages not pigmented (Fig. 16). The coloration is similar to the color pattern of the cuticular spines of the hermit crab Dardanus megistos (Herbst, 1804). This was first noticed by Martin (2012). I can confirm the color similarity based on both the Coral Sea (Daneliya, 2012) and the Tasman Sea material, where the collection specimens have been life-photographed, though the actual mimicry still has to be documented.

Variation. I previously noted variation in the telson characters (Daneliya, 2012), and the new material from the Tasman Sea broadened our knowledge. Particularly, the number of the telson lateral spiniform setae vary from 8 to 16 (no longer geographically significant); the telson cleft with 15 to 23 spinules ( 34 in the type locality); the pereopod 2 carpopropodus is 7-8-segmented (4-6-segmented in the Coral Sea); the pereopod 3-6 carpopropodus is 4-6segmented (no geographic discrimination); the uropodal endopod with 9 to 14 spiniform setae (not significant geographically).

Distribution. Coral Sea, Australia: Great Barrier Reef, Wistari Reef (Băcescu \& Bruce, 1980; type locality), Heron Island, Lizard Island (Daneliya, 2012), Middleton Reef (this study). Eastern Indian Ocean, Australia: Ashmore Reef (Murano, 1988); Dampier Archipelago (Hanamura, 2007). Tasman Sea (all in this study, first records from New South Wales): Port Kembla Harbour and south of Baronda Head (southern NSW) (Fig. 17). Firstly recorded in the Tasman Sea and off New South Wales coast of Australia. The specimen from near Baronda Head is the southernmost record of the species.

Habitat. Sublittoral species, found at depths of $0.5-15 \mathrm{~m}$; commensal on hermit crab D. megistos (Băcescu \& Bruce, 1980; Murano, 1988; Western Australian Museum Collections, 2020), but also under rocks, in rubble, algae and other sediment on the surface of reefs (Daneliya, 2012). In the Tasman Sea, found inside clam shells and other hard substrate, confirming facultative nature of its commensalism, already noted in the Coral Sea (Daneliya, 2012).

Life history. There was no confirmed species identification, but according to preliminary reports (Martin, 2012), H. (G.) harpaxoides may form families, living in association with $D$. megistos, and the body coloration of mysids may correspond to the coloration of cuticular spines of the hermit crab.

Remarks. Heteromysis (G.) harpaxoides was originally described well in detail by Băcescu \& Bruce (1980) from the Coral Sea. Eight years later, Murano (1988) reported it from the Indian Ocean coast off Western Australia. In another nine years Hanamura (2007) reported it for the third time, farther south along the Australian coast, near Dampier Archipelago. More recently, I provided illustrations of the species from its fourth record, again from the Coral Sea (Daneliya, 2012), including mouthparts and maxillipeds that were not illustrated originally. Here I limit myself to a description of the specimens from the Tasman Sea, without illustrating them (apart from the color Fig. 16). I provide a revised diagnosis of $H$. (G.) harpaxoides, based on a comparison with the other species in the subgenus.

\section{Heteromysis (Olivemysis) Băcescu, 1968}

Heteromysis (Olivemysis) Băcescu, 1968: 237.-Bowman \& Orsi, 1992: 739.-Bravo \& Murano, 1996: 483.Wittmann, 2000: 287; 2001: 104; 2008: 368, 370, 371; 2013a: 505.-Wittmann \& Chevaldonné, 2016: 7.-Wittmann \& Wirtz, 2017: 145, 148.-Wittmann \& Griffiths, 2017: 40.-Wittmann \& Abed-Navandi, 2019: 81, 82, 93; 2021: 136-138.-Lowry \& Stoddart, 2003: 448 (spelling correction).--Price \& Heard, 2008: 143; 2011: 33, 43, 44.-Price et al., 2018: 2, 8.-Daneliya, 2012: 135, 136, 141, 146, 147.- - Hanamura et al., 2012: 17.-San Vicente \& Monniot, 2014: 340.

Heteromysis (Olivaemysis).-Băcescu, 1970: 11, 14, 16.Băcescu, 1979: 143.-Băcescu, 1983: 6, 8, 11.—Băcescu \& Iliffe, 1986: 99, 100, 102.-Bamber, 2000a: 133.Hanamura \& Kase, 2001a: 17. Unjustified emendation.

Type species. Heteromysis rubrocincta Băcescu, 1968, by monotypy.

Diagnosis. Eyestalk with acute distomedial spine (spines) or tubercle in most of species; cornea slightly narrower or rarely about as wide as stalk. Male sternites with medial process. Antennular peduncle segment 3 with two distomedial flagellated spiniform setae: one directed anteriorly, shorter and thicker than another, directed laterally, seta. Ischium of pereopod 1 endopod about 1.5-2.5 times as long as wide; medially without denticles (only setae on slight tubercles). Merus of pereopod 1 endopod without distomedial process; its medial margin without flagellated spiniform setae, and lateral margin with barbed or serrated setae (this character still requires confirmation for some species). Carpopropodus of pereopod 1 moderate in size, shorter than merus (or occasionally as long as merus), with medial flagellated spiniform setae and without long and serrated paradactylary setae. Penis narrowing apically, with thin finger-like lobes. Male pleopods modified, with flagellated spiniform setae. Uropodal endopod shorter than exopod.

Comparison. The subgenus Olivemysis is characterized by rather the unique structure of the eyes, the pereopodal endopods, especially pereopod 1 , and the armature of the male pleopods. However, certain species may lack one of the characters. The eyes are typically conical with the cornea slightly narrower than the stalk, though in some species the cornea can be about as wide as the stalk; and the stalk typically having a strong acute distomedial spine, directed laterally, but occasionally absent or represented instead either by a tubercle or even by two spines in one species. The pereopodal endopod 1 has rather wide and relatively short carpopropodus, lacking the strong paradactylary setae. The carpopropodus segment 1 is usually about twice as long as wide, but in a couple of species it is three time as long as wide; it is also normally shorter than the merus, but again in one species it is about as long. All the species have the modified male pleopods, bearing brushlike set of short flagellated spiniform setae, although a variety of combinations exist concerning distribution of setae among the pleopods and their numbers, and these setae can occasionally be found also in the females. From 
Gnathomysis the subgenus Olivemysis also differs by the presence of the flagellated spiniform seta on the antennular peduncle segment 2 and 3 , the absence of the serration on the ischium of the pereopod 1 endopod, its carpopropodus being shorter than the merus (longer than the merus in Gnathomysis), the uropodal endopod shorter than the exopod (slightly longer or about as long in Gnathomysis). Finally, from Neoheteromysis it is distinguished by the presence of the flagellated spiniform setae on the antennular peduncle segment 2 and 3, the absence of the serrations of the pereopod 1 dactylus (uniquely found in Neoheteromysis), and the short size of the flagellated setae on the male pleopods (rather long in Neoheteromysis).

Remarks. The subgenus Olivemysis was described by Băcescu (1968) for the species of Heteromysis with the dimorphic pleopods 4 and sometimes also pleopods 3 , and the modified spiniform setae on the antenna 1 peduncle, which he later called "phanerae" (Băcescu, 1970) or “flagellated spines" (Băcescu, 1979) or "Olive Tattersall's spines" (Băcescu, 1983). He also changed the name spelling into Olivaemysis (Băcescu, 1970) and described species with the sternal processes, originally considered by him characteristic to Heteromysis s. str. only (Băcescu, 1968). Brattegard (1969, 1970, 1973, 1974a, b, 1975, 1980) and Modlin (1984, 1987a, b, c) preferred not to use subgeneric names at all, although they dealt with the species, included into Olivemysis. Bowman \& Orsi (1992) returned to the original spelling of Olivemysis. Bamber (2000a) used Olivaemysis spelling again, while Wittmann (2000) preferred Olivemysis. Hanamura \& Kase (2001a) did not accept the subgenus, and again used Olivaemysis spelling. Fenton in Lowry \& Stoddart (2003) was the first to particularly notice the incorrect spelling for the subgenus as Olivaemysis, although previously using it herself (Fenton, 1986), and revised it. Wittmann (2008) described another species of Olivemysis with the sternal processes and stressed that it is not purely characteristic for the nominotypical subgenus, which was not done by Băcescu (1970). Finally, Wittmann (2008) also stressed that Băcescu's (1970) emendation of the subgenus name to Olivaemysis was unjustified and thus incorrect according to the Code. Despite considerable work done with the subgenus, its proper diagnosis appeared only in Price \& Heard (2011), who included the differentiation of the two distomedial setae, with the flagellated seta directed anteriorly and a simple long seta directed laterally; the distinction of the pereopod 1 endopod, which was moderately robust
("H. waitei type" in Băcescu's [1979] terminology); and the difference in the length of the uropodal rami, where the uropodal endopod was shorter than the exopod. The last modification of the subgeneric definition came with Wittmann \& Abed-Navandi (2021). They noted that the antennular flagellated seta ("bifid flagellate spine", in their terminology) was directed distomedially; the pereopod 1 endopod ("thoracic endopod 3") was prehensile, which is the tribal character; the absence of serrations and distomedial process ("tooth-like extension") on the merus, and of the paradactylary setae on the propodus of the pereopod 1 endopod; the eyestalk had distomedial process in form of spine or tubercle in most of the species. The originally described modification in the pleopods 3 and 4 was expanded to include all five pleopods, although a wide variety of combinations exist with the number of the modified pleopods, and the common feature is still the fact of presence of the modifications.

The representatives of the microps-group in the subgenus Heteromysis s. str., as well as the genus Ischiomysis, also have the distomedial flagellated spiniform seta on the antennular peduncle segment 3 . In the microps-group it is usually rather long, about as long as the second, laterally directed spiniform seta. In Ischiomysis this seta is as short, but seemingly thinner than in Olivemysis. However, the presence of the flagellated spiniform setae is no longer considered unique for Olivemysis. Nevertheless, as I could see from the current material, both distomedial setae of the antennular peduncle segment 3 are flagellated in Olivemysis as well as in the members of the microps-group. Taking this and other characters that arise from the comparison of different subgenera into account, I updated the diagnosis of Olivemysis. Referring to the update, I also include more species in the subgenus.

Composition. The subgenus contains 47 species, among which two, H. (O.) abrucei Băcescu, 1979 and H. (O.) murrayae sp. nov. are found in the Tasman Sea. Comparing species from other parts of the world I noticed that the following species must also be included into Olivemysis and are re-classified here into that subgenus; new subgeneric reclassifications: Heteromysis (Olivemysis) bredini Brattegard, 1970, Heteromysis (O.) brucei O. S. Tattersall, 1961, Heteromysis (O.) disrupta Brattegard, 1970, Heteromysis (O.) odontops Walker, 1898, Heteromysis (O.) waitei W. M. Tattersall, 1927. Heteromysis thailandica, previously part of Olivemysis, clearly belongs to the nominate subgenus of Heteromysis (see the relevant section above).

\section{Key to the Tasman Sea species of the subgenus Olivemysis}

$1 \quad$ Rostrum apically narrowly rounded to nearly pointed (Fig. 18A). Eyestalk with distomedial spine (Fig. 18A). Telson lateral margins with 14-27 spiniform setae, occupying entire length (Fig. 18B) H. (O.) abrucei Băcescu, 1979

1' Rostrum apically broadly rounded (Fig. 23A). Eyestalk with distomedial tubercle (without spine). Telson lateral margins with three to seven anterior and six to nine posterior spiniform setae, with gap between two groups (Fig. 23B) H. (O.) murrayae sp. nov. 


\section{Heteromysis (Olivemysis) abrucei Băcescu, 1979}

\section{Figs $18-21$}

Heteromysis (Olivaemysis) abrucei Băcescu, 1979: 143, fig. 1A-I (incorrect spelling in the subgeneric name).Băcescu \& Müller, 1985: 9, fig. 1I-P.-Fenton, 1986: 203, 145, fig. 2.51H, I.-Murano, 1988: 27, 35, 36, 46.

Heteromysis abrucei.—Băcescu \& Bruce, 1980: 71.-Neyt, 2002: 11.-Hanamura \& Kase, 2001a: 18.

Heteromysis (Olivemysis) abrucei.-Lowry \& Stoddart, 2003: 448.-Price \& Heard, 2011: 44.-Daneliya, 2012: 136, 141, 417.- San Vicente \& Monniot, 2014: 336.Wittmann \& Abed-Navandi, 2019: 94; 2021: 137, 139.

Heteromysis (Heteromysis) abrucei.-Petrescu \& Wittmann, 2009: 59.

Type specimens. Holotype, male, $5 \mathrm{~mm}$, Australia, Queensland, Great Barrier Reef, near Heron Island, Moore Reef, st. 563, on coral Acropora, 30 Dec 1976, coll. A. J. Bruce (MGAB 49192). M. Băcescu was planning to deposit the holotype at the AM (Băcescu, 1979), but eventually put them at the MGAB (Petrescu \& Wittmann, 2009). He also mentioned an allotype female and a paratype male from the same sampling, but neither has been found in any museum collections.

Tasman Sea material. Male (+slide), female, Inflammable Liquids Berth, Port Kembla Outer Harbour, 34⒉'57"S $150^{\circ} 54^{\prime} 15^{\prime \prime} \mathrm{E}, 0.5 \mathrm{~m}$, pylon/piling scraping, 13 May 2000 , coll. NSW Fisheries, PK ILB P3-0 (AM P.63480; originally det. by G. C. B. Poore in 2000); 2 males, $5.5-6.5 \mathrm{~mm}$, female, $6 \mathrm{~mm}$, 4 subadult specimens (one without head), south end of No. 3 Jetty, Port Kembla Outer Harbour, $34^{\circ} 28^{\prime} 36^{\prime \prime S} 150^{\circ} 54^{\prime} 30^{\prime \prime E}, 0.5 \mathrm{~m}$, pylon/piling scraping, 16 May 2000, coll. NSW Fisheries, PK J3O P2-0 (AM P.63481; originally det. by G. C. B. Poore in 2000); damaged specimen, Port Jackson, White Bay east, $33^{\circ} 51^{\prime} 40^{\prime \prime} \mathrm{S}$ $151^{\circ} 11^{\prime} 25^{\prime \prime} \mathrm{E}, 3 \mathrm{~m}$, scrapings from cement facing, $18 \mathrm{Apr}$ 2001, coll. AM party_-Sydney Ports Survey, Sydney Ports 51, hand collected on SCUBA (AM P.62274; originally det. by R. T. Springthorpe in 2001); 2 females, 5.5-6 mm, Port Jackson, Garden Island east, 33॰51'45"S 151 ${ }^{\circ} 13^{\prime} 47^{\prime \prime} \mathrm{E}, 3 \mathrm{~m}$, scrapings from metal struts, 21 May 2001, same collector and gear, Sydney Ports 28 (P.62273; det. R. T. Springthorpe in 2001); 8 females, 4.5-6 mm, 3 damaged specimens, 2 cephalothoraces, 7 abdomens, Port Jackson, Chowder Bay, $33^{\circ} 50^{\prime} 29^{\prime \prime} \mathrm{S} 151^{\circ} 15^{\prime} 20^{\prime \prime} \mathrm{E}, 3 \mathrm{~m}$, scrapings from cement piles, 6 Jun 2001, same collector and gear, Sydney Ports 14 (P.62272; det. R. T. Springthorpe in 2001); female, $5 \mathrm{~mm}, 2$ damaged specimens, Port Jackson, Balls Head Bay north, 33 ${ }^{\circ} 50^{\prime} 34^{\prime \prime S}$ $151^{\circ} 11^{\prime} 31 " \mathrm{E}, 3 \mathrm{~m}$, on Mytilus galloprovincialis in scrapings from wooden piles, 24 Apr 2001, same collector and gear, Sydney Ports 1 (P.62271; det. R. T. Springthorpe in 2001); female, $6.5 \mathrm{~mm}$, Botany Bay, Channel Marker 4, 33 ${ }^{\circ} 59^{\prime} 18^{\prime \prime} \mathrm{S}$ $151^{\circ} 12^{\prime} 36^{\prime \prime E}, 7 \mathrm{~m}$, pylon scraping, 21 Oct 1998 , coll. NSW Fisheries, BB CH4 P1-7 (P.58593).

Diagnosis. Rostrum (Fig. 18A) angular, apically narrowly rounded to nearly pointed, reaching proximal or middle part of antennular peduncle segment 1; its lateral margins slightly concave. Eyestalk (Fig. 18A) with one distomedial spine; cornea slightly narrower or about as wide as stalk. Telson (Fig. 18B) slightly longer than last abdominal somite and $0.20-0.29$ as wide posteriorly as anteriorly. Telson cleft $0.27-0.30$ of telson length, with 17-19 spinules, occupying anterior $0.52-0.70$ of cleft length. Telson lateral margins slightly sinusoid, with 14-27 spiniform setae, occupying entire length; among two terminal, inner spiniform setae $0.58-0.86$ as long as outer; outer spiniform setae $0.10-0.13$ as long as telson and $1.1-1.2$ times as long as last posterolateral spiniform setae. Antennular peduncle (Fig. 18A) segment 2 with medial flagellated spiniform seta; segment 3 with two medial flagellated spiniform setae, one stronger and shorter or about as long as another thinner spiniform seta. Antennal scale (Fig. 18E) reaching proximal or middle part of antennular peduncle segment 3 and nearly reaching distal margin of antennal peduncle, 2.7-3.4 times as long as wide. Pereopod 1 endopod (Fig. 19C,D), ischium 1.6-1.8 times as long as wide, merus $2.5-2.7$ times as long as wide and 1.5-1.9 as long as ischium, carpopropodus segment 1 is $1.8-2.3$ times as long as wide and $0.69-0.71$ times as long as merus, with three or four groups of two (proximal group may also have one) about equal smooth flagellated spiniform setae, dactylus with unguis $0.43-0.54$ of carpopropodus; unguis smooth. Pereopod 2 (Fig. 20A) carpopropodus 3-segmented. Pereopod 3-6 (Figs. 20B,E, 21A) carpopropodus 6-9-segmented. Pleopods 3 and 4 of male (Fig. 21C) with 11-13 and 14-17 strong flagellated setae, respectively. Uropodal endopod (Fig. 18D) with two to four proximal spiniform setae.

Comparison. The species is not known to have any unique characters. It is most similar to $H$. (O.) brucei, found in Seychelles, from which H. abrucei differs by larger number of the telson lateral spiniform setae (17-27 against 11-15), fewer uropodal endopod spiniform setae (two to four against five), the smooth spiniform setae of the carpopropodus of the pereopod 1 and its dactylar unguis (uniquely serrated in $H$. brucei), the broader pereopod 1 merus (2.5-2.7 times as long as wide, compared to 4.4 in $\mathrm{H}$. brucei), with about ten rather long medial setae in the middle part (only two in H. brucei). It is also rather close to $H$. (O.) essingtonensis Murano, 1988, from the northern Australian coast, from which it differs by the presence of the distomedial spine on the eyestalk (absent in H. essingtonensis), slightly more spinules in the telson cleft (17-19 against 12 in H. essingtonensis), but less spiniform setae on the uropodal endopod (two-four against 13-15 in H. essingtonensis).

Description of Tasman Sea specimens. Rostrum angular, apically narrowly rounded to nearly pointed (Botany Bay and Port Jackson), as in type specimens, covering eye stalk bases. Eye stalk with strong distomedial spine. Cornea nearly as wide as distal part of stalk. Telson slightly (1.1) longer than last abdominal somite, 1.02 times as long as wide anteriorly and 4.9 times as wide anteriorly as posteriorly. Telson lateral margins entirely with 20-27 spiniform setae (14-22 in the Coral Sea and 17-20 in Somali), including two apical, with outer spiniform setae slightly bent outwards; inner apical spiniform setae $0.6-0.7$ as long as outer. Telson cleft rather deep, 0.3 of telson length, with parallel margins and 17-19 spinules in anterior half (same as in Somali and 20 in the types). Antennular peduncle rather strong; segment 2 with distomedial flagellated seta; segment 3 with two distomedial flagellated setae, one of them stronger, directed slightly inward, nearly as long as another, weaker, directed outward, and two simple setae directed forward. Antennal 


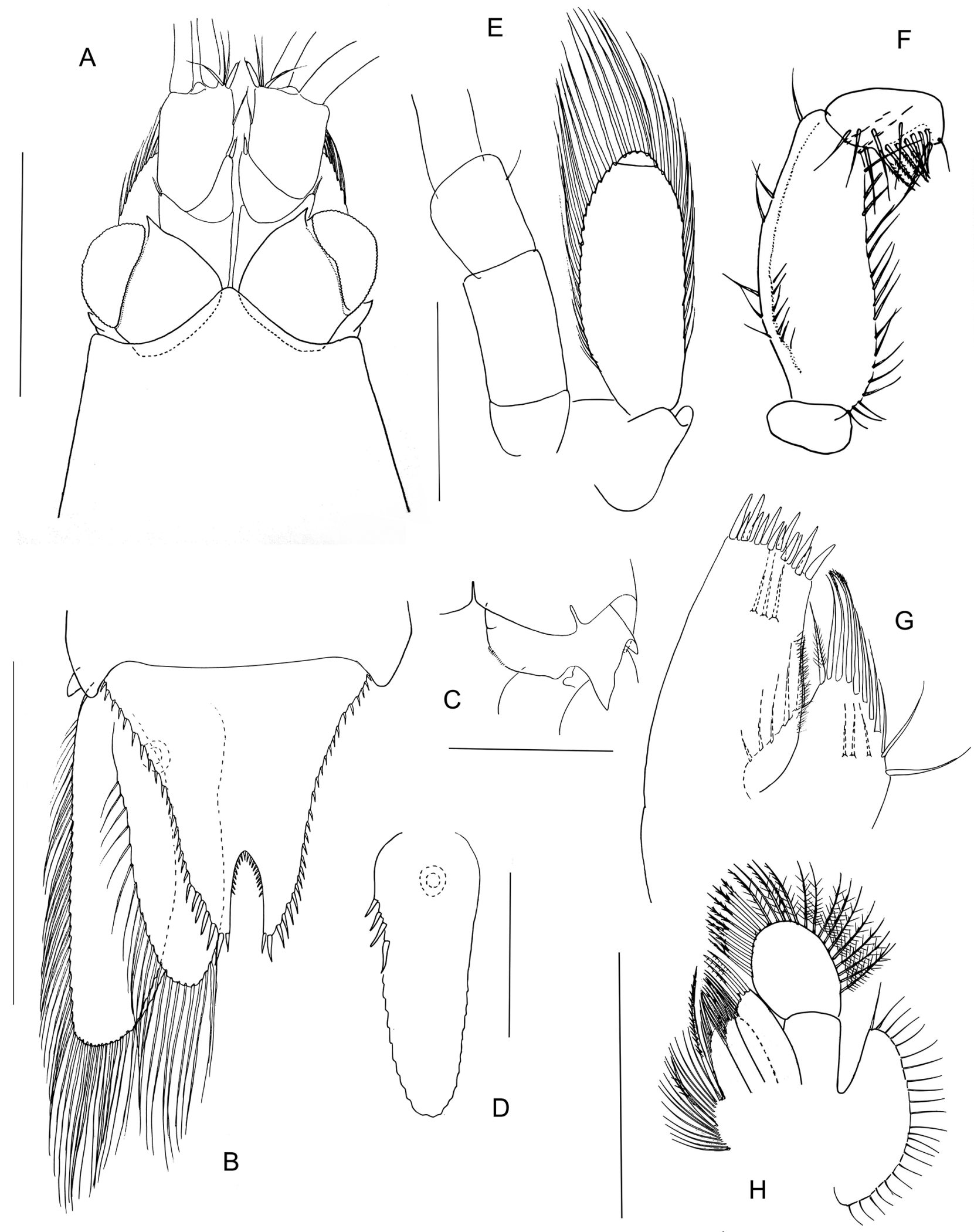

Figure 18. Heteromysis (Olivemysis) abrucei Băcescu, 1979, male, Tasman Sea, New South Wales, Port Kembla, AM P.63480. (A) head, dorsal; $(B)$ posterior part of body with telson and uropods, dorsal; $(C)$ posteroventral margin of abdominal segment 6 , and uropodal protopod; $(D)$ uropodal endopod, ventral; $(E)$ antennal peduncle and scale, ventral view; $(F)$ mandibular palp, anterior; $(G)$ maxilla 1 , anterior; $(H)$, maxilla 2 , posterior. Scales $(\mathrm{mm}): \mathrm{A}, \mathrm{B}=1 ; \mathrm{C}-\mathrm{H}=0.5$. 


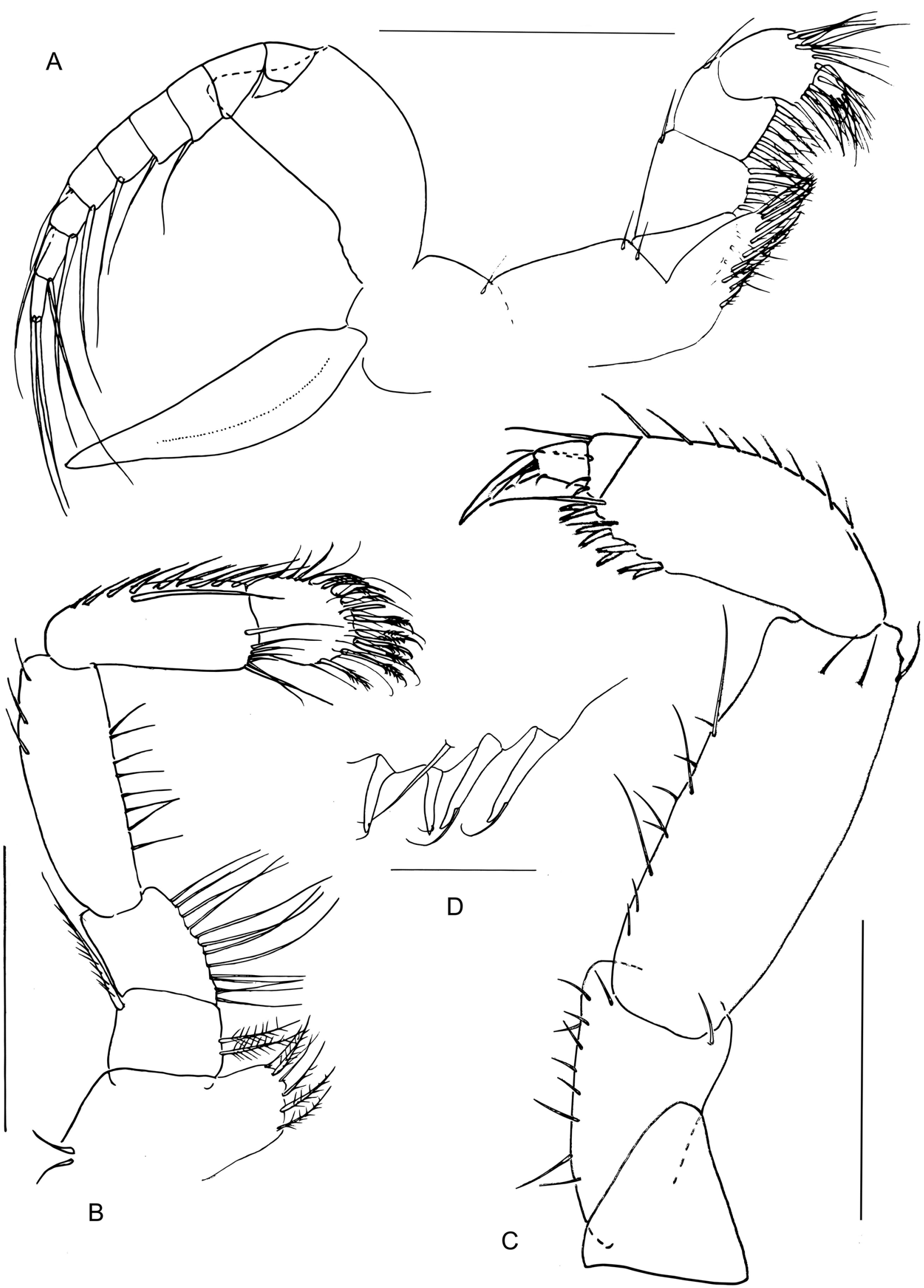

Figure 19. Heteromysis (Olivemysis) abrucei Băcescu, 1979, male, Tasman Sea, New South Wales, Port Kembla, AM P.63480. (A) maxilliped 1, anterior; $(B)$ maxilliped 2 endopod, posterior; $(C)$ pereopod 1 endopod, posterior; $(D)$ distolateral spiniform setae (one side) of pereopod 1 carpopropodus segment 1 , posterior. Scales (mm): $A-C=0.5 ; D=0.25$. 


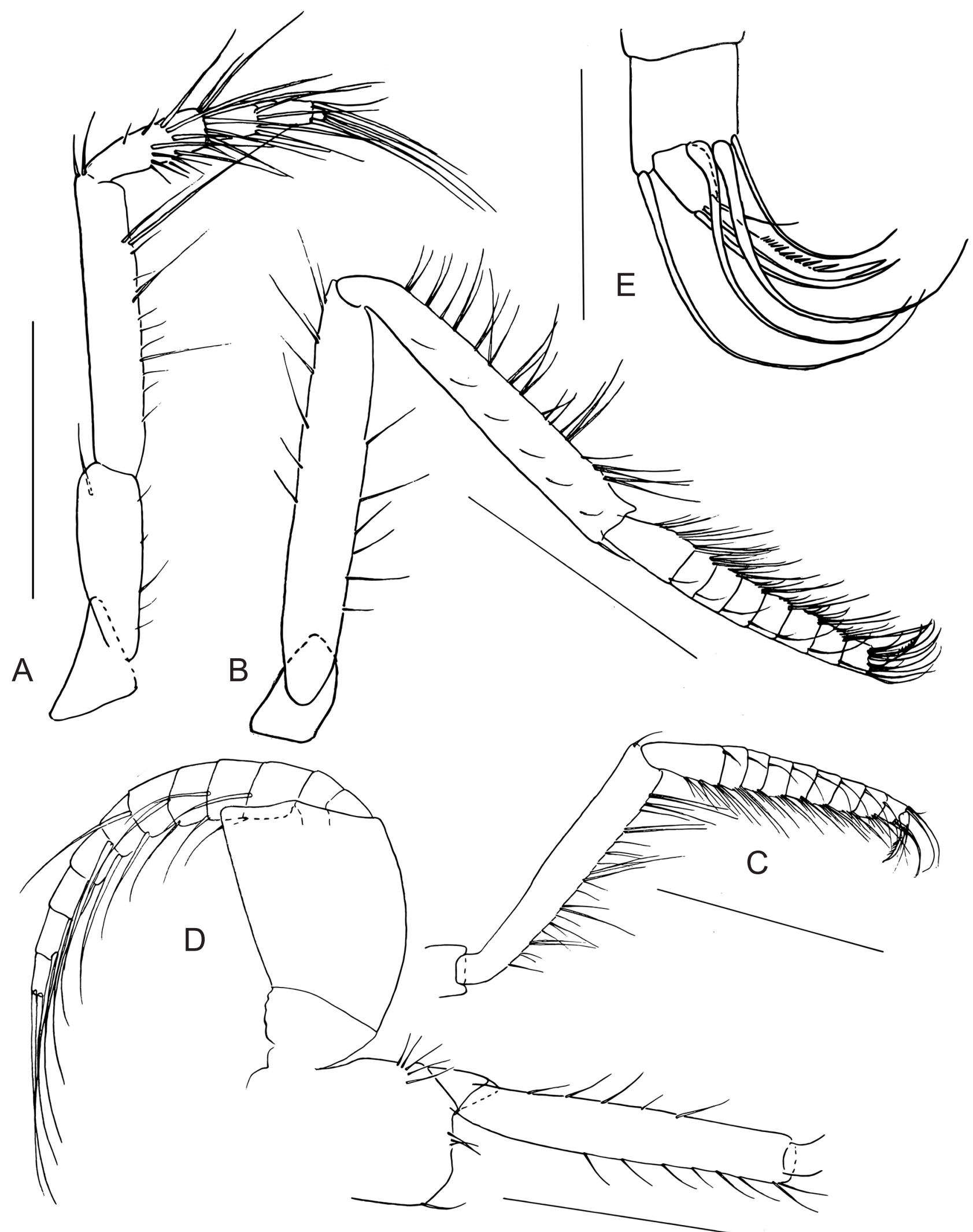

Figure 20. Heteromysis (Olivemysis) abrucei Băcescu, 1979, male, Tasman Sea, New South Wales, Port Kembla, AM P.63480. (A) pereopod 2 endopod, anterior; $(B)$ pereopod 3 endopod, anterior; $(C)$ distal part of pereopod 3 endopod, anterior; $(D)$ pereopod 5, exopod and proximal part of endopod, anterior; $(E)$ pereopod 5, distal part of endopod, anterior. Scales $(\mathrm{mm})$ : A, B, D, E = 0.5, C = 0.25. 


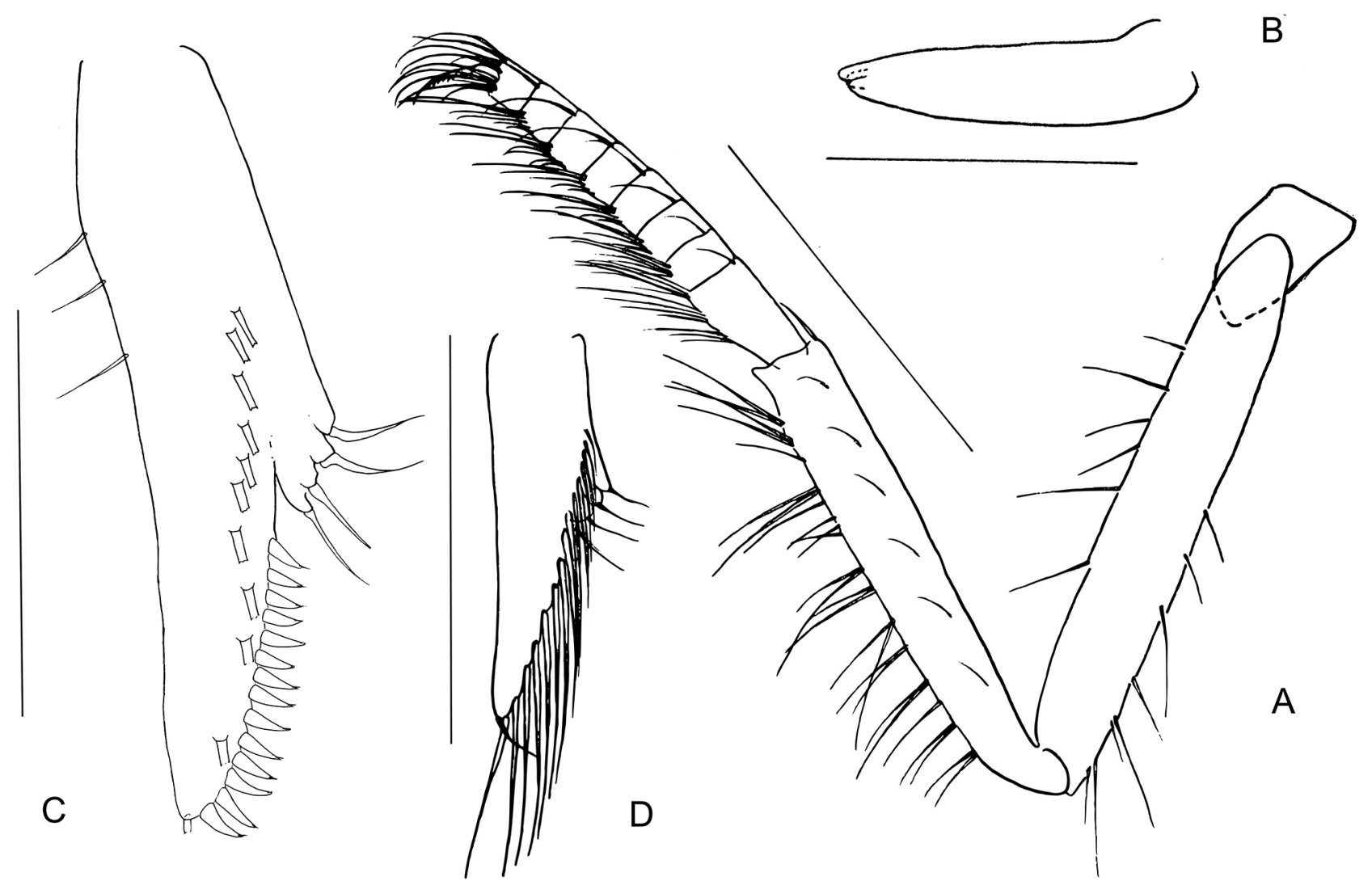

Figure 21. Heteromysis (Olivemysis) abrucei Băcescu, 1979, male, Tasman Sea, New South Wales, Port Kembla, AM P.63480. (A) pereopod 6 endopod, posterior; $(B)$ penis; $(C)$ pleopod 3, anterior; $(D)$ pleopod 5, anterior. Scales $(\mathrm{mm})$ : A-D = 0.5.

scale nearly reaching distal margin of antennal peduncle segment 3, and half of antennular peduncle segment 3 (reaching proximal part in type specimens), its length 2.5 width (3.0 in the types and 2.7 in Somali). Mandibular palp as typical for the genus. Maxilla 1 outer ramus with three caudal setae and about 14 strong spiniform setae. Maxilla 2 , exopod with 23 short setae, endopod segment 2 with plumose outer and serrated inner setae. Maxilliped 1 typical for the genus; exopod 8-segmented. Maxilliped 2 endopod, carpopropodus 0.8 times as long as merus; dactylus about as wide as carpopropodus, with about 10 serrated setae. Pereopod 1 endopod, merus 2.8 times as long as wide and 1.6 times as long as ischium; carpopropodus segment 1 is 2.1-2.3 times as long as wide and 0.7 times as long as merus, distomedially with six to eight paired flagellated setae, and sometimes with additional distomedial setae; unguis twice as long as dactylus, smooth. Carpopropodus of pereopod 2 is 3-segmented, with long setae, 0.8 times as long as merus; segment 1 is 1.2 times as long as segments 2 and 3 together. Pereopod 3-6 exopod 10-segmented; endopod merus 0.9 times as long as ischium and carpopropodus $0.8-0.9$ times as long as merus; carpopropodus 6-9-segmented (7-segmented in the type material and in Somali); dactylar unguis serrated; paradactylary setae smooth, sickle-shaped. Penis tubiform, with short finger-like apical lobes. Pleopods 3 and 4 of male with 13-15 strong flagellated setae (15 in pleopod 4 in Somali specimens, and 11 and 17, in pleopod 3 and 4, respectively, in the types). Pleopod 5 with setae about half as long as ramus. Uropodal endopod 0.8 the length of exopod, with three or four medial spiniform setae in proximal part (two or three in the type specimens, and four in Somali).
Body length of males $5.5-6.5 \mathrm{~mm}$, females $4.6-6.5 \mathrm{~mm}$ (3.5-5.0 $\mathrm{mm}$ in the type locality).

Color. In the Coral Sea, Băcescu (1979) and Băcescu \& Bruce (1980) reported generally translucent whitish or uniform golden tegument; the carapace, abdomen, antennal peduncles, anterior parts of eyestalks and telson with small red dots; the eye cornea white. Similar coloration was described for Heteromysis (Olivemysis) brucei, H. (O.) dardani Wittmann, 2008, H. (O.) ningaloo Daneliya, 2012 and $H$. (O.) wirtzi Wittmann, 2008. The Somali specimens of $H$. abrucei were shown to have generally pink body and dark red eyes (Băcescu \& Müller, 1985).

Distribution. West Indo-Pacific. Coral Sea. Australia, Queensland: southern Great Barrier Reef, Heron Island, Moore Reef (type locality) (Băcescu, 1979; Băcescu \& Bruce, 1980). Tasman Sea. Australia, New South Wales: Port Jackson (Hutchings et al., 2013), Botany Bay, Port Kembla (new material) (Fig. 22). West Indian Ocean. Somalia (Băcescu \& Müller, 1985).

Habitat and life history. Upper sublittoral species, found at depths of $0.5-7 \mathrm{~m}$. Originally, it was found on the coral Acropora sp. (Băcescu, 1979), subsequently also collected from a nearby location on corals and reef flats (Băcescu \& Bruce, 1980). In Somali, it was found on sand among coral reefs (Băcescu \& Müller, 1985). In this study, all the material comes from scraping of metal, wooden and cement structures in harbours, probably indicating its ecological plasticity, and ability to live away from coral reefs in cooler sea. Females from the Coral Sea had two and four embryos (Băcescu \& Bruce, 1980). 

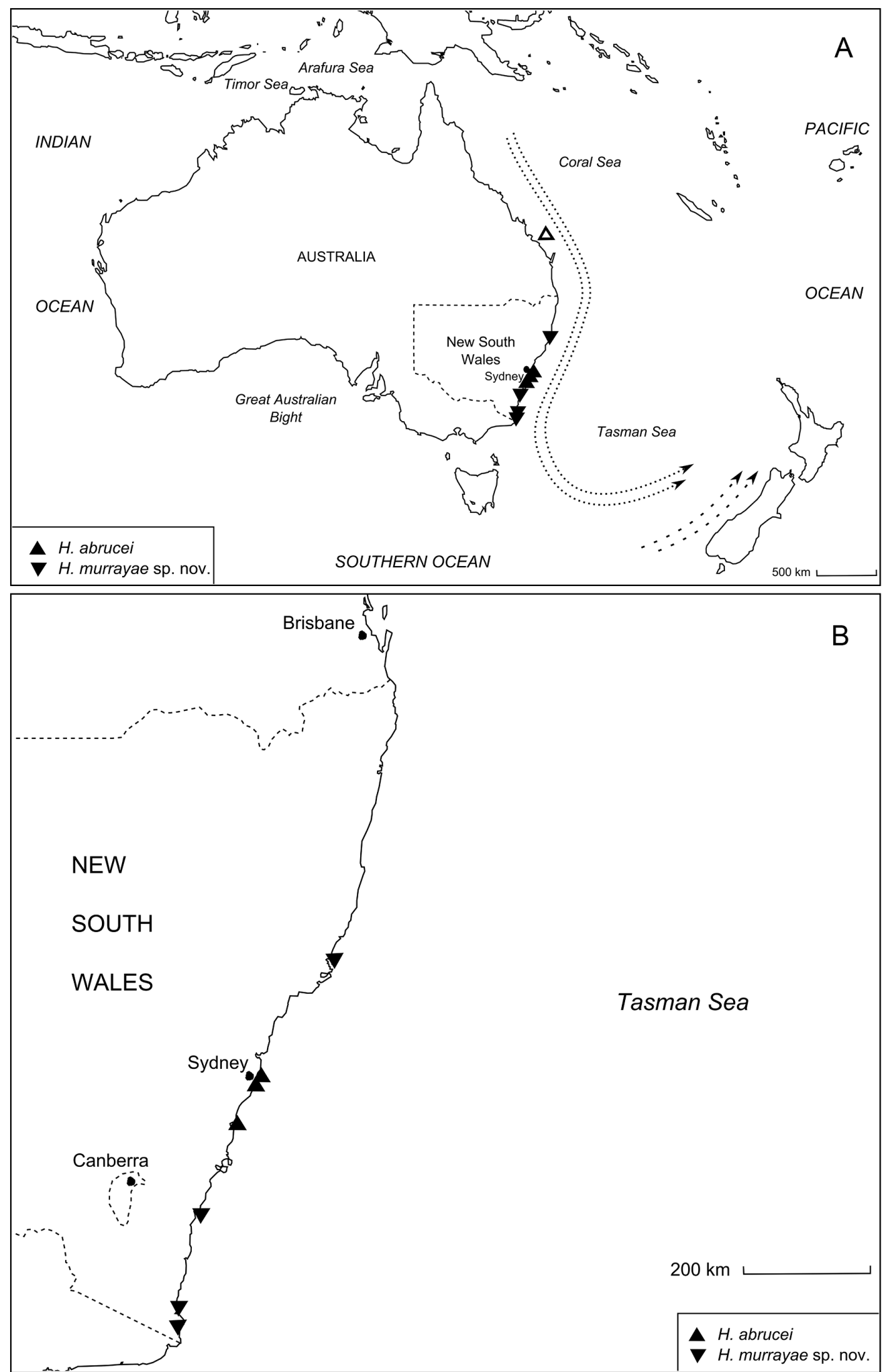

Figure 22. Distribution of the Tasman Sea Heteromysis (Olivemysis) species. (A) H. (O.) abrucei and $H$. (O.) murrayae sp. nov. in the Australian waters (the white sign indicates former record); $(B) H$. (O.) abrucei and $H$. (O.) murrayae sp. nov. in the Tasman Sea.

Remarks. The species was described from the Coral Sea in detail and included in the subgenus Olivemysis (as Olivaemysis) by Băcescu (1979). It was distinguished from the most similar species, H. (O.) brucei comb. nov., known only from Seychelles, West Indian Ocean, by larger size (5 $\mathrm{mm}$ against $3-4 \mathrm{~mm}$ ), larger number of the telson lateral spiniform setae (20 against 11), but less number of the uropodal endopod spiniform setae (three against five). Later, more specimens were collected from the nearby locality (Băcescu \& Bruce, 1980), with body length 3.5-4.5 mm, making it indistinguishable from $H$. brucei by size, 14 or 15 telson lateral spiniform setae (intermediate between the types 
and $\mathrm{H}$. brucei) and only two uropodal endopod spiniform setae. Băcescu \& Müller (1985) reported H. abrucei from Somalia in the West Indian Ocean. The specimens had 17-20 lateral spiniform setae on the telson and four spiniform setae on the uropodal endopod (approaching even closer in this character to $H$. brucei). Apart from the difference in coloration, the specimens from Somalia were surprisingly similar to the Australian specimens. The specimens from the Tasman Sea that I inspected had 20-27 telson lateral spiniform setae, and three or four spiniform setae on the uropodal endopod. Thus, only the number of the lateral spiniform setae of the telson remained to distinguish the two species. On the other hand, comparing H. abruce $i$ with H. brucei, Băcescu (1979) overlooked that the spiniform setae of carpopropodus of pereopod 1 and its dactylar unguis were serrated (as described and illustrated by O. S. Tattersall, 1967), the first character extremely rare and the second unique for the subgenus Olivemysis. In addition, the pereopod 1 merus was rather slender (4.4 times as long as wide, compared to $2.5-2.7$ in $\mathrm{H}$. abrucei), with two rather long medial setae in the middle part (about 10 along the margin in $\mathrm{H}$. abrucei). So far, nothing is known about the structure of the male pleopods in $H$. brucei. Formally, $H$. brucei was not considered part of the subgenus, although originally discussed as the most similar to H. abrucei. Despite the absence of data on the pleopods, I change its status here and include it into Olivemysis due to the presence of the distomedial flagellated spiniform setae on the antennular peduncles, the distomedial spine on the eyestalk and typical for Olivemysis form of the pereopod 1 endopod. In Murano's (1988) opinion, H. (O.) quadrispinosa Murano, 1988, and even more $H$. (O.) essingtonensis, were closely related to $H$. abrucei. He distinguished the second species by the narrowly rounded anterior margin of the carapace (obtusely pointed in $H$. abrucei), the absence of the distomedial spine on the eyestalk (present in H. abrucei), the uropodal endopod with 13-15 spiniform setae (against three or, as we can see from the previous and our findings, two to four spiniform setae). The Tasman Sea specimens have the narrowly rounded anterior margin of the carapace. Thus, the two species are similar by this character too. Hanamura \& Kase (2001a) summarized the known key characters of $H$. abrucei together with other Indo-Pacific species. For some reason, H. abrucei was included into the subgenus Heteromysis s.str. by Petrescu \& Wittmann (2009), although it was originally described and subsequently treated as part of Olivemysis by all the workers, including subsequent mentions (Price \& Heard, 2011; Daneliya, 2012). Considering previous studies, I also mentioned that $H$. abrucei had the pointed anterior margin of the carapace (Daneliya, 2012), but from the new material we can see that this character is rather variable even within the Tasman Sea, and it can also be narrowly rounded, with the lateral margins covering the eyestalk bases, not noticed in the type specimens. In addition, the new specimens had the antennal scales reaching half of the antennular peduncle segment 3. I also expressed an opinion that $H$. abrucei was one of the most similar species to $H$. (O.) ningaloo Daneliya, 2012. Wittmann \& Abed-Navandi (2019) described $H$. (O.) domusmaris Wittmann et Abed-Navandi, 2019, and compared it also with $H$. abrucei. The new species was reported to be distinguished by the flagellated spiniform setae on the segments 1 and 2 of the antennular peduncle, the presence of the outer spiniform extension on the antennal sympod, the apically more rounded rostrum, the greater number of the flagellated spiniform setae on the male pleopod 4 , and by an interrupted series of fewer spiniform setae on the lateral margins of the telson. From the Tasman Sea collection we can now see that $H$. domusmaris differs from H. abrucei by the three characters: 1 , the presence of the flagellated spiniform setae on the segment 1 of the antennular peduncle; 2 , the greater number of flagellated spiniform setae on the male pleopod 4; and 3, the interrupted series of fewer spiniform setae on the lateral margins of the telson. Based on comparison with all species of Olivemysis, I provide here a revised diagnosis of $H$. abrucei with inclusion of more characters and compare it with the most similar species.

\section{Heteromysis (Olivemysis) murrayae sp. nov.}

urn:Isid:zoobank.org:act:F0C5B0AA-BCF7-479C-898D-63ECC92011BF

Figs 23-25

Etymology. The species name is dedicated to a polychaete expert Anna Murray, the collector of the holotype and many other mysid specimens, for her contribution to zoology and marine biology.

Holotype. Female (+slide), $7 \mathrm{~mm}$, Twofold Bay, Red Point, $37^{\circ} 06.11^{\prime} \mathrm{S} 149^{\circ} 57.06^{\prime} \mathrm{E}, 13 \mathrm{~m}$, on ascidian Herdmania grandis (as H. momus), 20 May 1995, coll. A. Murray, st. NSW 1128, by hand on SCUBA (Australian Museum P.98685).

Paratypes. Female, 2 subadults, same as holotype (AM P.98685); female, $7 \mathrm{~mm}$, Forster, South Bennet Head, $32^{\circ} 11.18^{\prime} \mathrm{S} 152^{\circ} 32.3^{\prime} \mathrm{E}, 7 \mathrm{~m}$, rocky reef with gutters, kelp Ecklonia radiata and sessile invertebrates, encrusted rock overhang, $20^{\circ} \mathrm{C}, 19 \mathrm{Mar} 2003$, coll. RV Baragula, P. B. Berents, R. T. Johnson, S. J. Keable, S. J. Kiely, A. Murray \& R. T. Springthorpe, st. NSW 2176, airlift (AM P.98687); male, $6.5 \mathrm{~mm}, 2$ females, 7-7.5 mm, Forster, Outer Latitude Rock, $32^{\circ} 12.65^{\prime} \mathrm{S} 152^{\circ} 34.1^{\prime} \mathrm{E}, 13 \mathrm{~m}$, rocky reef with gutters, E. radiata and sessile invertebrates, Herdmania sp. at base of crevice with crab and small bit of orange sponge, $18 \mathrm{Mar}$ 2003, same collectors and gear, st. NSW 2167 (AM P.98688); subadult female, $5.5 \mathrm{~mm}$, Batemans Bay, west of Tollgate Islands, $35^{\circ} 44.827^{\prime} \mathrm{S} 150^{\circ} 15.42^{\prime} \mathrm{E}, 7.5 \mathrm{~m}, 22.1 \mathrm{C}$, patches of reef, sand, stones and E. radiata, Herdmania grandis (as H. momus), 29 Mar 2004, coll. RV Baragula \& RV Sula, P. B. Berents, K. Attwood, R. T. Johnson, S. J. Keable, S. J. Kiely, K. Monro, A. Murray and R. T. Springthorpe, J. Watson, st. NSW 2638, by hand on SCUBA (AM P.98689); male (damaged), 3 females, $7-9 \mathrm{~mm}, 3$ subadult, 8 juveniles, Merimbula, Long Point, southeast of Wharf, $36^{\circ} 54.06^{\prime} \mathrm{S}$ $149^{\circ} 55.79^{\prime} \mathrm{E}, 12.7 \mathrm{~m}$, on $H$. grandis (as H. momus) attached to boulders, 15 May 1995, coll. A. Murray, st. NSW 1053, by hand on SCUBA (AM P.98690); 2 females, 9-10 mm, 3 subadults, Merimbula Warf, 36 $53.92^{\prime} \mathrm{S} 149^{\circ} 55.64^{\prime} \mathrm{E}, 6.6 \mathrm{~m}$, in H. grandis (as H. momus), 18 May 1995, coll. A. Murray, NSW 1095 (AM P.98691).

Diagnosis. Rostrum (Fig. 23A) angular, apically broadly rounded, reaching proximal part of antennular peduncle segment 1. Eye with cornea narrower than stalk. Eyestalk with distomedial tubercle (without spine). Telson (Fig. 23B) about as long as last abdominal segment, 1.1 times as long as wide anteriorly and 0.2 times as wide posteriorly 


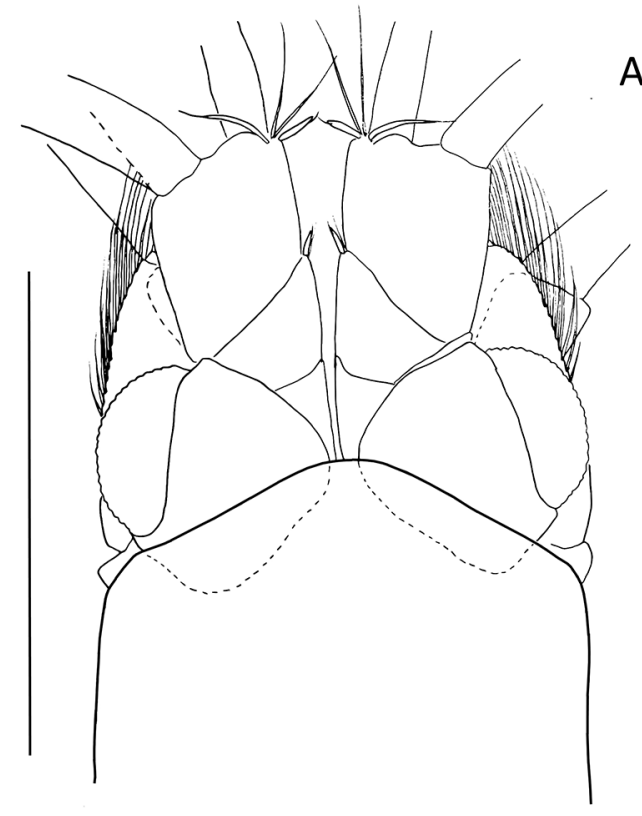

A

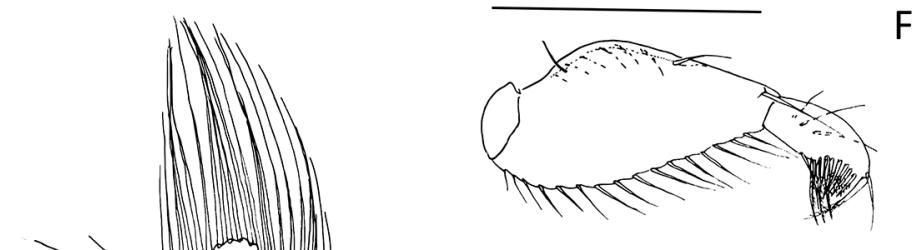

$\mathrm{F}$
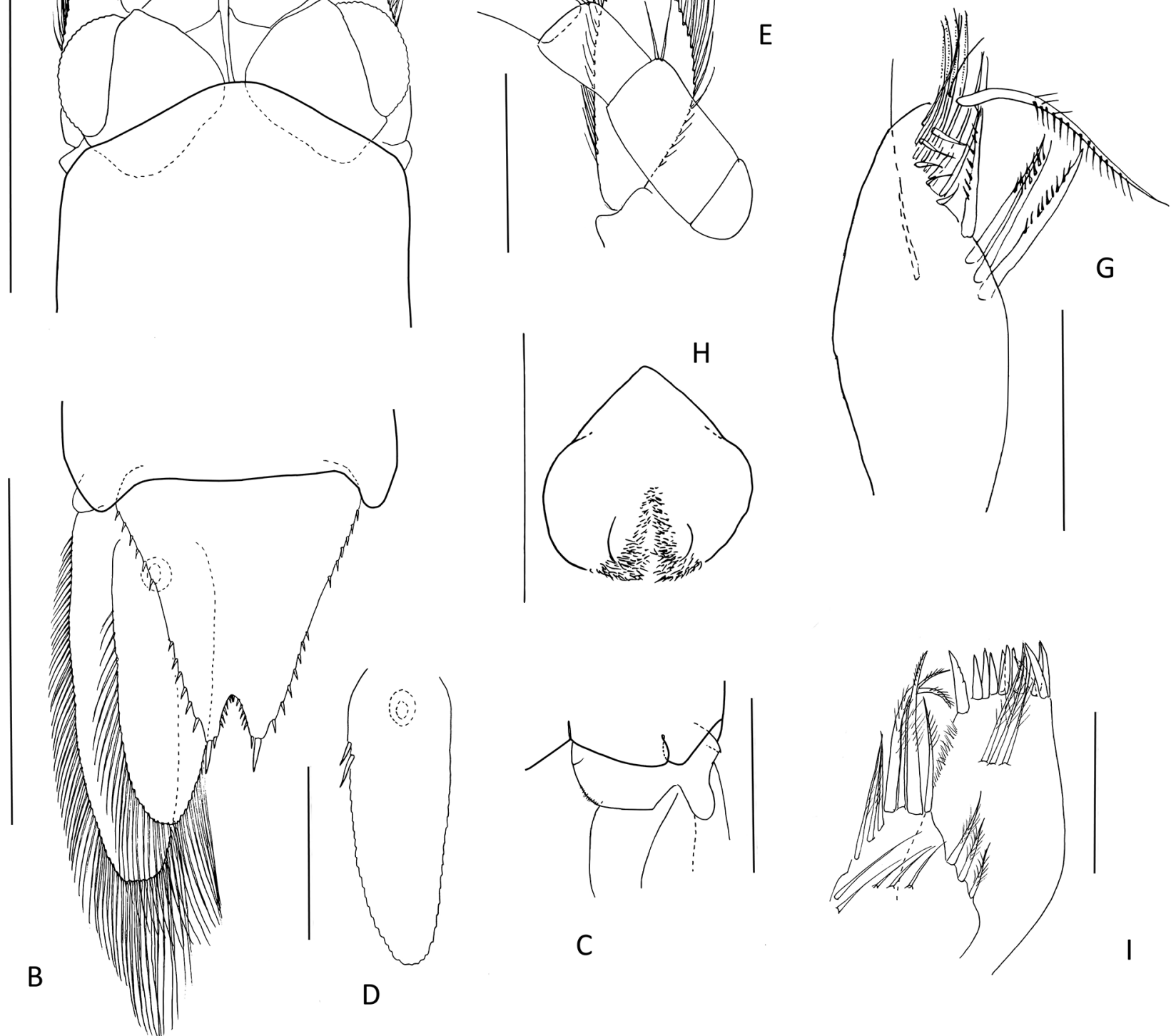

Figure 23. Heteromysis (Olivemysis) murrayae sp. nov., holotype, female, 7 mm, AM P.98685. $(A)$ head, dorsal; $(B)$ posterior part of body with telson and uropods, dorsal; $(C)$ posteroventral margin of abdominal segment 6 , and uropodal protopod; $(D)$ uropodal endopod, ventral; $(E)$ antennal peduncle and scale, ventral view; $(F)$ mandibular palp, posterior; $(G)$ mandibular palp segment 3, posterior; $(H)$ labrum, ventral; $(I)$ maxilla 1 , posterior. Scales $(\mathrm{mm})$ : A, B $=1 ; \mathrm{C}-\mathrm{F}, \mathrm{H}=0.5 ; \mathrm{G}, \mathrm{I}=0.25$.

as anteriorly. Telson lateral margins with three to seven anterior and six to nine posterior spiniform setae, with gap between two groups; outer apical spiniform setae rather long, $0.11-0.12$ of telson length; inner apical spiniform setae rather short, $0.3-0.4$ as long as outer. Telson cleft rather broad and shallow, $0.15-0.20$ times telson length, reaching level of one or two last lateral spiniform seta, with 11-15 short spinules, occupying $0.6-0.7$ of cleft depth. Antennular segment 2 (Fig. 23A) with distomedial flagellated spiniform seta; segment 3 with distomedial inner flagellated spiniform seta about half as long as outer. Antennal scale (Fig. 23A, E) reaching middle of antennular peduncle segment 3 and longer than antennal peduncle, 2.4-2.5 times as long as wide. Pereopod 1 (Fig. $24 \mathrm{D})$ ischium $1.4-1.5$ as long as wide; merus $2.4-2.5$ as long as wide and 1.7-1.8 as long as ischium. Carpopropodus of pereopod 1, segment 1 is $2.1-2.3$ as long as wide and 0.6-0.7 as long as merus, with two or three pairs of long smooth flagellated posterodistal spiniform setae. Dactylus 0.4 of carpopropodus, with smooth unguis. Carpopropodus of pereopod 2 (Fig. 24F,G) is 3-segmented, pereopod 3 (Fig. 


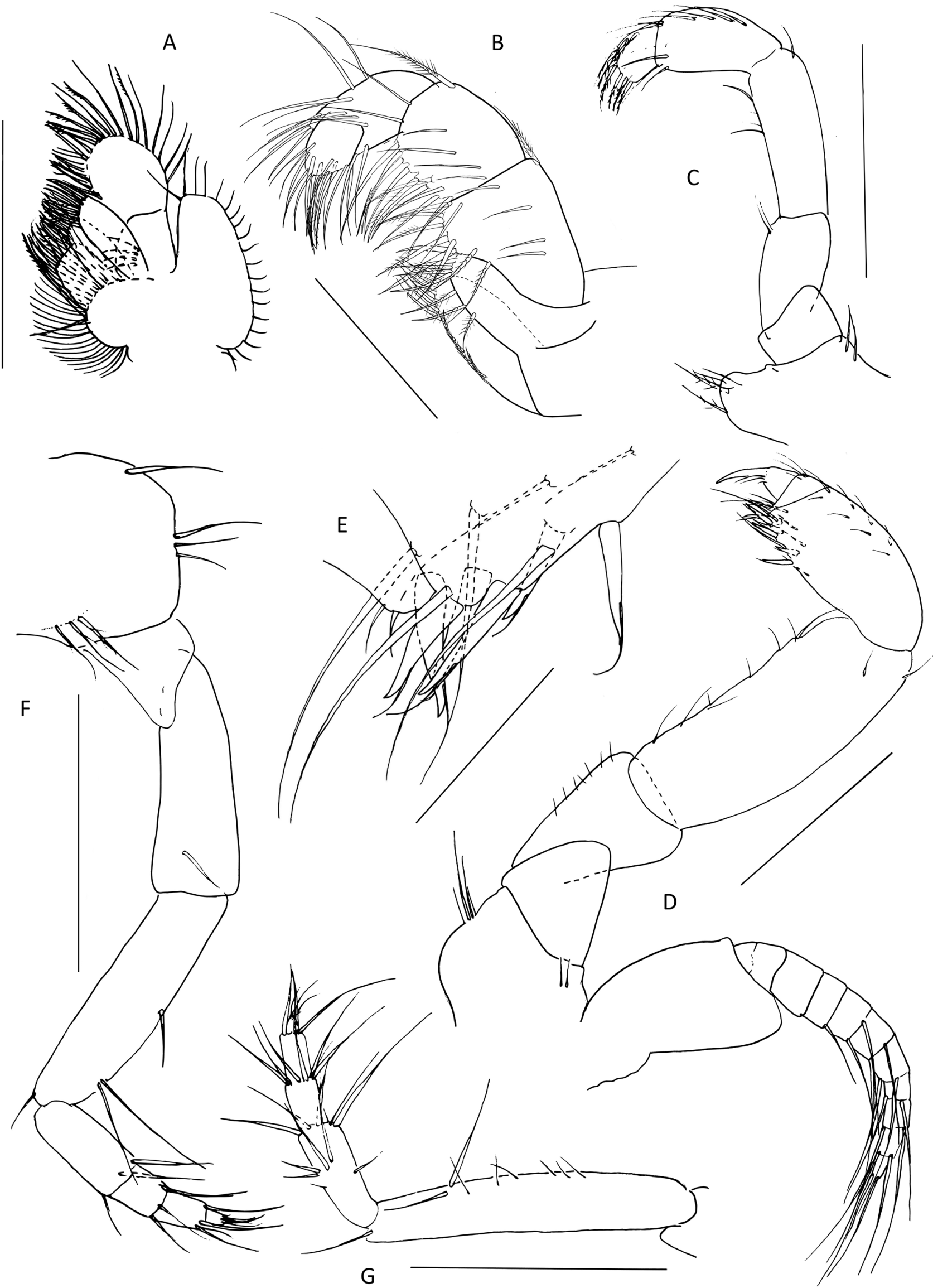

Figure 24. Heteromysis (Olivemysis) murrayae sp. nov. $(A-F)$ holotype, female, $7 \mathrm{~mm}$, AM P.98685; $(G)$ paratype, female, 7 mm, New South Wales, Forster, AM P.98687. (A) maxilla 2, posterior; $(B)$ maxilliped 1 endopod, posterior; $(C)$ maxilliped 2 endopod, posterior; $(D)$ pereopod 1, posterior; $(E)$ distolateral spiniform setae of pereopod 1 carpopropodus segment 1 , posterior; $(F)$ pereopod 2 endopod, posterior; $(G)$ pereopod 2 endopod, posterior. Scales $(\mathrm{mm})$ : A, C, D, F, G $=0.5 ; \mathrm{B}, \mathrm{E}=0.25$. 


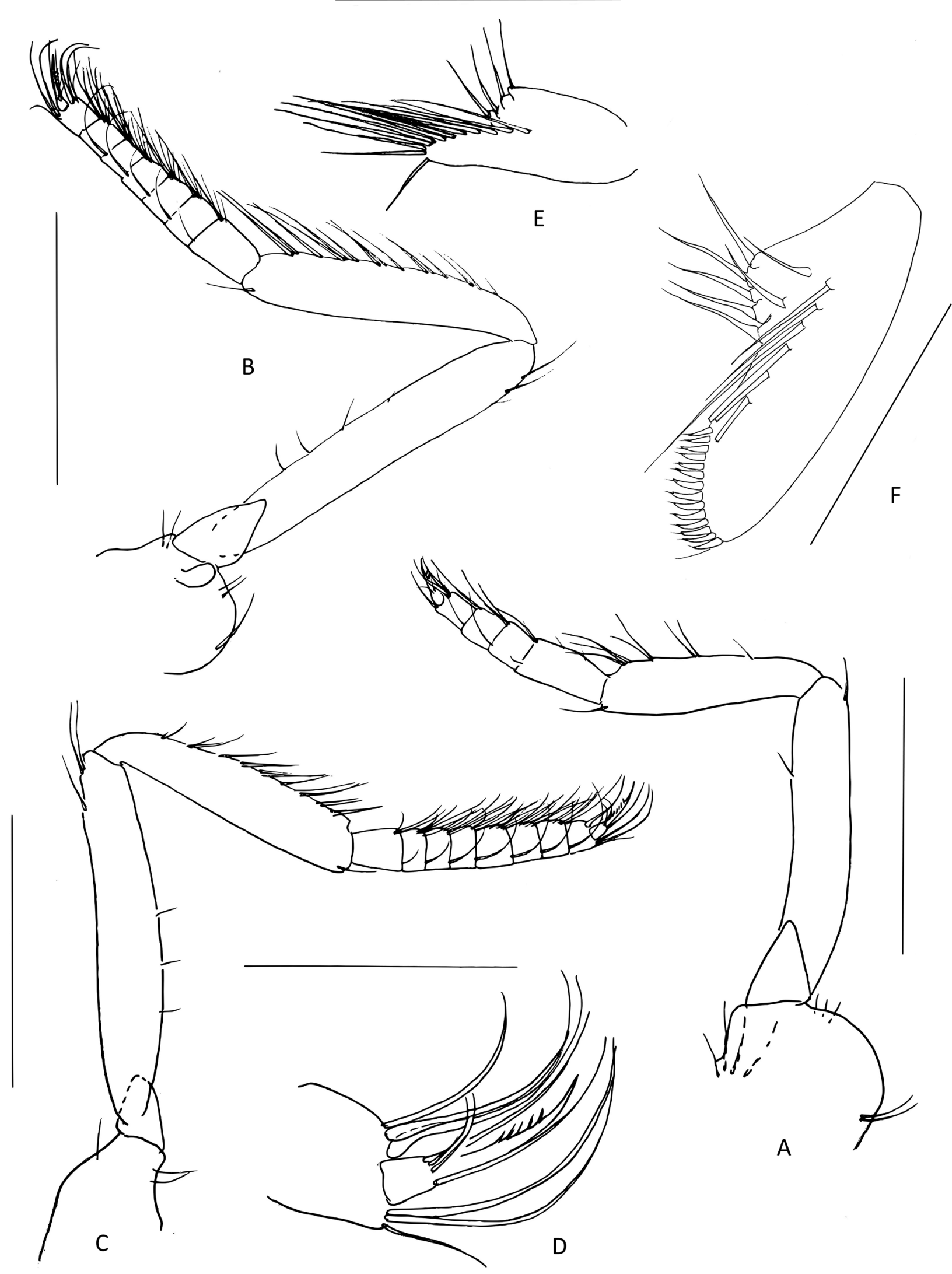

Figure 25. Heteromysis (Olivemysis) murrayae sp. nov. $(A-E)$ holotype, female, $7 \mathrm{~mm}$, AM P.98685; $(F)$ paratype, male, 6.5 mm, New South Wales, Forster, AM P.98688. (A) pereopod 3 endopod, posterior; $(B)$ pereopod 4 endopod, posterior; $(C)$ pereopod 6 endopod, posterior; $(D)$ distal part of pereopod 6 endopod, posterior; $(E)$ pleopod 5 , anterior; $(F)$ pleopod 4 , anterior. Scales $(\mathrm{mm})$ : A-C, E, F = $0.5 ; \mathrm{D}=0.25$. 
25A) is 4-5-segmented, pereopods 4-6 (Fig. 25B,C) is 7-9 segmented. Pereopod 3-6 unguis serrated (Fig. 25D). Male pleopod 3 with 11 flagellated spiniform setae; pleopod 4 (Fig. 25F) with 14 flagellated spiniform setae. Uropodal endopod (Fig. 23D) with two or three medial spiniform setae in proximal part.

Body length of male $6.5 \mathrm{~mm}$, females $7-10 \mathrm{~mm}$.

Comparison. Heteromysis murrayae sp. nov. is one of the rare cases of species clearly belonging to the subgenus Olivemysis, but lacking the distomedial spine on eyestalk, having instead a tubercle. Another of its rare features is the nearly rounded anterior margin of the carapace, known in the subgenus only in Heteromysis (Olivemysis) xanthops Ii, 1964, from Japan, a species also lacking the eyestalk spine. This species can be the only likely candidate of a close relation to $H$. murrayae, and the latter is readily distinguished by the shallower telson cleft $(0.15-0.16$ of the telson length against 0.26 in $H$. xanthops), with fewer spinules (11-15 against 28 in $H$. xanthops), the telson lateral spiniform setae along the entire margins and with the gap (in the posterior half in H.xanthops), the stronger pereopod 1 endopod, with the merus 2.5 as long as wide (3.5-4.0 in H. xanthops), the carpopropodus segment 1 twice as long as wide (three times as long as wide in $H$. xanthops), more flagellated spiniform setae on the male pleopod 4 (14 against seven in H. xanthops), and less medial spiniform setae on the uropodal endopod (two or three against 14 in H. xanthops).

Description of holotype. Anterior margin of carapace broadly rounded, covering eyestalk bases. Telson longer than last abdominal somite; 1.1 times as long as wide anteriorly; posterior width 0.24 anterior width. Cleft acuteangular, rather shallow, 0.2 of entire telson length, with 12 spinules, growing ventrally, behind cleft margin. Lateral margins with middle gap: six anterior and six and nine posterior spiniform setae, including two apical. Inner apical spiniform seta rather short, 0.4 times as long as outer. Eye stalks without dorsomedial spine, but clearly anteriorly produced corner in form of tubercle. Cornea narrower than stalk. Antennular peduncle rather strong; segment 2 with distomedial flagellated spiniform seta; segment 3 with two distomedial flagellated spiniform setae, one of them stronger, directed inward, about half as long as another, weaker, directed outward, and two simple setae directed forward. Antennal scale reaching half of peduncle segment 3 , its length 2.5 width. Mandibular palp as typical for the genus. Maxilla 1 outer ramus with three caudal setae and about 12 strong spiniform setae. Maxilla 2, exopod with 19 short setae, endopod segment 2 with plumose outer and serrated inner setae. Maxillipeds typical for the genus; maxilliped 1 exopod 8-segmented. Thoracopod exopods $2-5$ are 10 segmented. Pereopod 1 endopod, merus 2.6 times as long as wide and 1.8 times as long as ischium; ischium only with medial setae; carpopropodus 2.2 times as long as wide and 0.7 times as long as merus, distomedially with six paired flagellated spiniform setae, and simple long seta at base of each spiniform seta; unguis 1.7 times as long as dactylus. Pereopod 2 merus 1.2 times as long as ischium; carpopropodus 3-segmented, with long setae, 0.7 times as long as merus; segment 1 is 1.2 times as long as segments 2 and 3 together. Pereopod 3 endopod merus 0.7 times as long as ischium, with four bunches of one to three setae; carpopropodus 0.9 times as long as merus; carpopropodus 4-segmented. Pereopod 4-6 ischium 5.7-6.4 times as long as wide, with three or four lateral and three distomedial setae; merus $0.7-0.8$ times as long as ischium, with nine or ten groups of one or two setae. Pereopod 3-6 dactylus rather small; dactylary unguis 3.4 times as long as dactylus, serrated; paradactylary setae smooth, sickle-shaped. Pleopod 5 with setae 0.7 times as long as ramus. Uropodal endopod 0.8 the length of exopod, with two medial spiniform setae in proximal part.

Description of male. Pleopods 3 and 4 with 11-14 strong flagellated setae.

Distribution. Australia, New South Wales: Twofold Bay (type locality), Merimbula Bay, Batemans Bay and Forster (Fig. 22).

Habitat. Sublittoral species found at depths of 6.6 to 13 $\mathrm{m}$, in association with ascidian Herdmania grandis (Heller, 1878) or on rocky reef with gutters, Ecklonia radiata and sessile invertebrates, sand and stones.

\section{Additional taxonomic observations}

I report here one genus, which is not found in the Tasman Sea, but it is important in the discussions of this paper (see the section on Problems of the genus Heteromysoides).

\section{Heteromysinae Norman, 1892}

$$
\text { Heteromysini Norman, } 1892
$$

\section{Platyops Băcescu et Iliffe, 1986}

Platyops Băcescu et Iliffe, 1986: 100, 102.-Müller, 1993: 211.- - Nouvel et al., 1999: 79. - San Vicente \& Monniot, 2014: 333, 334, 341.-Wittmann et al., 2014: 341.

Type species. Platyops sterreri Băcescu et Iliffe, 1986, by monotypy.

Diagnosis. Telson narrowly trapezoidal (nearly triangular), apically truncated, without cleft, bearing rather long spiniform setae. Eyes with distomedial spine directed forward; eye cornea shifted to lateral side; eyestalk without distolateral lobe. Segment 3 of antennular peduncle with thin distomedial setae, not directed backwards. Pereopod 2 carpopropodus multisegmented. Pereopods 3-6 preischium without process; ischium without flagellated spiniform setae. Uropodal endopod without spiniform setae.

Comparison. The most characteristic feature of this genus is the eye structure, particularly the presence of a strong anterior spine, directed forward. A spine on the eyestalk is found in certain members of Heteromysis, but the direction of the spine is unique. This is the only genus in the tribe, in which the telson cleft is missing. Platyops does not seem to be particularly close to any other genus of Heteromysini. At the same time it has all the characters of the tribe: pereopod 1 endopod is differentiated from the pereopod 2 endopod, prehensile (in P. dennisi and P. sterreri [Băcescu et Iliffe, 1986]), with 2-segmented carpopropodus (uniquely 3 -segmented only in P. stenoura comb. nov., see below), pereopod 2 endopod is differentiated from pereopods $3-6$, and other features. 
Remarks. Băcescu \& Iliffe (1986) remarked that Platyops was convergent with Heteromysoides, which was indeed a manifestation that the genus is related to the heteromysine genera. Original placement of Platyops in Mysini caused it to be missing among the heteromysine genera in subsequent works, before Nouvel et al. (1999) finally placed in within Heteromysini. Probably by a mistake it was mentioned as a part of the subfamily Leptomysinae (San Vicente \& Monniot, 2014). However, because of the weekly prehensile nature of pereopod 1 endopod in the type species, it found its position in the heteromysine tribe Mysidetini (Wittmann et al., 2014). With the renewed concept of Heteromysini, I revise here the position of Platyops and transfer it to this tribe.

Composition. Three species are included into Platyops: Platyops dennisi (Bowman, 1985) comb. nov., Platyops simplex (Hanamura et Kase, 2001) comb. nov. (formerly Heteromysoides), Platyops stenoura (Hanamura et Kase, 2004) comb. nov. (formerly Heteromysoides) and P. sterreri.

\section{Biogeographic comments}

We are only beginning to study the mysid fauna of the Tasman Sea. Hence, I can provide only preliminary general comments about the distribution of the Tasman Sea Heteromysis species. Heteromysis is one of the largest mysid genera, and, as I already calculated in the taxonomic section, it currently contains 105 species. Most of them are confined to the tropical and subtropical waters of the World. It is not surprising then, as it had been predicted by Fenton (1986), that we have discovered numerous species in the Tasman Sea.

Among the seven species, two new to scienceHeteromysis (H.) keablei sp. nov. and H. (Olivemysis) murrayae sp. nov.-are found only in the Tasman Sea. Further studies will show if they are true endemics or more widely distributed. Heteromysis (H.) tasmanica is a cooler water species, previously found along the southeastern coast of South Australia, Victoria and Tasmania. The New South Wales record is its northernmost, but still confined to the southernmost part of the state. The remaining four species, Heteromysis (H.) communis, $H$. (H.) macropsis, $H$. (G.) harpaxoides and $H$. (O.) abrucei are more widespread West Indo-Pacific species and seem to be distributed along the eastern Australian coast under the influence of the East Australian Current. It was particularly surprising to discover here $H$. (G.) harpaxoides in several localities. This species has been reported as a commensal of the genus Dardanus, the tropical hermit-crab, which is not yet recorded in the Tasman Sea.

The Tasman Sea species of Heteromysis have close affinities only to the West Indo-Pacific species. This invokes two inferences. First, the Tasman Sea Heteromysini fauna is part of the West Indo-Pacific fauna. Second, the West Indo-Pacific Heteromysini fauna itself, probably, evolved independently from influences of other warm regions.

So far, Heteromysis has not been found along the New Zealand coast of the Tasman Sea. Considering the direction of the East Australian Current, it finally reaches the northwest coast of New Zealand as a convergent current after Australia, while the southwest coast of New Zealand is dominated by the cold Western Current. Thus, under such conditions we would not expect similarly rich Heteromysini fauna in New Zealand as along the Australian coast.
ACKNOWLEDGEMENTs. The material was collected, processed and provisionally identified by the staff of the Australian Museum and Research Institute (AMRI), the Commonwealth Scientific and Industrial Research Organisation (CSIRO) and the Museum Victoria (NMV). I would like to acknowledge the work of the following people, mentioned on labels and collection datafiles, for this initial invaluable work: S. J. Keable, S. J. Kiely, K. B. Attwood, P. B. Berents, P. A. Hutchings, R. T. Johnson, A. R. Jones, J. K. Lowry, S. J. Keable, S. J. Kiely, K. Monro, A. Murray, G. C. B. Poore, A. L. Reid, R. T. Springthorpe, H. E. Stoddart and J. Watson. The hydroids for this study were identified by J. Watson (NMV). I am especially grateful for the assistance of Stephen Keable, Helen Stoddart and other scientific, collection management and administrative staff of AMRI during my stay at the museum. The live photograph of $H$. (G.) harpaxoides is published here with kind permission of R. T. Springthorpe. I am also thankful to S. T. Ahyong (ICZN), N. Evenhuis (ICZN), S. Thorpe and F. WelterSchultes (ICZN) for the discussion and suggestions about the status of Heteromysoides. Karl Wittmann, two anonymous referees, Shane Ahyong and Shane McEvey provided invaluable information and suggestions about the manuscript. This study was made possible for me with an AMRI Visiting Collection Fellowship in 2015.

\section{References}

Bamber, R. N. 2000a. A new species of Heteromysis (Crustacea: Mysidacea) from a "Blue Hole" in the Bahamas. Species Diversity: An International Journal for Taxonomy, Systematics, Speciation, Biogeography, and Life History Research of Animals 5: $129-134$

https://doi.org/10.12782/specdiv.5.129

Bamber, R. N. 2000b. Mysids (Crustacea, Mysidacea) from Hong Kong, with a Description of a New Species of Heteromysis (Mysinae: Heteromysini). In The Marine Flora and Fauna of Hong Kong and Southern China V, ed. B. Morton, pp. 57-64. Proceedings of the Tenth International Marine Biological Workshop: The Marine Flora and Fauna of Hong Kong and Southern China, Hong Kong, 6-26 April, 1998. Hong Kong, Hong Kong University Press.

Banner, A. H. 1948. A taxonomic study of the Mysidacea and Euphausiacea (Crustacea) of the northeastern Pacific, Part II. Mysidacea, from tribe Mysini through subfamily Mysidellinae. Transactions of the Royal Canadian Institute 27: 65-124 (7 plates).

Băcescu, M. 1941. Les mysidacés des eaux Méditerranéennes de la France (spécialement de Banyuls) et des eaux de Monaco. Bulletin de l'Institut Océanographique 795: 1-46.

Băcescu, M. 1968. Heteromysini nouveaux des eaux cubaines: Trois espèces nouvelles de Heteromysis et Heteromysoides spongicola n.g. n.sp. Revue Roumaine de Biologie. Serie de Zoologie 13(4): 221-237.

Băcescu, M. 1970. New spongicolous Heteromysis of the Caribbean Sea (H. gomezi n.sp. and H. mariani n.sp.). Revue Roumaine de Biologie. Serie de Zoologie 15(1): 11-16.

Băcescu, M. 1975. Contributions to the knowledge of the mydis [sic] (Crustacea) from the Tanzanian waters. University Science Journal (University of Dar es Salaam) 1(2): 39-61.

Băcescu, M. 1976. Contribution à la connaisance des Mysidacés (Crustacés) de la Côte Lybienne, avec la description de deux nouvelles espèces, Neoheteromysis mülleri n.sg. n.sp. et Heteromysis lybiana n.sp. Revue Roumaine de Biologie. Série de Biologie Animale 21(2): 85-91.

Băcescu, M. 1979. A small contribution to the knowledge of the mysids from the north-eastern Great Barrier Reef of Australia. Travaux du Muséum national d'Histoire naturelle "Grigore Antipa» 20(1): 143-147.

Băcescu, M. 1983. New Heteromysini from the coral area near Heron Island (SE Queensland)-Australia. Revue Roumaine de Biologie. Serie de Biologie Animale 28(1): 3-11. 
Băcescu, M. 1986. Two new species of Heteromysis from the coral reefs of northern Australia. Travaux du Muséum national d'Histoire naturelle «Grigore Antipa» 28: 19-24.

Băcescu, M., and A. J. Bruce. 1980. New contributions to the knowledge of the representatives of genus Heteromysis s.l. from the Australian coral reefs. Travaux du Muséum national d'Histoire naturelle «Grigore Antipa»21(1): 63-72.

Băcescu, M., and T. M. Iliffe. 1986. Bermudamysis g.n., Platyops g.n. and other mysids from Bermudian caves. Stygologia 2(1/2): 93-104.

Băcescu, M., and G. I. Müller. 1985. Heteromysoides berberae n. sp. et autres Mysidacés dans les eaux littorales du NE de la Somalie. Revue Roumaine de Biologie. Serie de Biologie Animale 30(1): 7-10.

Băcescu, M., and M. Ortiz. 1984. Contribution to the knowledge of the Mysidacea (Crustacea) of the Cuban insular shelf waters. Travaux du Muséum national d'Histoire naturelle "Grigore Antipa» 24: 15-23.

Bonnier, J., and C. Pérèz. 1902. Sur un crustacé commensal des pagures, Gnathomysis Gerlachei, nov. sp., type d'une famille, nouvelle de schizopodes. Comptes Rendus Hebdomadaires des Séances de l'Académie des Sciences 134: 117-119. https://doi.org/10.5962/bhl.part.19865

Bowman, T. E., and J. J. Orsi. 1992. Deltamysis holmquistae, a new genus and species of Mysidacea from the SacramentoSan Joaquin estuary of California (Mysidae: Mysinae: Heteromysini). Proceedings of the Biological Society of Washington 105(4): 733-742.

Bowman, T. E. 1981. First description of the male opossum shrimp, Heteromysis bermudensis bermudensis (Crustacea: Mysidacea). Proceedings of the Biological Society of Washington 94(2): 458-461.

Bowman, T. E. 1985. Heteromysoides dennisi, a new mysidacean crustacean from Cemetery Cave, Grand Bahama Island. Proceedings of the Biological Society of Washington 98(4): 945-948.

Brattegard, T. 1969. Marine biological Investigations in the Bahamas 10. Mysidacea from shallow water in the Bahamas and southern Florida. Part 1. Sarsia 39: 17-106.

https://doi.org/10.1080/00364827.1969.10411155

Brattegard, T. 1970. Mysidacea from shallow water in the Caribbean Sea. Sarsia 43: 111-154. https://doi.org/10.1080/00364827.1970.10411174

Brattegard, T. 1973. Mysidacea from shallow water on the Caribbean Coast of Colombia. Sarsia 54: 1-65. https://doi.org/10.1080/00364827.1973.10411249

Brattegard, T. 1974a. Additional Mysidacea from shallow water on the Caribbean Coast of Colombia. Sarsia 57: 47-86. https://doi.org/10.1080/00364827.1974.10411270

Brattegard, T. 1974b. Mysidacea from shallow water on the Caribbean coast of Panama. Sarsia 57: 87-108. https://doi.org/10.1080/00364827.1974.10411271

Brattegard, T. 1975. Shallow-water Mysidacea from the Lesser Antilles and other Caribbean regions. Studies on the Fauna of Curaçao and other Caribbean Islands 157: 102-115.

Brattegard, T. 1980. Platymysis facilis gen. et sp. nov. (Crustacea: Mysidacea: Heteromysini) from the Saba Bank, Caribbean Sea. Sarsia 65(1): 49-52. https://doi.org/10.1080/00364827.1980.10431471

Bravo, M. F., and M. Murano. 1996. A new species of the genus Pseudomysidetes (Mysidacea) from Japan and reallocation of this genus to the Heteromysini. Crustaceana 69(4): 476-484. https://doi.org/10.1163/156854096X01050

Calman, W. T. 1932. XIII. A cave dwelling crustacean of the family Mysidae from the island of Lanzarote. The Annals and Magazine of Natural History, Ser. 10, 10(55): 127-131.

https://doi.org/10.1080/00222933208673549
Chevaldonné, P., P.-A. Rastorgueff, D. Arslan, and Ch. Lejeusne. 2014. Molecular and distribution data on the poorly known, elusive, cave mysid Harmelinella mariannae (Crustacea: Mysida). Marine Ecology 35(3): 305-317.

https://doi.org/10.1111/maec.12139

Clarke, W. D. 1955. A new species of the genus Heteromysis (Crustacea, Mysidacea) from the Bahama Islands, commensal with a sea-anemone. American Museum Novitates, 1716: 1-13.

Czerniavsky, V. I. 1882. Monografia mizid preimushchestvenno Rossiyskoi Imperii. Ch. 2. Trudy Sankt-Peterburgskogo obshchestva estestvoispytatelei 12: 1-102. [The monograph of mysids predominantly of the Russian Empire. Part 2.] (in Russian, diagnoses in Latin)

Dakin, W. J., and A. N. Colefax. 1940. The plankton of the Australian coastal waters off New South Wales. Part 1. Publications of the University of Sydney, Department of Zoology, Monograph No. 1, 1-211, figs 1-300, pls. I-IV.

Daneliya, M. E. 2012. Description of Heteromysis (Olivemysis) ningaloo new species and interesting records of $H$. (Gnathomysis) harpaxoides Băcescu \& Bruce (Crustacea: Mysida: Mysidae) from the Australian coral reefs. Records of the Western Australian Museum 27(2): 135-147.

https://doi.org/10.18195/issn.0312-3162.27(2).2012.135-147

Daneliya, M. E., W. W. Price, and R. W. Heard. 2018. Revision of the Siriella brevicaudata species group (Crustacea: Mysida: Mysidae) from the West Indo-Pacific. European Journal of Taxonomy 426: 1-80. https://doi.org/10.5852/ejt.2018.426

Escobar-Briones, E., and L. A. Soto. 1990. Heteromysis mexicana, a new species from Campeche Bank, Gulf of Mexico (Crustacea: Mysidacea). Proceedings of the Biological Society of Washington 103(1): 131-139.

Escobar-Briones, E., and L. A. Soto. 1991. Biogeografia de los Misidáceos (Crustacea: Peracarida) del Golfo de México. Caribbean Journal of Science 27(1-2): 80-89.

Fage, L., and T. Monod. 1936. La faune marine de Jameo de Agua, lac souterrain de l'île de Lanzarote (Canaries). Archives de zoologie expérimentale et générale 78: 97-113; 9 figs.

Fenton, G. E. 1986. Ecology and Taxonomy of Mysids (Mysidacea, Crustacea). PhD Thesis. University of Tasmania, Hobart.

Fukuoka, K. 2004. A new species of Heteromysis (Mysida, Mysidae) associated with sponges, from the Uraga Channel, Central Japan, with notes on distribution and habitats within the genus Heteromysis. Crustaceana 77(11): 1353-1373. https://doi.org/10.1163/1568540043165976

Fukuoka, K., and M. Murano. 2002. Mysidacea (Crustacea) from the south-eastern Andaman Sea with descriptions of six new species. Phuket Marine Biological Center, Special Publication 23(1): 53-108.

Gordan, J. 1957. A bibliography of the Order Mysidacea. Bulletin of the American Museum of Natural History 112(4): 279-394.

Hale, H. M. 1929. The Crustaceans of South Australia. Part II. In Handbooks of the Flora and Fauna of South Australia. Adelaide: British Science Guild (South Australian Branch).

Hanamura, Y. 2007. A small collection of mysids (Crustacea: Mysidacea) from the Dampier Archipelago, Western Australia. Records of the Western Australian Museum. Supplement 73: 35-39.

https://doi.org/10.18195/issn.0313-122x.73.2007.035-039

Hanamura, Y., and T. Kase. 2001a. Two new shallow-water mysids of the genus Heteromysis (Crustacea: Mysidacea) from a submarine cave of Christmas Island, Eastern Indian Ocean. Species Diversity: An International Journal for Taxonomy, Systematics, Speciation, Biogeography, and Life History Research of Animals 6: 11-21.

https://doi.org/10.12782/specdiv.6.11 
Hanamura, Y., and T. Kase. 2001b. A new species of Heteromysoides (Mysidacea: Mysidae) from submarine caves of Okinawa, southwestern Japan, with a key to the world species. Crustacean Research 30: 65-71.

https://doi.org/10.18353/crustacea.30.0_65

Hanamura, Y., and T. Kase. 2004. Heteromysoides (Crustacea: Mysidacea: Heteromysini) from a submarine cave on Grand Cayman, the Caribbean Sea: descriptions of a new and a rare species. Journal of Natural History 38(17): 2145-2152. https://doi.org/10.1080/00222930310001625914

Hanamura, Y., R. Siow, A. Man, and F. M. Kassim. 2012. Further record of Heteromysis proxima W. M. Tattersall, 1922 (Mysida) from the Malacca Strait. Crustacean Research 41: 11-18. https://doi.org/10.18353/crustacea.41.0 11

Hansen, H. J. 1910. The Schizopoda of the Siboga Expedition. E. J. Brill, Leiden. https://doi.org/10.5962/bhl.title. 10421

Hansen, H. J. 1925. On the comparative morphology of the appendages in the Arthropoda. In Studies on Arthropoda. II, pp. 1-176, 8 pls. Copenhagen: Gyldendalska Boghandel.

Hilgendorf, F. 1879. Die von Herrn W. Peters in Mocambique gesammelten Crustaceen. Monatsberichte der Königlichen Preussischen Akademie des Wissenschaften zu Berlin 1879: 782-851, 4 pl. [Dated 1878, published 1879.]

Holt, E., and W. Tattersall. 1906. I.-Preliminary notice of the Schizopoda collected by H.M.S. 'Discovery' in the Antarctic Region. Journal of Natural History Series 7 17(97): 1-11. https://doi.org/10.1080/00222930608562484

Hutchings, P. A. 1983. The wetlands of Fullerton Cove, Hunter River. N.S.W. Coast and Wetlands 3: 12-21 https://doi.org/10.31646/wa.67

Hutchings, P. A., S. T. Ahyong, M. B. Ashcroft, M. A. McGrouther, and A. L. Reid. 2013. Sydney Harbour: its diverse biodiversity. Australian Zoologist 36(3): 255-320.

https://doi.org/10.7882/AZ.2012.031

ICZN (International Commission on Zoological Nomenclature). 1999. International Code of Zoological Nomenclature. The International Trust for Zoological Nomenclature, London. [Accessed 24 June 2020].

http://www.nhm.ac.uk/hosted-sites/iczn/code

Ii, N. 1964. Fauna Japonica, Mysidae (Crustacea). Tokyo: Biogeographic Society of Japan.

Illig, G. 1930. Die Schizopoden der deutschen Tiefsee-Expedition. In Wissenschaftliche Ergebnisse Deutschen Tiefsee-Expedition auf dem Dampfer "Valdivia” 1898-1899, 22: 397-625, ed. C. Chun. Jena: Gustav Fischer.

International Hydrographic Organization. 1953. Limits of Oceans and Seas. International Hydrographic Organization, Special Publication No 23, 3rd edition, IMP, Monégasque-Monte-Carlo. https://doi.pangaea.de/10013/epic.37175.d001

Kathman, R. D., W. C. Austin, J. C. Saltman, and J. D. Fulton. 1986. Identification Manual to the Mysidacea and Euphausiacea of the Northeast Pacific. Canadian Special Publication of Fisheries and Aquatic Sciences 93: 1-411.

Kossmann, R. 1880. Ordo Schizopoda. In Zoologische Ergebnisse einer im Auftrage der öniglichen Academie der Wissenschaften zu Berlin Ausgeführten Reise in die Küstengebiete des Rothen Meeres Herausgegeben mit Unterstützung der Königlichen Academie, ed. R. Kossmann, pp. 87-98. Zweite Hälfte, Erste Lieferung: III. Malacostraca (2. Theil: Anomura). Leipzig: Wilhelm Engelmann.

Lagardère, J. P., and H. Nouvel. 1980. Les Mysidacés du talus continental du golfe de Gascogne. II. Familles des Lophogastridae, Eucopiidae et Mysidae (Tribu des Erythropini exceptée). Bulletin du Muséum National d'Histoire Naturelle, sér. 4, Section A 2: 375-412, 3: 845-887.
Lavesque, N., L. Pascal, B. Gouillieux, J.-C. Sorbe, G. Bachelet, and O. Maire. 2016. Heteromysis (Heteromysis) microps (Crustacea, Mysidae), a commensal species for Upogebia pusilla (Crustacea, Upogebiidae) in Arcachon Bay NE Atlantic Ocean). Marine Biodiversity Records 9: 14 (pp. 1-6). https://doi.org/10.1186/s41200-016-0001-1

Ledoyer, M. 1989. Les Mysidaces (Crustacea) des grottes sousmarines obscures de Mediterranee nord-occidentale et du proche Atlantique (Portugal et Madere). Marine Nature: International Journal on Marine Natural Sciences 2(1): 39-62.

Lowry, J. K., and H. E. Stoddart. 2003. Crustacea: Malacostraca: Syncarida, Peracarida. In Zoological Catalogue of Australia, 19 (2a), 531 pp, ed. W. W. K. Houston and A. Wells. Melbourne: CSIRO Publishing, Australia.

Martin, S. 2012. Dardanus megistos. White-spotted hermit crab. In Invertebrates of the Coral Sea. Brisbane: The University of Queenstand. [Accessed 09 April 2021] https://www.gbri.org.au/OldClasses/2012/Dardanusmegistos|StormMartin.aspx

Mauchline, J., and M. Murano. 1977. World list of Mysidacea, Crustacea. Journal of the Tokyo University of Fisheries 64: 39-88.

Mauchline, J. 1980. The biology of mysids. In The Biology of Mysids and Euphausiids, ed. J. Mauchline. Advances in Marine Biology 18: 1-275, 320-375.

Meland, K., J. Mees, M. Porter, and K. J. Wittmann. 2015. Taxonomic review of the orders Mysida and Stygiomysida (Crustacea, Peracarida). PLoS ONE 10(4): e0124656. https://doi.org/10.1371/journal.pone.0124656

Meland, K., and E. Willassen. 2007. The disunity of "Mysidacea" (Crustacea). Molecular Phylogenetics and Evolution 44: 1083-1104. https://doi.org/10.1016/j.ympev.2007.02.009

Modlin, R. F. 1984. Mysidacea from the Florida Middle Ground, northeast Gulf of Mexico, with descriptions of three new species of Heteromysis and a key to the Heteromysini of the Western Atlantic. Journal of Crustacean Biology: A Quarterly of the Crustacean Society for the Publication of Research on Any Aspect of the Biology of Crustacea 4(2): 287-297. https://doi.org/10.2307/1548026

Modlin, R. F. 1987a. Heteromysini from Grand Bahama Island: Description of Heteromysis agelas, new species, first description of male $H$. floridensis, and notes on $H$. guitarti (Crustacea: Mysidacea). Proceedings of the Biological Society of Washington 100(2): 296-301.

Modlin, R. F. 1987b. Heteromysis kensleyi and H. coralina, new species from the shallow waters off Looe Key, Florida (Mysidacea: Heteromysini). Proceedings of the Biological Society of Washington 100(3): 653-658.

Modlin, R. F. 1987c. Mysidacea from shallow waters in the vicinity of Carrie Bow Cay, Belize, Central America, with descriptions of two new species. Journal of Crustacean Biology: A Quarterly of the Crustacean Society for the Publication of Research on Any Aspect of the Biology of Crustacea 7(1): 106-121. https://doi.org/10.1163/193724087X00090

Murano, M. 1988. Heteromysids (Crustacea; Mysidacea) from northern Australia with description of six new species. The Beagle: Occasional Papers of the Northern Territory Museum of Arts and Sciences 5(1): 27-50.

Murano, M. 1998. Further study on Australian heteromysids (Crustacea: Mysidacea). The Beagle: Occasional Papers of the Northern Territory Museum of Arts and Sciences 14: 29-39.

Murano, M., and K. Fukuoka. 2003. Two new species of the genus Heteromysis (Crustacea: Mysida: Mysidae) occurred in the Aquarium of the Kushimoto Marine Park Center, Japan. Bulletin of the National Science Museum. Series A: Zoology 29(4): 185-196.

Murano, M., and Y. Hanamura. 2002. A new species of Heteromysis (Crustacea: Mysida: Mysidae) from Japan. Plankton Biology and Ecology: A Publication of the Plankton Society of Japan on any Aspect of the Marine and Freshwater Plankton 49(2): 75-80. 
Müller, H.-G. 1993. World Catalogue and Bibliography of the Recent Mysidacea. Wissenschaftler Verlag, Tropical Products Trading Center, Germany

Neyt, K. 2002. Morfologische Studie van een Nieuwe Soort van de Ordo van de Mysidacea uit de Westelijke Indische Oceaan. Unpublished manuscript, Institute voor Dierkunde, Universiteit Gent, Mariene Biologie.

Noël, P., T. Monod, and L. Laubier. 2014. Crustacea in the Biosphere. In Treatise on Zoology-Anatomy, Taxonomy, Biology. The Crustacea. Revised and updated, as well as extended from the Traité de Zoologie, vol. 4, part B, 54: 3-115, ed. J. C. von Vaupel Klein, M. Charmantier-Daures, and F. R. Schram. Leiden: Brill.

Norman, A. M. 1892. On British Mysidae, a family of Crustacea Schizopoda. The Annals and Magazine of Natural History, Ser. 6(56), 10: 143-166.

https://doi.org/10.1080/00222939208677385

Nouvel, H. 1940. Observations sur la sexualité d'un mysidacé, Heteromysis armoricana n. sp. Bulletin de l'Institut Océanographique 789: 1-11.

Nouvel, H. 1949. Mysidacea. In Fiches d'Identification du Zooplankton, ed. P. Jespersen and F. S. Russell. Copenhagen. Conseil Permanent International pour l'Exploration de la Mer, no. 18: 1-6; no. 19: 1-4; no. 20: 1-4; no. 21 : 1-4; no. 22: 1-4; no. 23 : $1-4$; no. 24 : $1-4$; no. 25 : $1-4$; no. 26 : $1-3$; no. $27: 1-4$.

Nouvel, H. 1957. Mysidacés provenant de deux échantillons de "Djembret" de Java. Zoologische Mededelingen 35(22): 315-331.

Nouvel, H. 1964. Heteromysis gerlachei (Bonnier \& Pérez) et les espèces actuellement confondues sous le nom d'Heteromysis harpax (Crustacea Mysidacea). Zoologische Mededelingen 39: 37-44 (plates III-VII).

Nouvel, H., J. P. Casanova, and J. P. Lagardère. 1999. Ordre des Mysidacés. Mémoires de l'Institut Océanographique, Monaco 19: 39-86.

Ortiz, M., and R. Lalana. 2017. Los Misidáceos (Lophogastrida, Stygiomysida y Mysida), de Cuba: historia, claves dicotómicas, figuras y bibliografía. Revistas Investigationes Marinas 37(2): 61-79. [The opossum shrimps (Lophigastrida, Stygiomysida and Mysida): history, dichotomic keys, figures and bibliography.] (In Spanish, with English abstract.)

Petrescu, I., and K. J. Wittmann. 2009. Catalogue of the Mysida type collection (Crustacea, Peracarida) from the "Grigore Antipa" National Museum of Natural History (Bucureşti). Travaux du Muséum national d'Histoire naturelle "Grigore Antipa» 52: 53-72.

https://doi.org/10.2478/v10191-010-0008-5

Pérez, Th., L. Albenga, J., Starmer, and P. Chevaldonné. 2016. Biodiversité des grottes sous-marines des îles Marquises: un patrimoine naturel caché et méconnu, pp. 287-310. In Biodiversité terrestre et marine des îles Marquises, Polynésie française, ed. R. Galzin, S.-D. Duron, and J.-Y. Meyer. Société française d'ichtyologie.

Pillai, N. K. 1961. Additions to the Mysidacea of Kerala. Bulletin of the Central Research Institute, University of Kerala. Series C: Natural Sciences 8: 15-35.

Pillai, N. K. 1965. A review of the work on shallow water Mysidacea of the Indian waters. Proceedings of the Symposium on Crustacea, held at Ernakulam from January 12 to 15, 1965. Symposium Series 2: 1681-1728. Marine Biological Association of India, Mandapam Camp.

Pillai, N. K. 1968. Heteromysis zeylanica Tattersall (Crustacea: Mysidacea), an associate of madreporarian corals in South Indian waters. The Journal of the Bombay Natural History Society 65: 45-57.

Price, W. W., and R. W. Heard. 2000. Studies of the Crustacea of the Turks and Caicos Islands, British West Indies. IV. Heteromysis (Heteromysis) spottei, a new species (Peracarida: Mysidacea: Mysidae) from Pine Cay. Proceedings of the Biological Society of Washington 113(1): 88-94.
Price, W. W., and R. W. Heard. 2008. Crustacea of the Cayman Islands, British West Indies II. Heteromysis (Olivemysis) ebanksae, a new species (Mysida: Mysidae) from Little Cayman and Grand Cayman Islands. Proceedings of the Biological Society of Washington 121(2): 143-149. https://doi.org/10.2988/07-25.1

Price, W. W., and R. W. Heard. 2011. Two new species of Heteromysis (Olivemysis) (Mysida, Mysidae, Heteromysinae) from the tropical northwest Atlantic with diagnostics on the subgenus Olivemysis Băcescu, 1968. Zootaxa 2823: 32-46. https://doi.org/10.11646/zootaxa.2823.1.2

Price, W. W., Heard, R. W., and R. Vargas. 2018. Heteromysis cocoensis n. sp. (Crustacea: Mysida: Mysidae) from coastal waters of Isla del Coco, Costa Rica. Nauplius 26: e2018012. https://doi.org/10.1590/2358-2936e2018012

Rotschi, H., and L. Lemansson. 1967. Bathymentry and topography of the Coral and Tasman Seas. Oceanography and Marine Biology Annual Revue 5: 49-97.

San Vicente, C., and F. Monniot. 2014. The ascidian-associated mysid Corellamysis eltanina gen. nov., sp. nov. (Mysida, Mysidae, Heteromysinae): a new symbiotic relationship from the Southern Ocean. Zootaxa 3780(2): 323-346. https://doi.org/10.11646/zootaxa.3780.2.6

Sars, G. O. 1877. Nye Bidrag til Kundskaben om Middelhavets Invertebratfauna I. Middelhavets Mysider. Archiv der Mathematik Naturvidenskaberne 2: 10-119. https://doi.org/10.5962/bhl.title.10404

Sars, G. O. 1883. Oversigt af Norges Crustaceer med foreløbige Bemaerkninger over de nye eller mindre bekjendte Arter. I. (Podophthalmata - Cumacea - Isopoda - Amphipoda). Forhandlinger $i$ Videnskabs-Selskabet I Christiania, 18: 1-124. [Dated 1882, published 1883.]

Sars, G. O. 1885. Report on the Schizopoda collected by H.M.S. Challenger during the years 1873-76. Report on the Scientific Results of the Voyage of the H.M.S. Challenger During the Years 1873-76 Under the Command of Captain George S. Nares, R.N., F.R.S. and the late Captain Frank Tourle Thomson, R.N. Zoology 13: 1-228, pls. 221-238.

Sawamoto, S. 2014. Current status of mysid taxonomy in Southeast Asia. Marine Research in Indonesia 39(1): 1-14. https://doi.org/10.14203/mri.v39i1.80

Shimomura, M., and Y. Fujita. 2017. First description of the female of Heteromysoides simplex Hanamura \& Kase, 2001 (Mysidacea: Mysidae) collected from a submarine cave on Ie-jima Island, Ryukyu Islands, southwestern Japan. Proceedings of the Biological Society of Washington 130: 75-83. https://doi.org/10.2988/17-00001

Smith, S. I. 1874. Invertebrate animals of Vineyard Sound and adjacent waters. Reports of the United States Commissioner of Fisheries, 1871-1872: 452-460, 573-578. [Dated 1873, published 1874.]

Smith, S. I. 1879. The stalk-eyed crustaceans of the Atlantic coast of North America north of Cape Cod. Transactions of the Connecticut Academy of Arts and Sciences 5: 27-138. https://doi.org/10.5962/bhl.title. 10046

Staff of the Zoological Society of London (1972) The Zoological Record. Volume 106. 1969. Crustacea. Part I (Recent) and Part II (Fossil). Zoological Society, London.

Tattersall, O. S. 1949. A rare species of mysid from the Plymouth area. Nature 163: 450. https://doi.org/10.1038/163450a0

Tattersall, O. S. 1955. Mysidacea. Discovery Reports 28: 1-190. https://doi.org/10.5962/bhl.part.16838

Tattersall, O. S. 1961. Mysidacea from the coasts of tropical West Africa. Atlantide Reports 6: 143-159.

Tattersall, O. S. 1962. Report on a collection of Mysidacea from South African off-shore and coastal waters (1957-59) and from Zanzibar (1961). Proceedings of the Zoological Society of London 139: 221-247.

https://doi.org/10.1111/j.1469-7998.1962.tb01828.x 
Tattersall, O. S. 1965. The Fauna of the Ross Sea. 4. Mysidacea. New Zealand Oceanographic Institute Memoir 27: 9-25 (1 plate).

Tattersall, O. S. 1967. A survey of the genus Heteromysis (Crustacea: Mysidacea) with descriptions of five new species from tropical coastal waters of the Pacific and Indian Ocean, with a key for the identification of the known species of the genus. Transactions of the Zoological Society of London 31: 157-193. https://doi.org/10.1111/j.1096-3642.1967.tb00366.x

Tattersall, W. M. 1908. Crustacea VII. Schizopoda. In National Antarctic Expedition, 1901-1904, Natural History. London: British Museum (Natural History), Zoology, 4: 1-42, 8 pls.

Tattersall, W. M. 1922. Indian Mysidacea. Records of the Indian Museum 24: 445-504.

Tattersall, W. M. 1927a. Australian opossum shrimps (Mysidacea). Records of the South Australian Museum 3: 235-257.

Tattersall, W. M. 1927b. XI. Report on the Crustacea Mysidacea. In Zoological Results of the Cambridge Expedition to the Suez Canal, 1924. Transactions of the Zoological Society of London 22: $185-198$.

https://doi.org/10.1111/j.1096-3642.1927.tb00331.x

Tattersall, W. M. 1940. Sydney University plankton investigations, under the direction of Professor W. J. Dakin, D.Sc. Report on a small collection of Mysidacea from the coastal waters of New South Wales. Records of the Australian Museum 20(5): 327-340. https://doi.org/10.3853/j.0067-1975.20.1940.583

Tattersall, W. M. 1951. A review of the Mysidacea of the United States National Museum. Bulletin of the United States National Museum 201: 1-292.

https://doi.org/10.5962/bhl.part.16843

Tattersall, W., and O. Tattersall. 1951. The British Mysidacea. London, Ray Society.

Taylor, M. D. 2008. Spatial and temporal patterns of habitat use by three estuarine species of mysid shrimp. Marine and Freshwater Research 59: 792-798. https://doi.org/10.1071/MF07247

Tudge, C. C. 1995. Hermit Crabs of the Great Barrier Reef and Coastal Queensland. Leiden: Backhyus Publishers.

Vannini, M., G. Innocenti, and R. K. Ruwa. 1993. Family group structure in mysids, commensals of hermit crabs (Crustacea). Tropical Zooligy 6: 189-205. https://doi.org/10.1080/03946975.1993.10539219

Vannini, M., R. K. Ruwa, and G. Innocenti. 1994. Notes on the behaviour of Heteromysis harpax, a commensal mysid living in hermit crab shells. Ethology, Ecology \& Evolution, Special Issue 3: 137-142.

https://doi.org/10.1080/03949370.1994.10721987

Western Australian Museum Collections. 2020. Hermit crab opossum shrimp Heteromysis harpaxoides. [Accessed 20 June 2020]

http://museum.wa.gov.au/online-collections/names/heteromysis-harpaxoides

Wittmann, K. J. 1996. Morphological and reproductive adaptations in Antarctic meso- to bathypelagic Mysidacea, with description of Mysifaun erigens n. g. n. sp. In Deep-sea and Extreme Shallow-water Habitats: Affinities and Adaptations, ed. F. Uiblein, J. Ott, and M. Stachowitsch. Biosystematics and Ecology Series 11: 221-231.

Wittmann, K. J. 2000. Heteromysis arianii sp. n., a new benthic mysid (Crustacea, Mysidacea) from coralloid habitats in the Gulf of Naples (Mediterranean Sea). Annalen des Naturhistorischen Museums in Wien. Serie B, Für Botanik und Zoologie 102: 279-290.

Wittmann, K. J. 2001. Centennial changes in the near-shore mysid fauna of the Gulf of Naples (Mediterranean Sea), with description of Heteromysis riedli sp. n. (Crustacea, Mysidacea). Marine Ecology 22(1/2): 85-109.

https://doi.org/10.1046/j. 1439-0485.2001.00741.x
Wittmann, K. J. 2004. Retromysis nura new genus and species (Mysidacea, Mysidae, Heteromysini) from a superficial marine cave in Minorca (Balearic Islands, Mediterranean Sea). Crustaceana 77(7): 769-783.

https://doi.org/10.1163/156854004774248672

Wittmann, K. J. 2008. Two new species of Heteromysini (Mysida, Mysidae) from the island of Madeira (N.E. Atlantic), with notes on sea anemone and hermit crab commensalisms in the genus Heteromysis S. I. Smith, 1873. Crustaceana 81(3): 351-374. https://doi.org/10.1163/156854008783564037

Wittmann, K. J. 2013. Mysids associated with sea anemones from the tropical Atlantic: descriptions of Ischiomysis new genus, and two new species in this taxon (Mysida, Mysidae, Heteromysinae). Crustaceana 86(4): 487-506.

https://doi.org/10.1163/15685403-00003166

Wittmann, K. J. 2020. Heteromysis (Heteromysis) abednavandii sp. n.: a new species from coral reef aquaria in the Aqua Terra Zoo, Vienna, Austria (Mysida, Mysidae). Annalen des Naturhistorischen Museums in Wien, B 122: 141-158.

Wittmann, K. J., and D. Abed-Navandi. 2019. A new species of Heteromysis (Mysida: Mysidae) from public coral reef aquaria in Vienna, Austria. Crustacean Research 48: 81-97. https://doi.org/10.18353/crustacea.48.0_81

Wittmann, K. J., and D. Abed-Navandi. 2021. Four new species of Heteromysis (Crustacea: Mysida) from public aquaria in Hawaii, Florida, and Western to Central Europe. European Journal of Taxonomy 735: 133-175. https://doi.org/10.5852/ejt.2021.735.1247

Wittmann, K. J., A. P. Ariani, and J.-P. Lagardère. 2014. Orders Lophogastrida Boas, 1883, Stygiomysida Tchindonova, 1981, and Mysida Boas, 1883 (also known collectively as Mysidacea), pp. 189-396, 404-406. In Treatise on Zoology-Anatomy, Taxonomy, Biology. The Crustacea. Revised and updated, as well as extended from the Traité de Zoologie, ed. J. C. von Vaupel Klein, M. Charmantier-Daures, and F. R. Schram, vol. 4, part B (54). https://doi.org/10.1163/9789004264939_006

Wittmann, K. J., and A. P. Ariani. 2019. Amazonia versus Pontocaspis: a key to understanding the mineral composition of mysid statoliths (Crustacea: Mysida). Biogeographia-The Journal of Integrative Biogeography 34(1): 1-15. https://doi.org/10.21426/B634142438

Wittmann, K. J., and C. L. Griffiths. 2017. Three new species of Heteromysis (Mysida, Mysidae, Heteromysini) from the Cape Peninsula, South Africa, with first documentation of a mysidcephalopod association. ZooKeys 685: 15-47. https://doi.org/10.3897/zookeys.685.13890

Wittmann, K. J., and P. Wirtz. 2017. Heteromysis sabelliphila sp. nov. (Mysida, Mysidae, Heteromysinae) in facultative association with sabellids from the Cape Verde Ilands (subtropical N. E. Atlantic). Crustaceana 90(2): 131-151. https://doi.org/10.1163/15685403-00003624

Wittmann, K. J., and P. Chevaldonné. 2016. Description of Heteromysis (Olivemysis) ekamako sp. nov. (Mysida, Mysidae, Heteromysinae) from a marine cave at Nuku Hiva Island (Marquesas, French Polynesia, Pacific Ocean). Marine Biodiversity 47, 879-886. [Published online in 2016] https://doi.org/10.1007/s12526-016-0522-1

Yolanda, R., Sh. Sawamoto, and V. Lheknim. 2019. A new species in the genus Heteromysoides (Crustacea, Mysida, Mysidae) from Songkhla Lagoon, southern Thailand. Zoosystematics \& Evolution 95(2): 235-242. https://doi.org/10.3897/zse.95.39214

Zimmer, C. 1909. VI. Die nordischen Schizopoden. In Nordisches Plankton, ed. K. Brandt and C. Apstein, pp. 1-178. Zoologischer Teil, Dritter Band: Crustacea. Kiel and Leipzig: Lipsius und Tischer. 